Leandro Augusto da Silva

\title{
Categorização de Imagens Médicas baseada em Transformada Wavelet e Mapas Auto-Organizáveis
}

Tese apresentada à Escola Politécnica da Universidade de São Paulo para obtenção do Título de Doutor em Engenharia Elétrica. 
Leandro Augusto da Silva

\section{Categorização de Imagens Médicas baseada em Transformada Wavelet e Mapas Auto-Organizáveis}

Tese apresentada à Escola Politécnica da Universidade de São Paulo para obtenção do Título de Doutor em Engenharia Elétrica.

Área de concentração: Sistemas Eletrônicos

Orientador:

Prof. Dr. Livre Docente

Emilio Del Moral Hernandez 
Este exemplar foi revisado e alterado em relação à versão original, sob responsabilidade única do autor com a anuência de seu orientador.

São Paulo, 23 de Abril, de 2009.

Leandro Augusto da Silva

Emilio Del Moral Hernandez

FICHA CATALOGRÁFICA

Silva, Leandro Augusto da

Categorização de imagens médicas baseada em transformada wavelet e mapas auto-organizáveis (Edição Revisada) / L.A. da Silva. -- São Paulo, 2009.

$111 \mathrm{p}$.

Tese (Doutorado) - Escola Politécnica da Universidade de São Paulo. Departamento de Engenharia de Sistemas Eletrônicos.

1. Redes neurais (Classificação) 2. Mineração de dados 3. Análise de dados 4 . Análise de conglomerados 5. Descoberta de conhecimento 6. Imagem digital (Sistemas;Processos) 7. Análise de ondaletas I. Universidade de São Paulo. Escola Politécnica.

Departamento de Engenharia de Sistemas Eletrônicos II. t. 
aos meus pais Vera e Cirilo pelo apoio, compreensão e carinho... 


\section{Apoio}

Agradeço a CAPES pelo fomento à pesquisa e pelos recursos para participação em eventos. 


\section{Agradecimentos}

Ao amigo, companheiro e orientador Prof. Emilio Del Moral Hernandez pela oportunidade e confiança, bem como pelos incontáveis conselhos, apoio e incentivos para a vida acadêmica.

Ao Prof.Sérgio Shiguemi Furuie pelas horas de discussão, pelo tempo dedicado e pelo incentivo para realização do trabalho.

Ao Dr. Ramon Alfredo Moreno pelo tempo dedicado, apoio e co-orientação à pesquisa.

Ao inesquecível professor Vagner Bernal Barbeta pelos conselhos e incentivos no período da graduação e por me oferecer a primeira oportunidade na minha carreira científica.

Ao professor Reinaldo Bianchi pela oportunidade na carreira científica no período de graduação e incentivo a continuar na carreira acadêmica.

Aos colegas Clodis Boscarioli, Renato Sassi, Danilo Meneses Lage, Fernando Sales, Mônica Matsumoto, Marina Rebelo, Marcelo Santos, Mauricio Higa, Alice Bacic e Carlos da Silva Santos pelas revisões, sugestões e críticas ao trabalho.

Aos colegas Humberto Sandmann, Eduardo Akira Kinto, Júlio César Saldaña Pumarica, Priscila Braga Calíope, Edson Caoru Kitani, Itamar Magno Barbosa e Antônio Henrique Pinto Selvatici pelo apoio.

À colega Maria Cecília da Silva Figueira por se envolver nesta pesquisa para seu trabalho de iniciação científica.

Aos alunos da Escola Politécnica Alexandre Luiz Chiuffa, João Renato Molnar, Leandro Makoto Neves Hoshina, Nattan Inácio de Oliveira Lima pelo desenvolvimento do programa RECIMME, apresentado nesta tese.

À minha irmã Christiane, ao meu cunhado Anderson e ao meu sobrinho Bruno pelo apoio, carinho e compreensão.

À querida Tatiana Soares Kuhn pelo companheirismo, amizade e amor e a toda sua família pelo carinho.

Aos meus tios, Sandra e José Pucciarelli, pelo apoio e carinho que têm permitido 
toda a trajetória Da minha carreira e aos meus primos Amilcar, Raphael e Giovani por compartilharem seus confortos.

A toda minha família (Lima e Silva) por sempre me dar apoio e carinho e compreender a minha ausência.

A todos os funcionários da Escola Politécnica, em especial à Maria Cristina Borba, ao Marcelo, à Claudia e à Simone, do Laboratório de Sistemas Integráveis; principalmente ao Cícero, ao Natanael, à Claudia e à Francesca; e ao Departamento de Pesquisa e Desenvolvimento do Instituto do Coração, principalmente à Lúcia e à Elizangeli o meu muito obrigado. 


\section{Resumo}

Nos tempos atuais, as imagens médicas são fonte de dados fundamentais na medicina moderna. As imagens armazenadas em uma base de dados de acordo com as respectivas categorias são um importante passo para aplicações como mineração de dados e recuperação de imagens por conteúdo. Estas aplicações podem apoiar médicos e estudantes na decisão de diagnóstico, permitir pesquisas e ser usadas como material didático.

O trabalho propõe o uso de Mapas Auto-Organizáveis (SOM) e Transformada Wavelet combinada com momentos de $\mathrm{Hu}$ para a categorização de imagens médicas. Para tanto, são realizados experimentos para definição do tamanho do mapa SOM, uso do mesmo na categorização, definição da melhor família wavelet e nível de decomposição, sumarização dos coeficientes wavelets descartados por momento de $\mathrm{Hu}$ e experimentos comparativos com outras abordagens de categorização.

Além dos experimentos de classificação comparativos em termos de taxa de acerto, é apresentada uma proposta de contribuição para uso do Mapa SOM na classificação. Nesta proposta, os resultados de classificação e o tempo de recurso computacional despendido pelo Mapa SOM mostram-se eficientes, quando comparados aos resultados e tempo apresentados pelo tradicional classificador $K$ vizinhos mais próximos. 


\section{Abstract}

Nowadays, images are fundamental data source in modern medicine. The images stored in a database according with categories are an important step for data mining and contentbased image retrieval. They can support doctors and students in diagnostic decisions and provide research and didactic material.

This work addresses the use of Self-Organizing Map (SOM) and discrete wavelet transform joint with Hu's moments to medical image categorization. Furthermore, extensive experiments to define map size were done, employing the map in categorization, the best wavelet family and level of decomposition were defined, the coefficient discarded was summarized by Hu's moments and contrastive studies with another successfull approach of categorization were done.

Moreover, an approach to use SOM map in categorization is addressed, in which the SOM map for classification carried on better performance and computational time than traditional $K$ nearest neighbor algorithm. 


\section{Sumário}

\section{Lista de Figuras}

\section{Lista de Tabelas}

1 Introdução 1

1.1 O uso de Imagens Médicas no Diagnóstico e a Importância do seu Armazenamento Categorizado . . . . . . . . . . . . . . . 1

1.2 Categorização de Imagens Médicas: Trabalhos Correlatos . . . . . . . . . . 4

1.3 Objetivo do Trabalho . . . . . . . . . . . . . . . . . 7

1.4 Estrutura do Texto . . . . . . . . . . . . . . . . . . . 8

2 Imagens na Medicina Moderna: Aquisição, Armazenamento e Potenciais $\begin{array}{ll}\text { Aplicações } & 9\end{array}$

2.1 O uso de Imagens na Medicina Moderna . . . . . . . . . . . . . . . . . 10

2.2 Sistema de Informação em Saúde . . . . . . . . . . . . . . . . . . . 10

2.3 Potencial aplicação do armazenamento organizado de imagens médicas . . 12

2.3.1 Recuperação de Imagens por Conteúdo . . . . . . . . . . . . . . . . 13

2.4 Considerações Finais . . . . . . . . . . . . . . . . . . . . 14

3 Extração de Características $\quad 16$

3.1 Extratores de Características . . . . . . . . . . . . . . . 17

3.2 Transformada Wavelet . . . . . . . . . . . . . . . . . . . 20

3.2 .1 Análise em Multi-Resolução . . . . . . . . . . . . . . . . . . . . 21

3.3 Análise de Momentos . . . . . . . . . . . . . . . . . . . . 25 
3.4 Histogramas Esparsos baseados em Patches . . . . . . . . . . . . . . . . . . 30

3.5 Combinação de técnicas para a extração de características: Transformada Wavelet e Momentos de $\mathrm{Hu}$. . . . . . . . . . . . . . . . . . . . . . . . . 31

3.6 Considerações Finais . . . . . . . . . . . . . . . . . . . . . 33

4 O Mapa Auto-Organizável e suas Potencialidades na Categorização de Imagens $\quad 34$

4.1 Classificadores Automáticos . . . . . . . . . . . . . . . . 34

4.2 Mapa Auto-Organizável . . . . . . . . . . . . . . . . . . . 36

4.3 Arquitetura . . . . . . . . . . . . . . . . 36

4.4 Algoritmo de Aprendizado . . . . . . . . . . . . . . . . . . . . . 37

4.5 Medidas de Desempenho do Mapa Auto-Organizável . . . . . . . . . . . . 42

4.6 Aplicação do Mapa SOM em Problemas de Categorização . . . . . . . . . . . 44

4.7 Considerações Finais . . . . . . . . . . . . . . . . . . . . . . . 47

5 Proposta para uso do SOM na categorização de imagens 49

5.1 Categorizando imagens com Mapa SOM . . . . . . . . . . . . . . . . . 49

5.2 Resolvendo os problemas de fronteira para a classificação . . . . . . . . . . 53

5.3 Bases de dados para os experimentos de categorização . . . . . . . . . . . 56

5.4 Métodos Experimentais para validação da proposta de categorização . . . . 62

5.4.1 Metodologia para Extração dos Coeficientes Wavelets mais Representativos ............................ 62

5.4 Metodologia para Categorização . . . . . . . . . . . . . . . . 64

5.5 Considerações Finais . . . . . . . . . . . . . . . . . . . . 66

6 Avaliação experimental do categorizador de imagens $\quad 68$

6.1 Experimentos de definições usando a base de exploração . . . . . . . . . . 68

6.2 Experimentos usando a base de validação . . . . . . . . . . . . . . . . . . . 74

6.3 Categorizador de imagens médicas: CATIMME e RECIMME . . . . . . . . 79 
6.4 Considerações Finais . . . . . . . . . . . . . . . . . . . . . . . . . . 84

$\begin{array}{llr}7 & \text { Discussão e Conclusão } & 86\end{array}$

7.1 Contribuições apresentadas na tese . . . . . . . . . . . . . . . . 90 90

7.2 Trabalhos Futuros . . . . . . . . . . . . . . . . . 91

$\begin{array}{ll}\text { Referências Bibliográficas } & 94\end{array}$

$\begin{array}{ll}\text { Apêndice A - Índice de Davies-Boldin } & 100\end{array}$

Apêndice B - Metodologia para segmentação do mapa SOM 101

$\begin{array}{ll}\text { Anexo A - Produção bibliográfica } & 103\end{array}$

A.1 Publicação em revista . . . . . . . . . . . . . . . . . . 103

A.2 Publicações em capítulos de livro . . . . . . . . . . . . . . . . 103

A.3 Publicações em congressos internacionais . . . . . . . . . . . . . 103

A.4 Publicações em congressos nacionais . . . . . . . . . . . . . 105

Anexo B - Descrição dos programas para categorização de imagens $\quad 106$ 


\section{Lista de Figuras}

1.1 Modelo para classificação automática em categorias. . . . . . . . . . . . . 5

1.2 Esquema de categorização automática de uma imagem nova em relação às categorias existentes. . . . . . . . . . . . . . . . 5

2.1 Esquema básico do sistema de arquivamento de imagens médicas do InCor já com o módulo de máquina classificadora. . . . . . . . . . . . . . . . . . 11

2.2 Exemplo de um caso de aplicação do sistema CBIR. . . . . . . . . . . . . . . 14

3.1 Ilustração esquemática da extração de características em imagens de pé e de mão. . . . . . . . . . . . . . . . . . . . . . . . . . . . 16

3.2 Imagem Redimensionada. . . . . . . . . . . . . . . . . . . . . . . . . . . 19

3.3 Modelo esquemático da AMR. . . . . . . . . . . . . . . . . . . . . 22

3.4 Alguns exemplos de wavelets-mãe. . . . . . . . . . . . . . . . . . . . . 23

3.5 Exemplo de AMR usando função Haar em imagem de ressonância magnética. A dimensão original da imagem é $256 \times 256$. No exemplo, os coeficientes $c A_{3}$ têm a dimensão de $32 \times 32$. . . . . . . . . . . . . . . 24

3.6 Imagens de ressonância magnética rotacionadas para experimentos de momentos de Hu. . . . . . . . . . . . . . . . . . . . . . . . . . . . 28

3.7 Esquema de extração dos Histogramas Esparsos baseados em Patches para uma imagem de ressonância magnética. . . . . . . . . . . . . . . . . . . . . 31

4.1 Exemplo de arquitetura SOM com 16 neurônios na camada de saída (mapa $4 \times 4)$

4.2 Exemplos de vizinhanças no mapa SOM. A relação entre os neurônios define a vizinhança que pode ser retangular (4 neurônios) ou hexagonal (6 neurônios) . . . . . . . . . . . . . . . . . . . . . . 38 
4.3 A intensidade de adaptação das unidades individuais é indicada pelos diferentes círculos em tons de cinza e pelas gaussianas na horizontal e na vertical. Adaptado de (WU; RAHMAN; CHOW, 2005) . . . . . . . . . . . . . . 40

4.4 A partir da base de dados artificial (a) treina-se o SOM, o qual organiza os dados da base em um mapa rotulado (b). . . . . . . . . . . . . . . . . . 43

4.5 As imagens de entrada de diferentes classes $(A, B$ e $C$ ) passam pelo extrator e os vetores de características assim produzidos são usados para gerar o mapa (treinamento SOM) . . . . . . . . . . . . . . . . . . . . 44

4.6 Ilustração esquemática de como ficaria a tabela com os vetores de características da base de treinamento com os neurônios vencedores. . . . . . . . . 45

4.7 Esquema da metodologia de classificação considerando a máxima freqüência de categorias em cada neurônio vencedor (BMU) ou o histograma de classes. 46

4.8 Ao apresentar uma imagem para a classificação, o vetor de características é extraído e então comparado com os vetores de pesos. De acordo com a similaridade, as imagens do neurônio vencedor são recuperadas. . . . . . . 47

5.1 Resultados de treino em diferentes épocas $(t=0, t=50$ e $t=80)$ para uma base de dados gerada artificialmente. . . . . . . . . . . . . . . . 50

5.2 Mapa com histograma de vencimentos. . . . . . . . . . . . . . . . . 52

5.3 Padrões de entrada e neurônios vencedores com rótulos atribuídos a cada unidade do mapa e a cada padrão de entrada. . . . . . . . . . . . . . . . . 53

5.4 Ampliação de uma parte da Figura 5.3, considerando a apresentação de um novo padrão de entrada para ser classificado. . . . . . . . . . . . . . . . . . 54

5.5 Amostra de cada categoria da base de imagens. . . . . . . . . . . . . . . 57

5.6 Histograma da base de validação. . . . . . . . . . . . . . . . . . . . . . . . 60

5.7 Variabilidade Intra-classe. Todas as radiografias têm a mesma codificação (IRMA 1121-120-800-700). Adaptado de (LEHMANN et al., 2005) . . . . . . . 61

5.8 Similaridade Inter-Classe. Todas as mamografias em vista axial/craniocaudal são codificadas como $11^{* *} 3^{* *}-61^{*}-6^{* *}$ (linha superior), enquanto em outras orientações têm codificações $11^{* *} 4^{* *}-61^{*} 6^{* *}$ (linha inferior). Adaptado de (LEHMANN et al., 2005). . . . . . . . . . . . . . . . . . . 61

5.9 Esquema de decomposição por AMR (Análise em Multi-Resolução). . . . . 63 
5.10 Esquema de avaliação do conjunto de coeficientes $c A_{n}$, onde $n$ é o nível de decomposição. . . . . . . . . . . . . . . . . . . . . . . . 64

5.11 Esquema de uso do método leave-one-out para uma base de dados com 100 imagens. . . . . . . . . . . . . . . . . . . . 65

6.1 Experimentos de Robustez . . . . . . . . . . . . . . . . . . . . 73

6.2 Exemplo de rotulação do mapa SOM por histograma e por máxima votação. 75

6.3 Exploração do mapa SOM para visualização das imagens cujos vetores de características são os mais próximos dos respectivos vetores de pesos e visualização dos vetores de pesos. . . . . . . . . . . . . . . . . . . . . 76

6.4 Análises de tempo de classificação (a) e acerto de classificação (b) para o classificador Knn . . . . . . . . . . . . . . . . . . . . . 80

6.5 Análises de tempo de classificação (a) e acerto de classificação (b) para o classificador SOM. . . . . . . . . . . . . . . . . . . . . 81

6.6 Interface do CATIME (Categorizador de Imagens Médicas). . . . . . . . . 82

6.7 Interface do RECIMME (Recuperador de Imagens Médicas). . . . . . . . . 83

B.1 Esquema para segmentação do mapa SOM (VESANTO; ALHONIEMI, 2000). 101

B.1 Interface para classificação automática desenvolvida no MatLab . . . . . . 107

B.2 Interface para classificação automática desenvolvida com programação WEB.110

B.3 Exemplo de arquivo XML para estruturação das informações do paciente. . 111 


\section{Lista de Tabelas}

3.1 Apresentação dos 7 momentos de Hu calculados para cada imagem da Figura 3.6. . . . . . . . . . . . . . . . . . . . 29

5.1 Exemplos de categoria das imagens usadas nos experimentos. O código IRMA está explicado na Tabela $5.2 \ldots$. . . . . . . . . . . . . . . . 58

5.2 Detalhamento dos códigos IRMA . . . . . . . . . . . . . . . . . 59

6.1 Resultados experimentais usando o coeficiente de aproximação em diferentes níveis de decomposição wavelets. . . . . . . . . . . . . . . . . . . . . . . 69

6.2 Resultados de classificação do SOM usando diferentes famílias wavelets. . . 70

6.3 Resultados experimentais usando o coefiente de aproximação e os coeficientes de detalhamento com nível 3 de decomposição. . . . . . . . . . . . . . 70

6.4 Resultados experimentais que comparam as diferentes medidas de desempenho para os diferentes tamanhos de mapa SOM. . . . . . . . . . . . . . . 71

6.5 Resultado do classificador SOM treinado com o coeficiente de aproximação no terceiro nível de decomposição, $c A_{3}$, e com a Imagem Redimensionada, IR, e resultado do classificador Knn para um vizinho mais próximo com $c A_{3}$ e com IR. . . . . . . . . . . . . . . . . . . . . . . 73

6.6 Resultado de classificação e tempo de treinamento para os diferentes tamanhos de mapa SOM usando a base de dados de validação. . . . . . . . . . . . 77

6.7 Resultados de classificação usando o classificador Knn com IR e Patchbased apresentados por Deselaers et. al. (DESELAERS et al., 2006). . . . . . 78

6.8 Resultados de classificação com o classificador Knn e com o classificador SOM considerando como vetores de características $c A_{3}$ e $c A_{3}$ combinado com os coeficientes descartados sumarizados na forma de momentos Hu. . . 78

6.9 Resultados de classificação considerando como acerto ao menos uma imagem da mesma classe para um conjunto de dez mais parecidas. . . . . . . . 84 


\section{Introdução}

Este capítulo descreve a importância e o estado atual da categorização de imagens médicas, contextualizando o tema central da tese. A revisão da bibliografia, o objetivo do trabalho e a estrutura desta tese serão apresentados neste capítulo.

\subsection{O uso de Imagens Médicas no Diagnóstico e a Im- portância do seu Armazenamento Categorizado}

Atualmente, o uso de imagens médicas se tornou informação essencial para o médico no diagnóstico de doenças (DOI, 2006). A riqueza de informação presente em imagens médicas permite que se examinem detalhes anatômicos e fisiológicos do paciente de forma a identificar patologias. O uso adequado da modalidade da imagem pode fornecer evidências físicas sobre a doença e até mesmo sobre a sua origem.

Devido ao seu uso corriqueiro, o volume de imagens produzido diariamente em um hospital é muito grande. Para se ter uma idéia, no Instituto do Coração de São Paulo (InCor-SP), considerado um hospital de médio porte, o volume de imagens produzido anualmente está na ordem de $13 \mathrm{~TB}$ (10 $10^{13}$ bytes). A modalidade das imagens geradas está distribuída em raio-X, ressonância magnética, tomografia computadorizada, entre outras. Por questões legais, as imagens são documentos do paciente e devem ser arquivadas pelo hospital por algumas dezenas de anos (MüLLER et al., 2004),(S.DEB; Y.ZHANG, 2004),(SANTOS; FURUIE, 2006).

Com a evolução dos equipamentos de aquisição, a grande maioria das imagens é gerada digitalmente. Os avanços tecnológicos e científicos proporcionaram a construção 
dos sistemas de informação do hospital, os quais permitem armazenar, junto às imagens, as informações do paciente (FURUIE et al., 2006). Estas informações podem ser dados pessoais do paciente do prontuário eletrônico, imagens e exames laboratoriais (SANTOS; FURUIE, 2006).

Desta forma, nos tempos atuais é possível que as imagens sejam armazenadas com informações clínicas do paciente e classificadas a partir do auxílio de dicionários padronizados, como SNOMED ${ }^{1}, \mathrm{MeSH}^{2}$ e o $\mathrm{UMLS}^{3}$, que dispõem de códigos para a região do corpo examinada, modalidade da imagem, particularidade da técnica usada no exame e contraste aplicado no exame. O armazenamento das imagens detalhado com informações clínicas e devidamente categorizado é importante para a recuperação da imagem, que é feita com o uso do PACS (Picture Archiving and Communication System) (HUANG, 2004)). Porém, nem todos os hospitais têm todos os sistemas anteriormente descritos. No caso ideal, onde se tem a infra-estrutura para armazenar um grande volume de dados, o PACS e o sistema de arquivamento de imagens com informações clínicas e dicionários, o hospital armazena em sua base de dados uma fonte riquíssima de informações. Entretanto, a maior parte dos PACS existentes permite somente o acesso às imagens usando informações de identificação do paciente de interesse, ou então, o acesso a outras imagens através de buscas textuais através de informações pré-definidas.

Comumente, as buscas textuais são baseadas nos dados do cabeçalho da imagem. Muitos dados são preenchidos manualmente pelo radiologista (ou técnico), que nem sempre usa dicionários padronizados. Contudo, as informações do cabeçalho ou a classificação feita por um especialista podem não ser confiáveis ou mesmo não estar disponíveis, pois a rotina clínica do radiologista é intensa, com atendimento a muitos pacientes e o detalhamento no armazenamento da imagem acaba se tornando algo de menor prioridade (GÄULD et al., 2002).

Transformar estes dados em informações de referência para o especialista constituise em um grande avanço. Para isso, é importante encontrar, neste enorme conjunto

\footnotetext{
${ }^{1}$ SNOMED - Systemized Nomenclature of Medicine, http://www.snomed.org

${ }^{2} \mathrm{MeSH}$ - Medical Subject Heading, http://nlm.nih.gov/mesh

${ }^{3}$ UMLS - Unified Medical Language Systems, http://nlm.nih.gov/research/umls
} 
de informações, casos similares e não apenas facilitar a recuperação dos dados de um único paciente. Estas informações similares podem ser importantes para acompanhar a evolução de doenças, evidenciar características de doenças, auxiliar médicos na decisão de diagnósticos, desenvolver novas áreas de pesquisas e prover auxílio didático, entre outros.

Este cenário fez com que surgissem novas pesquisas para transformar as imagens armazenadas no hospital em informações alternativas na busca de casos similares. A principal delas é o desenvolvimento de sistemas CBIR (Content-Based Image Retrieval), nas quais a busca passa a ser feita não mais por textos, mas com base em características extraídas das imagens. Entretanto, a busca baseada em características é uma tarefa difícil de ser feita pelo computador, pois pode existir inconsistência entre as características que o radiologista identifica e aquelas extraídas pelo sistema. A esta inconsistência é dado o nome de gap semântico (MüLLER et al., 2004). Há pesquisas, chamadas relevance feedback, que visam considerar a opinião do usuário após a recuperação das imagens. Desta forma, o sistema é interativo e, a cada opinião do usuário, a busca é refinada. Por outro lado, existe outra linha de pesquisa importante na tentativa de minimizar a inconsistência de semântica, que é a categorização automática das imagens (LEHMANN et al., 2005), foco deste trabalho.

Como já discutido, as imagens podem ser salvas em diversos níveis de granularidade como modalidade, parte do corpo examinada, código do dicionário, patologia, etc. Assim, a categorização automática será importante no armazenamento e na busca da imagem. Do ponto de vista de armazenamento, o médico poderia receber de um sistema automático uma primeira sugestão sobre a categoria da imagem e apenas confirmar se é correta ou não, o que pode garantir o armazenamento detalhado da imagem. Por outro lado, o uso do classificador na procura das imagens mais semelhantes poderia funcionar como uma forma de contextualizar a busca, o que além de focar em imagens da mesma classe, reduziria o espaço de busca, elevando a precisão do resultado de recuperação e a velocidade no tempo da resposta. 


\subsection{Categorização de Imagens Médicas: Trabalhos Cor- relatos}

Categorizar imagens médicas significa classificar imagens dentro de grupos pré-definidos. Na literatura, a categorização de imagens é dividida em manual ou automática (LEHMANN et al., 2005).

A categorização manual, comum na prática médica, é feita por médicos ou radiologistas durante o procedimento de documentação do diagnóstico, com o uso de dicionários padronizados. Técnicas modernas de informática em saúde como o arquivamento de imagens e sistema de comunicação (PACS) e modalidades digitais conectadas por protocolo de imagem digital e comunicação na medicina (DICOM) poderiam facilitar a tarefa de categorização, com o uso de informações adicionadas pelo médico às imagens, armazenadas na forma de metadados ${ }^{4}$ Estas informações poderiam ser úteis para a pré-classificação da imagem, por exemplo, em modalidade ou região do corpo examinada. Porém, as informações do cabeçalho nem sempre estão disponíveis ou nem sempre são confiáveis (GÄULD et al., 2002).

Por outro lado, a categorização automática de imagens, que não envolveria o médico ou o radiologista no processo, em geral é definida como um mapeamento de imagens em suas classes. Este processo envolve três princípios básicos (JAIN; DUIN; MAO, 2000):

i. representação: extração de características apropriadas à descrição da imagem;

ii. adaptação: seleção do melhor subconjunto de características que garante informação discriminante e

iii. generalização: treinamento e avaliação das características selecionadas por um classificador.

Desta forma, ao definir previamente as categorias, com o uso de dicionários e com o uso conjunto de imagens de cada categoria, será também necessário definir o extrator

\footnotetext{
${ }^{4}$ Metadados são dados capazes de descrever outros dados, ou seja, dizer do que se tratam, dar um significado real e plausível a um arquivo de dados (SILBERSCHATZS; KORYH; SUDARSHAN, 2006).
} 
de características e o classificador. A este conjunto, extrator de características e classificador, dá-se o nome de máquina classificadora. No diagrama esquemático da máquina classificadora, Figura 1.1, o conjunto de imagens categorizadas é usado para o treinamento da máquina classificadora. Após este processo, ao apresentar uma imagem, a máquina classificadora sugerirá uma categoria, como mostrado na Figura 1.2.

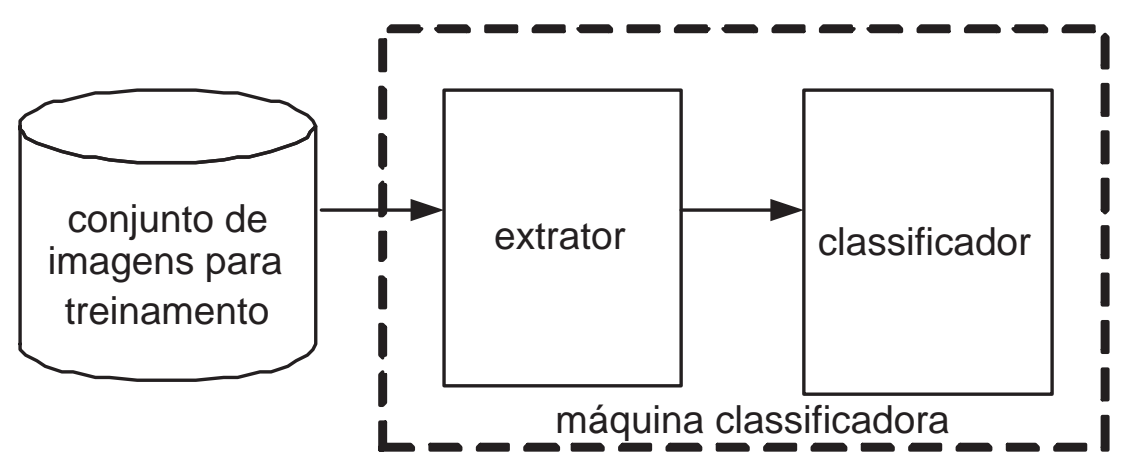

Figura 1.1: Modelo para classificação automática em categorias.

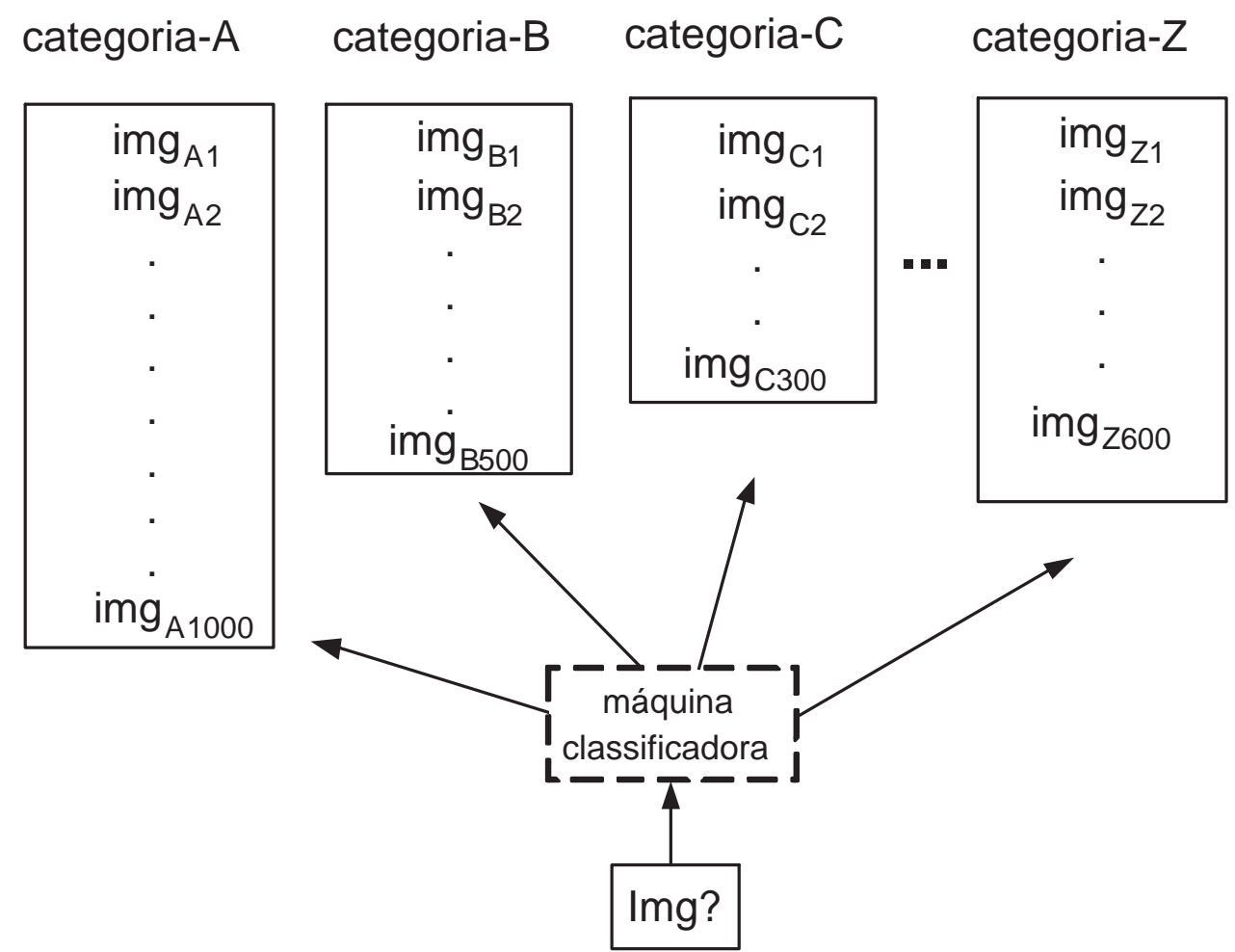

Figura 1.2: Esquema de categorização automática de uma imagem nova em relação às categorias existentes.

Uma forma alternativa de categorização automática, considerando grupos definidos por especialistas, seria utilizar modelos gerados por algoritmos de agrupamento, definindose, assim, grupos a partir de análises intrínsecas das imagens, com o uso das técnicas de 
mineração de dados (MEDASANI; KRISHNAPURAM, 1998),(SAUX; BOUJEMAA, 2002), ou através de técnicas de aprendizado de máquina (RAHMAN; BHATTACHARYA; DESAI, 2007).

Na categorização automática, as imagens são representadas por características e separadas por um classificador. No aprendizado, é necessário ter imagens categorizadas em algum nível de granularidade para a medição do desempenho do classificador.

Os trabalhos existentes divergem no nível de detalhes de caracterização. Alguns trabalhos propõem classificar orientação lateral e orientação frontal da radiografia do tórax, com erro em torno de 1\% (PIETKA; HUANG, 1992), (BOONE; SESHAGIRI; STEINER, 1992). Outros, como o trabalho de Pinhas e Greenspan (PINHAS; GREENSPAN, 2003), a taxa de erro para categorização de 851 imagens médicas em oito classes foi abaixo de 1\%. Em (KEYSERS et al., 2003), uma máquina classificadora para categorizar 1.617 imagens em seis classes pré-definidas de acordo com a parte do corpo apresentou erro de 8\%. Lehmann e colaboradores (LEHMANN et al., 2005) fizeram a categorização automática em um número extenso de categorias em relação aos trabalhos anteriores (80 categorias), descrevendo a modalidade, direção da imagem, parte do corpo e o sistema biológico examinado a partir de informações codificadas manualmente e obtiveram erro de $23,9 \%$ a partir de 6231 imagens de referência. Deselaers e colaboradores (DESELAERS et al., 2006) usaram uma extensa base de dados, com 10.000 imagens distribuídas em 116 categorias do código IRMA (Image Retrieval in Medical Applications), e obtiveram erro de 12,2\%.

Os trabalhos supracitados usam características específicas para cada representação, com exceção de Lehmann e colaboradores (LEHMANN et al., 2005) e Deselaers (DESELAERS et al., 2006) que usam características globais. Para a generalização, todos eles usam um classificador estatístico, o conhecido Knn, ou k-vizinhos mais próximos (DUDA; HART; STORK, 2000).

Em contrapartida aos trabalhos anteriores que usam Knn, Rahmann et al. (RAHMAN; BHATTACHARYA; DESAI, 2007) usaram um classificador com aprendizado (EAKINS, 2003). Neste trabalho, combinaram-se o aprendizado não-supervisionado fuzzy c-means e o aprendizado supervisionado Support Vector Machine (SVM). O processo híbrido tem 
o fuzzy c-mean para agrupar imagens em torno de centros, e o $S V M$ que é treinado com base nos centros gerados pelo fuzzy c-means e usado como classificador. Entretanto, as imagens também são representadas por características específicas.

\subsection{Objetivo do Trabalho}

De acordo com a literatura, nota-se que:

- a classificação automática é importante para o armazenamento detalhado da imagem que, por sua vez, é ponto importante para transformar conjuntos de imagens em informações de referências para médicos e radiologistas na tomada de decisão ou para estudantes e residentes na especialização de diagnóstico por imagens;

- grande parte dos trabalhos usam extratores de características específicos à aplicação e poucos usam extratores de características globais.

- o classificador Knn é o mais usual, porém, o seu desempenho é baseado em todas as imagens da base de dados, ou seja, a cada imagem nova a ser classificada, uma comparação com todas as imagens da base de dados é necessária e uma ordenação pelas imagens mais semelhantes é realizada.

Motivado por estas observações, o objetivo do trabalho é construir um modelo de máquina classificadora que envolve a transformada wavelets combinada com os momentos de Hu como base para a extração de características globais das imagens e com a rede neural artificial do tipo SOM como base para a classificação (SILVA et al., 2006), (SILVA et al., 2007). Os resultados deste estudo serão comparados aos principais resultados apresentados na literatura, avaliando-se o desempenho em termos de taxa de classificação correta e tempo de processamento.

Em suma, são propostos neste trabalho uma forma alternativa de máquina classificadora ainda não apresentada na literatura, uma abordagem combinando wavelets e momentos de $\mathrm{Hu}$ para a extração de características globais e um novo método de se utilizar SOM na classificação. 


\subsection{Estrutura do Texto}

Além da Introdução (Capítulo 1), que visa facilitar a compreensão do trabalho e contextualizá-lo, compõem a tese as seguintes partes:

No Capítulo 2, discute-se principalmente o sistema de informação de um hospital, explicitando-se a importância das imagens, as aplicações viabilizadas pela categorização, e como esta pode estar inserida no sistema de informação.

No Capítulo 3, introduzem-se as principais técnicas de extração de características existentes.

Uma rápida introdução teórica sobre Mapas Auto-Organizáveis (SOM) é apresentada no Capítulo 4. Apresentam-se, também, as medidas de desempenho utilizadas para avaliação do SOM e as diferentes formas de usá-lo em problemas classificação.

Discutem-se no Capítulo 5 a proposta do trabalho para usar SOM em uma tarefa de classificação, os problemas envolvidos com essa metodologia e como são tratados no trabalho. Os materiais e métodos utilizados no trabalho também são apresentados.

Os resultados de classificação usando a máquina classificadora proposta e também os resultados usando outras metodologias são apresentados no Capítulo 6.

Discutem-se no Capítulo 7 os conceitos apresentados na tese e os resultados obtidos nesta tese. Apontam-se neste capítulo também os trabalhos futuros. 


\section{Imagens na Medicina Moderna: Aquisição, Armazenamento e Potenciais Aplicações}

Imagens têm-se tornado uma ferramenta essencial na prática da medicina moderna, como evidenciado nos últimos 50 anos (DUNCAN; AYACHE, 2000),(DOI, 2006). A combinação de imagens com outros dados médicos, como laudos ou exames laboratoriais, pode formar um acervo rico em informações para fins didáticos e de pesquisas (TRAINA; ROSA; TRAINA-JR, 2003),(FURUIE et al., 2003),(FURUIE et al., 2006). Porém, o hospital deve estar equipado com uma infra-estrura capaz de fazer aquisição das imagens em formato proprietário, pois não pode haver perda, e de fazer também a combinação com os laudos preparados usando dicionários médicos.

Há ainda a necessidade da construção de uma base de dados vinculando imagens e laudos e, também, um módulo visualizador para exibir estas informações. Este capítulo tem a função de informar brevemente ao leitor como é um sistema de base de imagens médicas, desde o processo de aquisição até a visualização e, também, mostrar como a proposta da máquina classificadora pode ser inserida nesta infra-estrutura. Por fim, as aplicações que podem ser desdobradas desta infra-estrutura serão exemplificadas, principalmente a aplicação de recuperação de imagens por conteúdo (CBIR, Content-based Image Retrieval). 


\subsection{O uso de Imagens na Medicina Moderna}

A prática moderna em saúde mostra que o uso de imagens médicas se tornou instrumento essencial para o diagnóstico de doenças (MüLLER et al., 2004), (S.DEB; Y.ZHANG, 2004), (WHITE; JAIN, 1996). O uso da modalidade adequada da imagem em um diagnóstico, como raios-X, ressonância magnética $(\mathrm{RM})$, ultra-som, entre outras, pode fornecer evidências físicas sobre a doença e até mesmo sobre a sua origem. Por esta razão, há um crescente aumento de imagens produzidas diariamente e o uso deste repositório devidamente classificado e associado a outras informações transforma-se em um importante arquivo didático, ou mesmo, uma importante referencia para apoio à decisão (M.A.SANTOS; FURUIE, 2004) e (SANTOS; FURUIE, 2006).

\subsection{Sistema de Informação em Saúde}

O Sistema de Transação e Armazenamento de Imagens ou simplesmente PACS (Picture Archiving and Communication System) consiste na aquisição de imagens e dados, armazenamento e visualização (HUANG, 2004). O PACS trata da digitalização, compartilhamento e armazenamento de imagens médicas obtidas pelos diversos equipamentos de aquisição (ressonância magnética, raios-X, tomografia computadorizada, etc) em redes Intranet ou Internet. Além de armazenar imagens, o PACS é capaz de armazenar dados a elas associados e também fazer interface com sistemas de informação existentes no hospital: sistema de informação hospitalar (HIS, acrônimo de hospital information system) e sistema de informação da radiologia (RIS, acrônimo de radiology information system).

As imagens médicas geralmente estão em um padrão chamado de DICOM (Digital Imaging and Communications in Medicine). Este padrão permite que a imagem tenha outras informações a elas agregadas, como nome do paciente, idade, peso, entre outras, que são armazenadas no cabeçalho da imagem (header).

Os grandes avanços que o PACS permite são a redução no tempo de entrega do exame e a possibilidade de compartilhamento com outros profissionais. Quando utilizado com um 
visualizador, por exemplo, o iView do InCor (SANTOS; FURUIE, 2006), a imagem pode ser exibida com ferramentas de apoio ao processamento de imagens como zoom, melhora de contraste, marcações, seleções de ROI (Region of Interest). Uma outra forma de visualizar a imagem é com as informações clínicas (MORENO; FURUIE, 2007). A imagem, juntamente aos laudos ou exames, pode estar disponível em um único visualizador e, assim, ajudar em estudos clínicos ou diagnósticos.

A Figura 2.1 mostra o esquema do processo de aquisição de imagens no InCor. A aquisição de imagens é gerenciada por um PACS institucional, enquanto o relatório de texto é gerenciado pelo HIS. A visualização de ambos, imagem e relatório, pode ser feita pelo iView (SANTOS; FURUIE, 2006).

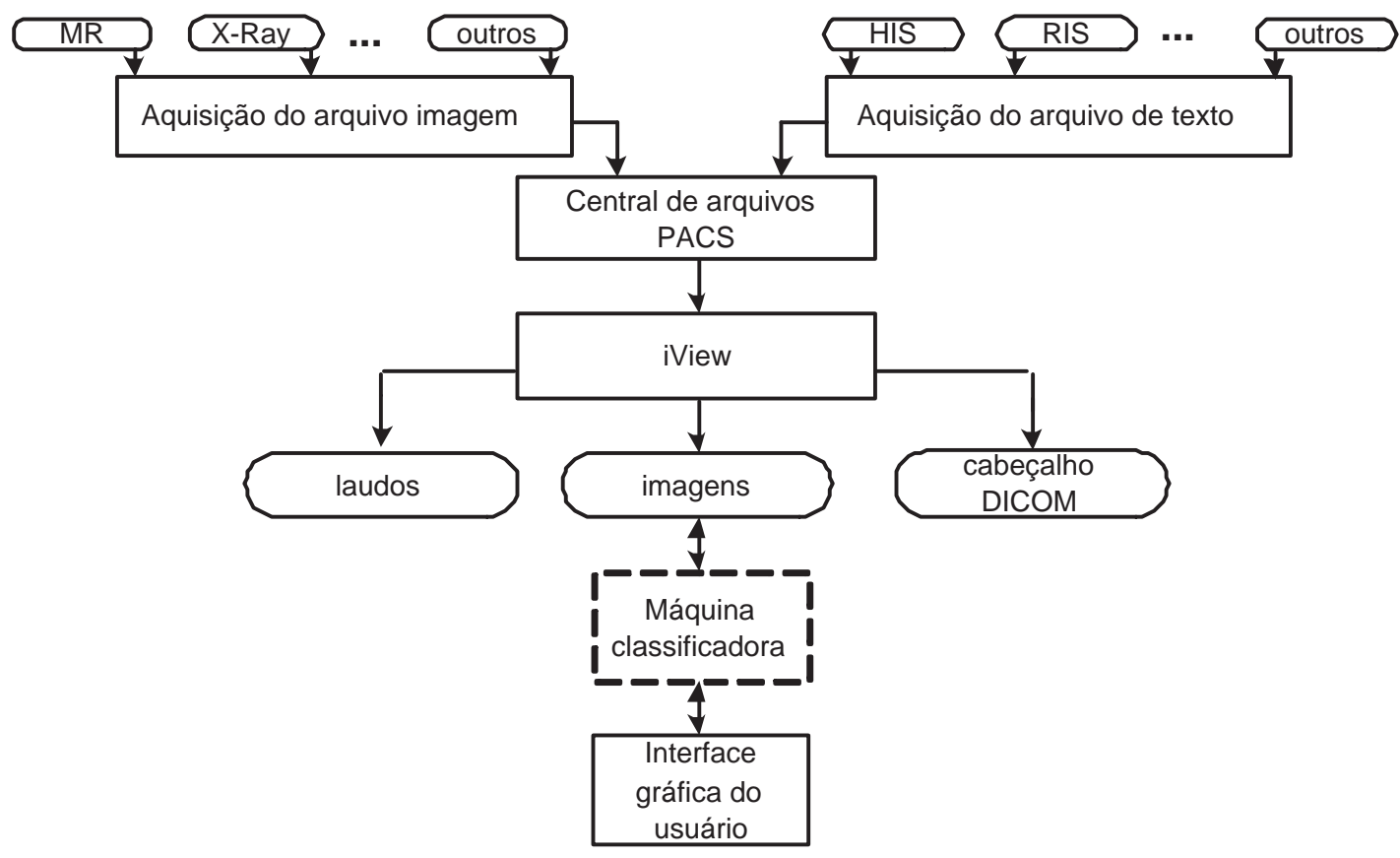

Figura 2.1: Esquema básico do sistema de arquivamento de imagens médicas do InCor já com o módulo de máquina classificadora.

Em um sistema PACS tradicional, é possível consultar a uma imagem específica de um paciente, usando parâmetros como seu nome, número da matrícula, número do estudo, etc. Porém, para usar as imagens arquivadas em um banco de dados como material de referência em apoio didático ou em apoio ao diagnóstico, deve haver a possibilidade de buscar imagens semelhantes, de forma que, ao apresentar uma imagem específica de um paciente, as imagens mais semelhantes da base de dados sejam localizadas e visualizadas 
em um sistema. Para isso, as imagens devem ser armazenadas segundo uma classificação, ponto onde se insere esta pesquisa.

A classificação necessitará de uma mudança no sistema de informação. Agora, antes da interface do usuário, a máquina classificadora deve ser inserida. O resultado está ilustrado na Figura 2.1. Ao classificar as imagens, pode-se usar também o visualizador para ver as mais semelhantes e, junto a estas, o diagnóstico, laudo e outras informações que estiverem disponíveis.

Em suma, o sistema de informação é um modelo de dados que relaciona o paciente e toda sua trajetória dentro de um hospital. Nele, o paciente, em seu primeiro cadastro, adquire um número de matrícula (identificação) que sempre é usado para qualquer procedimento hospitalar. Este processo está implementado em muitos hospitais ou está em desenvolvimento em muitos outros, pois reduz custos com repetição de exames e acelera a disponibilização do exame. A tendência é que os sistemas de informação de vários hospitais sejam integrados, o que já acontece em alguns hospitais-escolas pelo país.

Outro estudo importante que uma base de dados categorizada proporciona é a mineração de informação. A procura por padrões semelhantes em uma extensa base de dados permite reduzir custos com a informação de exames anteriormente feitos, descobrir causas e efeitos de doenças. Esta pesquisa também pode ser inserida neste contexto, no qual a mineração é feita com base nas imagens e não em textos, o que leva à necessidade de extrair informações da imagem.

\subsection{Potencial aplicação do armazenamento organizado de imagens médicas}

As imagens armazenadas, como já dito, podem ser usadas como referências em diagnósticos ou até mesmo no auxílio à tomada de decisão. Para isto, o uso de sistemas de recuperação de imagens por conteúdo, ou CBIR (Content-Based Image Retrieval) como são comumente conhecidos, é necessário. 


\subsubsection{Recuperação de Imagens por Conteúdo}

As imagens, de modo geral, contêm informações semânticas de difícil descrição por informações textuais. Isto explica o aumento no interesse de pesquisas em técnicas de mineração de dados em imagens e recuperação de imagens por conteúdo (CBIR) (SMEULDERS et al., 2000). A mineração de dados objetiva encontrar informações importantes através da análise em uma grande massa de dados e disponibilizar o resultado de forma a ser melhor entendido pelo observador humano (HAN; KAMBER, 2001).

Por outro lado, o CBIR visa procurar em uma base de dados imagens semelhantes a uma dada imagem de busca ou a características extraídas da imagem. Diferentemente da busca feita em um banco de dados convencional, em CBIR a busca é baseada em características como cor, forma ou textura das imagens, também chamadas de características de baixo nível.

Existem diferentes formas de se construir sistemas CBIR. Nas discussões feitas neste trabalho, a aplicação de recuperação é baseada em exemplo (MüLLER et al., 2004). A Figura 2.2 mostra um caso desta aplicação, onde, dada uma imagem de consulta, se faz uma comparação com as imagens que estão armazenadas em um banco de dados para encontrar as mais semelhantes e, conseqüentemente, recuperá-las.

Existem também diversas áreas de aplicação CBIR (CASTELLI; BERGMAN, 2001). Talvez a mais importante seja a medicina, na qual há um aumento constante no número de imagens geradas (LEHMANN et al., 2005). Porém, grande parte destas pesquisas foca em um conteúdo particular da imagem, região do corpo ou modalidade. Na medicina, o CBIR não deveria se restringir a um contexto específico, reforçando o fato de que as imagens médicas devem ser categorizadas.

Quando se diz que a recuperação é feita por imagem, significa que a recuperação é feita com base em características dela extraídas. A extração de características é feita de forma semelhante à que foi apresentada anteriormente na Seção 1.2. Entretanto, em CBIR, as características devem ser estruturadas para facilitar a busca pelas imagens mais 
semelhantes. Diferentes trabalhos para a estruturação das características são encontrados na literatura (WHITE; JAIN, 1996), (NG; SEDIGHIAN, 1996), (WEBER; SCHEK; BLOTT, ), (Y.RUI; HUANG, 1999), (BöHM; BERCHTOLD; KEIM, 2001), cujos estudos são chamados de técnica de indexação multidimensional. Existem também trabalhos que usam redes neurais em CBIR (KOIKKALAINEN; OJA, 1990), (ZHANG; ZHONG, 1995), (OH; KANEKO; MAKINOUCHI, 1999), (KOSKELA, 2003), (WU; RAHMAN; CHOW, 2005).

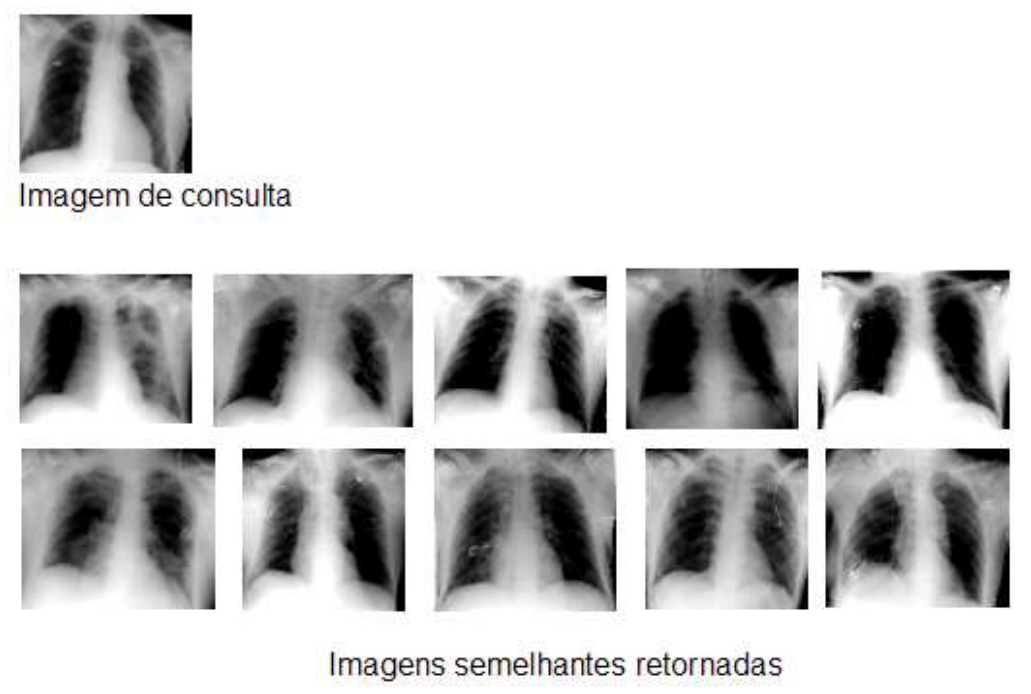

Figura 2.2: Exemplo de um caso de aplicação do sistema CBIR.

\subsection{Considerações Finais}

Neste Capítulo foi discutido sobre o sistema de informação de um hospital, apresentando o padrão de aquisição de imagens, PACS, e o formato em que as imagens, em todas as modalidades, são armazenadas, DICOM. A modernização de um hospital com um sistema de informação permite associar aos dados do paciente, adquiridos desde a sua entrada em um hospital, os exames de imagens ou de laboratórios por ele realizados. O armazenamento destas informações por longo prazo torna a base de dados do hospital um importante repositório de informações que podem ser úteis para fins de ensino, pesquisa e apoio ao diagnóstico.

Muitos avanços foram alcançados nos últimos anos na visualização de informações, mas ainda existem desafios para sua busca. A proposta deste trabalho permitirá armaze- 
nar a imagem de forma categorizada e contextualizar grupos de imagens em uma busca.

No próximo capítulo discute-se acerca das principais técnicas de extração de características, importantes para a contextualização e compreensão da proposta desta tese. 


\section{Extração de Características}

Extração de características é um processo de criação de um vetor representativo de componentes principais de uma imagem, servindo assim para representá-lo em um vetor $\mathbf{v}$, chamado de vetor de características com dimensão $d$, sendo que $\mathbf{v} \in \Re^{d}$ (LEHMANN et al., 2005). As características são valores extraídos da imagem usando técnicas específicas de análise de imagens ou, então, combinando diferentes técnicas. O vetor de características deve ser o mais descritivo possível, a ponto de, por exemplo, distinguir classes de imagens entre si. Um esquema de extração de características está ilustrado na Figure 3.1.

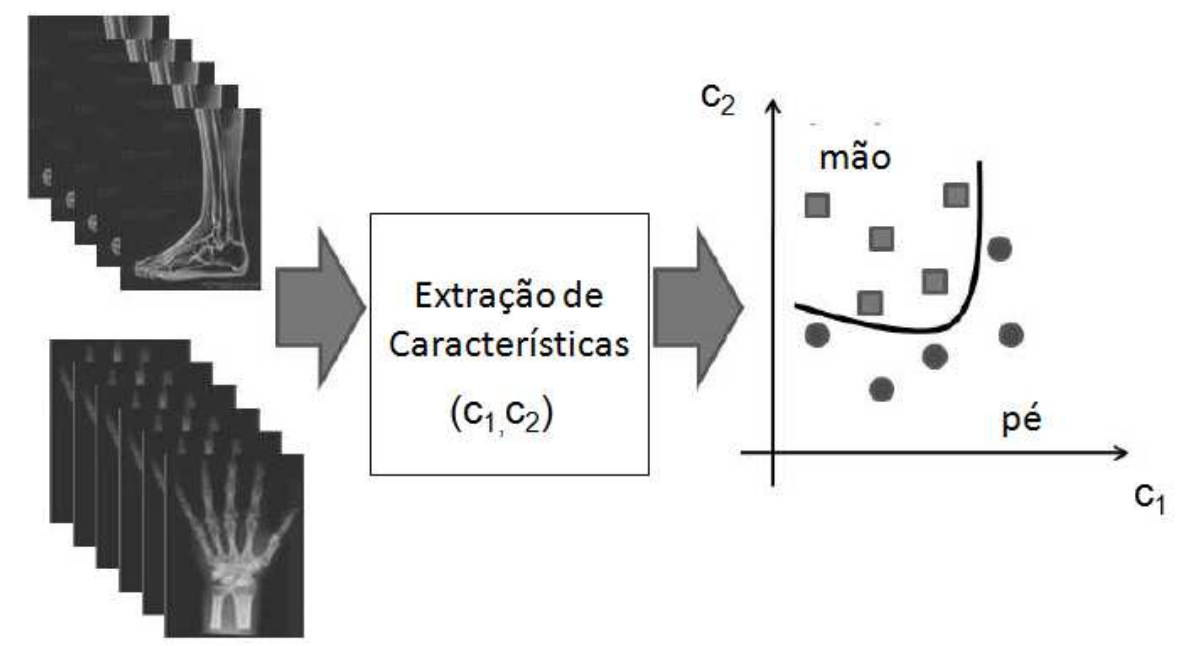

Figura 3.1: Ilustração esquemática da extração de características em imagens de pé e de mão.

No sistema de categorização de imagens, e também em sistemas CBIR, a extração de características é uma etapa bastante importante, pois é como as imagens são representadas no ambiente computacional. Em geral, as características comuns extraídas são: cor, textura e forma (MüLLER et al., 2004). Estas características desempenham bons resultados 
em aplicações específicas, como classificação de imagens de câncer de mama em patológico ou não patológico (SILVA; DEL-MORAL-HERNANDEZ; RANGAYYAN, 2008). Para aplicações mais amplas, como neste trabalho, nas quais o número de classes de imagens é bastante grande (muito maior que duas classes - patológico e não patológico), o desafio de extração de características torna-se um problema complexo.

Em problemas de recuperação de imagens por sistemas CBIR, as características extraídas das imagens devem ser equivalentes às características que o especialista examina no diagnóstico. Caso haja diferença entre as características extraídas por um sistema computacional e as características analisadas pelo especialista, as imagens recuperadas por um sistema CBIR não estarão de acordo com as imagens esperadas pelo usuário. A essa inconsistência dá-se o nome de gap semântico. Trabalhos recentes buscam um melhor extrator de características ou, então, procuram combinar alguns extratores para melhorar o desempenho de classificação ou melhorar a qualidade da recuperação.

Nas sessões seguintes serão discutidas as técnicas de extração de características que têm se destacado na literatura em função dos bons resultados. Uma explicação introdutória da Transformada Wavelet (TW) e uma explicação dos momentos de Hu também serão feitas nas próximas sessões para um melhor entendimento da proposta. Por fim, será detalhada a proposta de combinação da TW com os momentos de $\mathrm{Hu}$.

\subsection{Extratores de Características}

Como já discutido, as características são dirigidas ao tipo de classificação que deve ser feita (PIETKA; HUANG, 1992),(BOONE; SESHAGIRI; STEINER, 1992),(KEYSERS et al., 2003),(EAKINS, 2003),(SILVA; DEL-MORAL-HERNANDEZ; RANGAYYAN, 2008). Existem diferentes extratores (CASTELLI; BERGMAN, 2001). Entretanto, deve-se ter em mente que as características devem representar todas as granularidades desejadas em uma classificação mais ampla e não se restringir à cor, à forma ou à textura para representar uma categoria específica.

Além disso, no contexto de imagens médicas, é comum haver problemas como: 
- contraste: tecidos humanos e órgãos, assim como a modalidade do exame ou a calibração do aparelho de aquisição, resultam em imagens com diferentes contrastes.

- escala: em cada modalidade, pacientes de diferentes tamanhos são examinados;

- rotação: nem sempre é possível manter a posição do paciente no momento do exame;

- translação: a posição do paciente a cada exame em relação ao equipamento de aquisição é modificada.

Deve-se, portanto, pensar em técnicas que possam extrair características de muitas categorias e que sejam invariantes a contraste, escala, rotação e translação. Invariância a contraste é uma tarefa que pode ser satisfatoriamente resolvida, usualmente, aplicando-se algum tipo de normalização. Por outro lado, as outras invariâncias necessitam de técnicas mais sofisticadas, discutidas a seguir.

Lehmann e colaboradores (LEHMANN et al., 2005), usando uma base de imagens da rotina clínica do hospital, reuniram 10.000 imagens distribuídas em 80 categorias. Experimentos de classificação foram conduzidos comparando diversas técnicas de extração de características. Dentre as técnicas estão textura de Tamura, textura de Castelli, Transformada Discreta do Cosseno, características de borda por detector de Canny e redimensionamento do número de linhas e de colunas da imagem $(l \times c)$ original em vários níveis $(8 \times 8,16 \times 16,24 \times 24$ e $32 \times 32)$. A técnica que resultou em melhor resultado de classificação foi a de redimensionamento da imagem original de tamanho 256 para 32, como mostrado na Figura 3.2.

Por outro lado, existem os momentos de Zernike que garantem invariância a escala, translação e rotação. Estes momentos são magnitudes de um conjunto de momentos complexos e ortogonais da imagem, que garantem invariância à rotação. Invariância à escala e à translação é obtida normalizando a imagem primeiramente, usando como parâmetros os seus momentos geométricos regulares (KHOTANZAD; HONG, 1999). Zhang e Li (ZHANG; LU, 2001) fizeram estudos de comparações dos momentos de Zernike com descritores de Fourier, descritores de espaço de escala de curvatura e descritores de grid. 


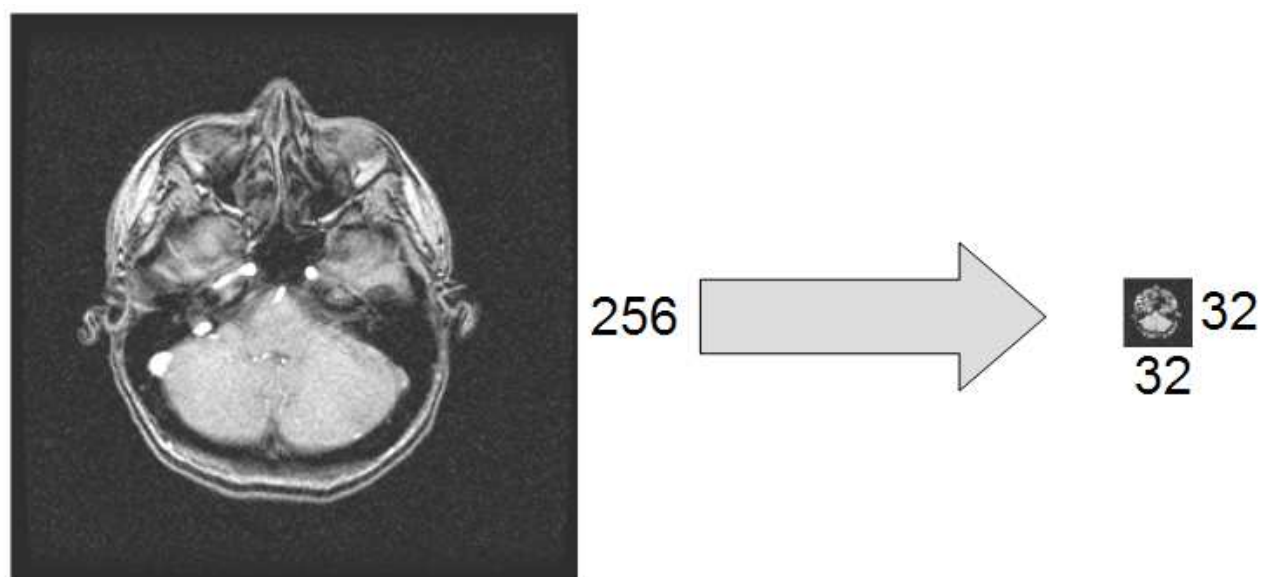

256

Figura 3.2: Imagem Redimensionada.

O conjunto de momentos de Zernike apresentou melhor resultado de recuperação sob o aspecto de robustez. Em termos de taxa, Felipe (FELIPE, 2005) utilizou os momentos de Zernike em seus experimentos com imagens de câncer de mama e conseguiu resultados satisfatórios de classificação, quando os momentos foram selecionados.

Deselaers e colaboradores (DESELAERS et al., 2006) propuseram os Histogramas Esparsos baseados em Patches. O patch é extraído para cada pixel da imagem. Após a extração dos patches de cada imagem e de todo o conjunto de imagens, calculam-se as componentes principais usando o PCA para redução da dimensão dos pactches. Por fim, os histogramas esparsos são gerados. Esta técnica, quando comparada com outras (textura, cor, forma e combinações entre elas) apresenta bons resultados de classificação em uma base de dados de 116 categorias e um total de 10.000 imagens. Por esta técnica ser a que apresenta melhor resultado na literatura, taxa de acerto de 83,8\% com o classificador Knn, na Seção 3.4 será feita uma melhor explicação sobre os Histogramas Esparsos baseados em Patches.

Uma forma alternativa para a extração de características é o uso de transformada wavelet (CASTELLI; BERGMAN, 2001)(CASTANóN, 2003). A transformada wavelet extrai componentes de alta e baixa freqüência da imagem original, em vários níveis de decomposição. Em cada nível, a imagem original é decomposta em conjuntos de coeficientes de tamanhos iguais. A transformada wavelet foi derivada da transformada de Fourier que 
utiliza funções senoidais (seno ou coseno), ou seja, as funções básicas são definidas pelo parâmetro freqüência (MALLAT, 1989). Por outro lado, transformada de wavelet utiliza funções de base que são definidas por dois parâmetros: posição e escala. Isto permite que as características de um sinal examinado sejam extraídas em função de uma posição determinada e de um tamanho desejado. Assim, há uma hipótese de que com o uso desta transformada consegue-se garantir invariância à escala e à translação e, por isso, será investigada neste trabalho. Na seção seguinte, será feita uma breve introdução sobre a transformada wavelets.

A extração de características é um elemento importante para a máquina classificadora. Características que não representam as imagens em suas categorias acarretam baixos desempenhos de classificação. A seguir, serão discutidos em mais detalhes os principais extratores de características da literatura.

\subsection{Transformada Wavelet}

A Transformada Wavelet (TW) é uma ferramenta matemática que surgiu para a análise de sinais e tem sido amplamente aplicada em processamento digital de imagens (CASTELLI; BERGMAN, 2001). Embora o propósito do capítulo seja discutir a TW em processamento digital de imagens, caso bidimensional (2-d), uma breve introdução teórica considerando um sinal contínuo, caso 1-d, será feita com intuito informativo.

A análise da TW contínua em 1-d é feita decompondo uma dada função $f$ em suas componentes com diferentes escalas e freqüências a partir da correlação de $f$ com a waveletmãe $\psi$ transladada e dilatada, onde $f \in L^{2}$ :

$$
\begin{gathered}
L_{\psi} f(a, b)=\int f(t) \psi_{a, b}(t) d t \\
\psi_{a, b}(t)=\frac{1}{\sqrt{a}} \psi\left(\frac{t-b}{a}\right)
\end{gathered}
$$

Dependendo da escolha de $\psi$ a função transformada permite extrair as descontinui- 
dades ou bordas de $f$, para a tarefa de classificação de padrões. O parâmetro $b$ permite deslocar a função $\psi$ no eixo do tempo $t$. O parâmetro de dilatação $a$ determina o tamanho da função janela $\psi\left(-\frac{b}{a}\right)$ : para valores pequenos de $a$ a TW aumenta a resolução de um pequeno detalhe do sinal $f$. O tamanho do detalhe é relacionado a uma faixa específica da freqüência; por exemplo, variando $a$, a função $f$ é examinada em diferentes freqüências. Por esta razão, a também é chamado de parâmetro de freqüência ou parâmetro de escala.

Com esta breve informação da transformada 1-d é possível reconhecer algumas das mais importantes propriedades da transformada wavelet para aplicações em processamento de imagens. Em aplicações de compressão de dados, a escolha da wavelets apropriada permite a investigação localizada de $f$ em tempo e freqüência, bem como a variação do parâmetro $a$, que permite a análise do sinal em diferentes freqüências. Em aplicações de detecção de borda, através da derivada da TW em direções específicas permite o reconhecimento de padrões invariante à rotação. No reconhecimento de padrões, a adaptação da função $\psi$ como uma aproximação do padrão permite o uso de wavelets em problemas de classificação do tipo de melhor casamento ou correlação cruzada em análises simultâneas em todas as freqüências de banda (CASTELLI; BERGMAN, 2001).

Porém, não são todas as funções $\psi$ que são usuais para a transformada 2-d. A condição admissível para uso é que a função tenha média zero, decaimento abrupto e esteja localizada tanto no espaço de tempo como no de freqüência.

\subsubsection{Análise em Multi-Resolução}

A Análise em Multi-Resolução (AMR) é uma técnica alternativa de extração de características, na qual wavelets é uma alternativa (MALLAT, 1989), (CASTELLI; BERGMAN, 2001). A análise AMR decompõe a imagem em níveis $(n)$, dentro de conjuntos de coeficientes: $c A_{n}$ representa as baixas freqüências da imagem; $c D_{n}^{h}$ (coeficientes horizontais), $c D_{n}^{v}$ (coeficientes verticais), $c D_{n}^{d}$ (coeficientes diagonais), que representam as altas freqüências da imagem. Para o próximo nível, $n+1$, o $c A_{n}$ é usado para a decomposição. A Figura 3.3 ilustra a análise AMR. 


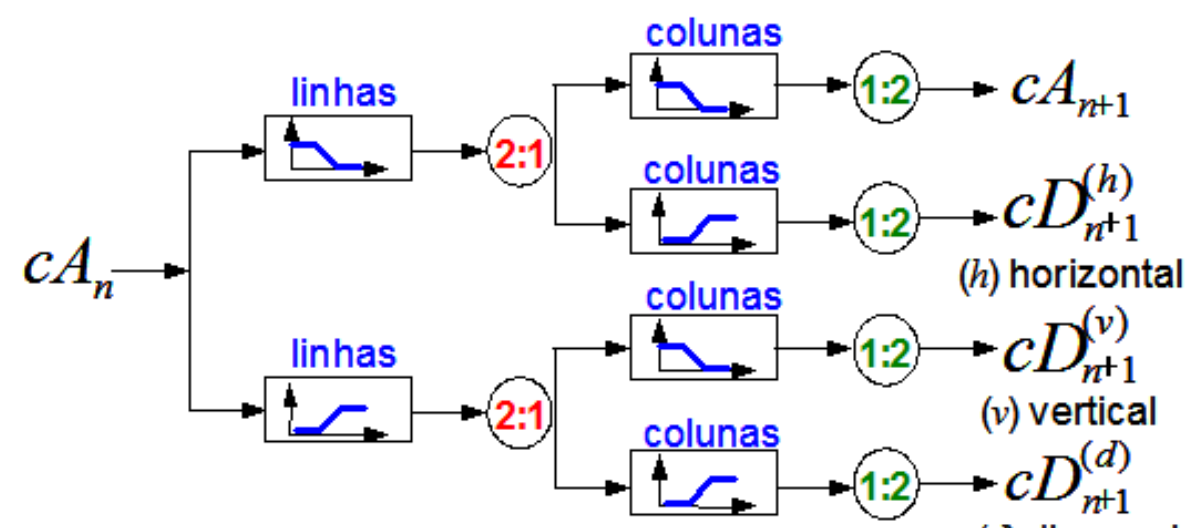

(d) diagonal

Filtro passa-baixas convolui linhas ou colunas com filtro

I Filtro passa-altas convolui linhas ou colunas com filtro

2:1 Downsample colunas mantém uma coluna de. duas

(1:2) Downsample linhas mantém uma linha de.duas

A - Aproximação - componentes de baixa freqüência do sinal

$D$ - Detalhes - componentes de alta freqüência do sinal

Figura 3.3: Modelo esquemático da AMR. 
Na decomposição é usada uma família de wavelets. Existe uma grande variedade de wavelets-mãe, incluindo Daubechies, Haar, Mexican Hat e Morlet, como mostrado na Figura 3.4.
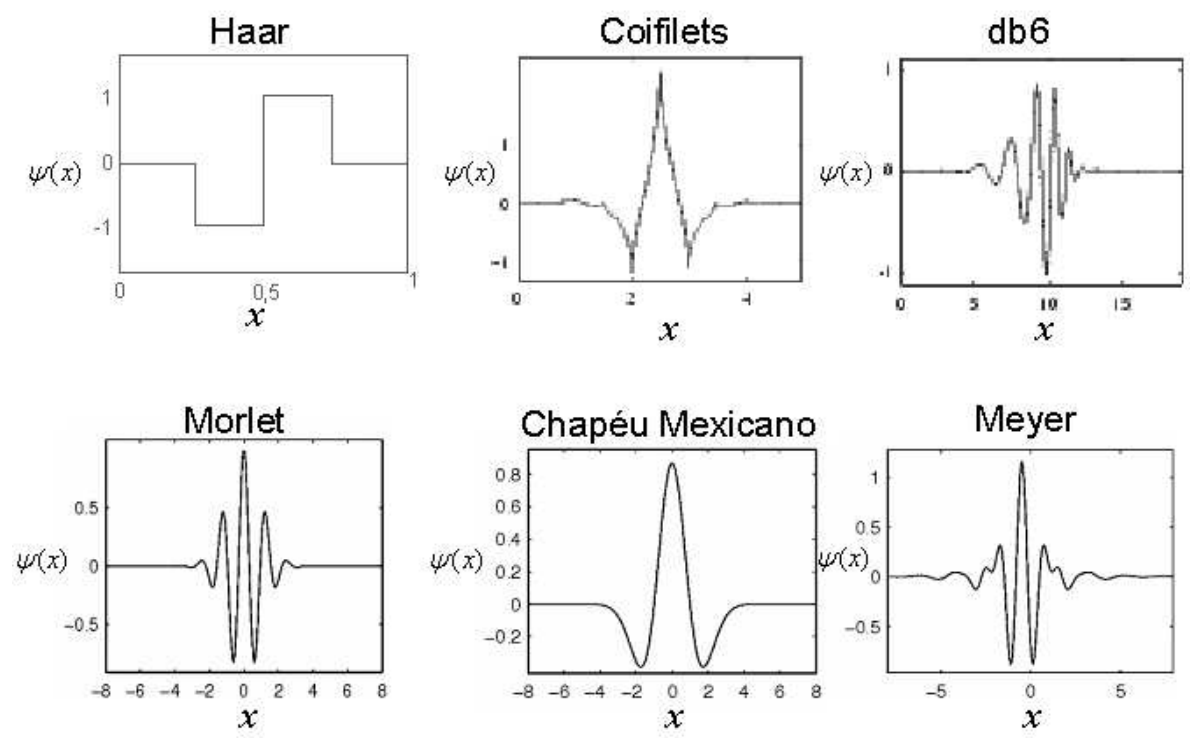

Figura 3.4: Alguns exemplos de wavelets-mãe.

Para cada aplicação, uma determinada família de wavelets é mais apropriada, como já comentado. Neste trabalho investiga-se o uso da wavelet Haar, pela simplicidade de implementação e por ela manter a morfologia da imagem original em escala reduzida. Um exemplo da aplicação da análise AMR usando wavelet Haar em uma imagem de ressonância magnética é apresentado na Figura 3.5. Nesta, a AMR é aplicada na imagem de ressonância magnética de dimensão $256 \times 256$ (Figura 3.5a), em 3 níveis de decomposição $(n=3)$ (veja Figura 3.5b) e, por fim, são mostradas as imagens resultantes de cada decomposição (Figura 3.5c).

Em aplicações médicas, é comum as imagens terem problemas de contraste, rotação, escala e translação. Antes de se aplicar a transformada wavelet, as imagens devem ser normalizadas pela maior intensidade. A transformada wavelets, pelas suas propriedades matemática, garante invariância à escala e à translação. Estudos iniciais serão apresentados para definir as propriedades do modelo da máquina classificadora quanto à robustez para estas invariâncias.

No contexto de classificador automático e CBIR, a extração de características por 
wavelets Haar é pouco utilizada. Várias outras técnicas como transformada do cosseno, textura e estrutura de forma têm sido investigadas e seus resultados estão resumidos no trabalho de Lehmann e outros (LEHMANN et al., 2005). Neste mesmo trabalho, o melhor resultado alcançado foi utilizando uma imagem redimensionada (Figura 3.2). A imagem redimensionada e a imagem decomposta por Haar são semelhantes, exceto que neste último, a imagem sofre um processo de filtragem que permite realçar a forma e a textura da imagem original. Porém, neste estudo, o conjunto de coeficientes que apresentar melhor resultado de classificação será o mais indicado para ser usado como vetor de características, mas os outros conjuntos preservam outras informações em outros níveis de detalhes. Para não descartá-los integralmente, pensou-se em combinar uma segunda técnica que resumisse esses conjuntos, mas sem aumentar demasiadamente a dimensão do vetor de características, e que mantivesse a invariância à rotação. Nesta busca pela melhor técnica, estudou-se a análise de momentos, discutida a seguir.
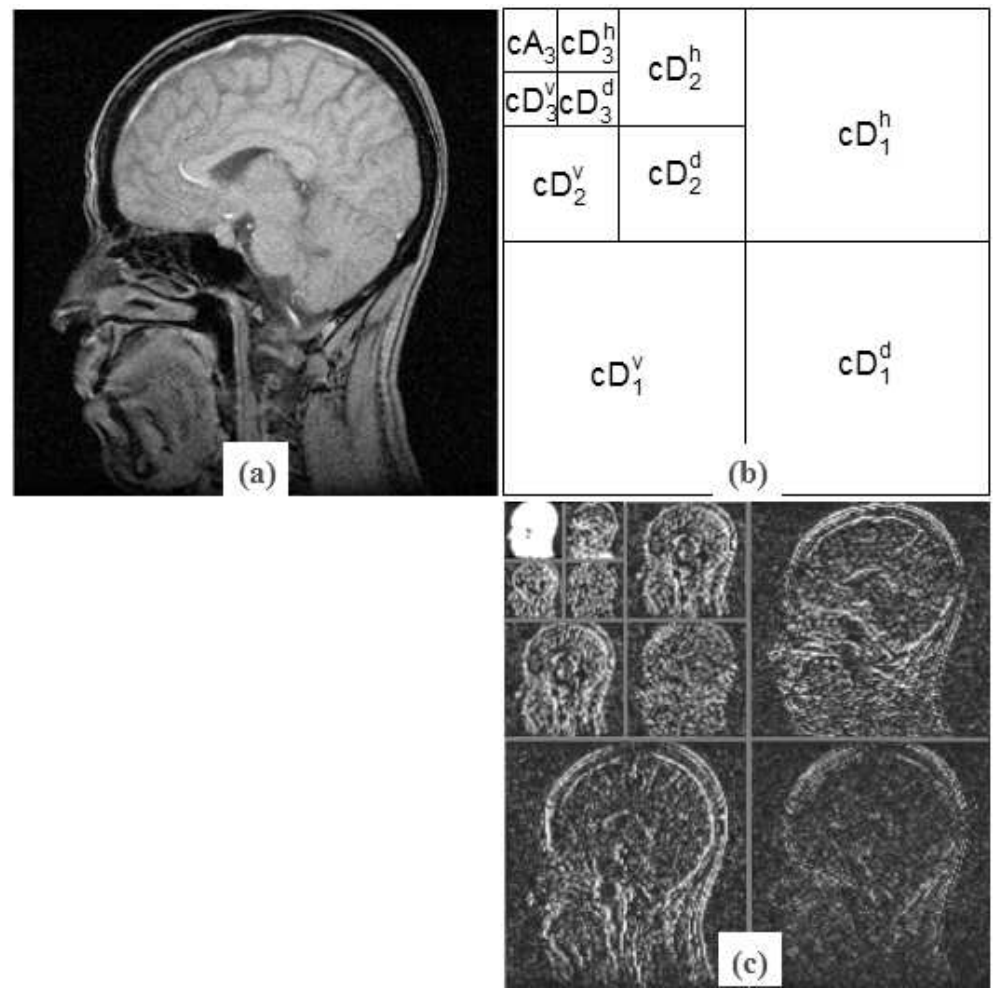

Figura 3.5: Exemplo de AMR usando função Haar em imagem de ressonância magnética. A dimensão original da imagem é $256 \times 256$. No exemplo, os coeficientes $c A_{3}$ têm a dimensão de $32 \times 32$. 


\subsection{Análise de Momentos}

Análise de Momentos é uma técnica alternativa para extração de características que, como wavelets, não necessita que a imagem seja previamente segmentada. As principais técnicas de extração de momentos são Zernike (KHOTANZAD; HONG, 1999) e Hu (HU, 1961). Em ambas as técnicas, necessita-se do cálculo dos momentos centrais, feito como mostrado na Equação 3.3:

$$
m_{p q}=\int_{-\infty}^{+\infty} \int_{-\infty}^{+\infty} x^{p} y^{q} f(x, y) d x d y
$$

onde p e q são índices para designar o número do pixel da imagem.

Para garantir invariância à translação e à escala, os momentos de Zernike devem ser normalizados e o cálculo de polinômios complexos feitos (para mais detalhes, veja (KhotanzAD; HONG, 1999)). Por outro lado, Hu (HU, 1961) baseado nos momentos centrais, propôs outros momentos que garantem invariância à translação e à escala.

$$
\mu_{p q}=\int_{-\infty}^{-\infty} \int_{-\infty}^{-\infty}(x-\bar{x})^{p}(y-\bar{y})^{q} f(x, y) d x d y
$$

onde

$$
\bar{x}=\frac{m_{10}}{m_{00}}
$$

e

$$
\bar{y}=\frac{m_{01}}{m_{00}}
$$

Para uma imagem digital, a equação 3.4 torna-se:

$$
\mu_{p q}=\sum_{x} \sum_{y}(x-\bar{x})^{p}(y-\bar{y})^{q} f(x, y)
$$

Os momentos centrais de ordem 3 permitem encontrar os eixos principais de inércia, 
os prolongamentos e as orientações de forma. Esses momentos centrais são (GONZALEZ; WOODS, 2007):

$$
\begin{aligned}
\mu_{10} & =\sum_{x} \sum_{y}(x-\bar{x})^{1}(y-\bar{y})^{0} f(x, y) \\
& =m_{10}-\frac{m_{10}}{m_{00}}\left(m_{00}\right) \\
& =0 \\
\mu_{11} & =\sum_{x} \sum_{y}(x-\bar{x})^{1}(y-\bar{y})^{1} f(x, y) \\
& =m_{11}-\frac{m_{10} m_{01}}{m_{00}} \\
\mu_{20} & =\sum_{x} \sum_{y}(x-\bar{x})^{2}(y-\bar{y})^{0} f(x, y) \\
& =m_{20}-\frac{2 m_{10}^{2}}{m_{00}}+\frac{m_{10}^{2}}{m_{00}} \\
& =m_{20}-\frac{m_{10}^{2}}{m_{00}} \\
\mu_{02} & =\sum_{x} \sum_{y}(x-\bar{x})^{0}(y-\bar{y})^{2} f(x, y) \\
& =m_{02}-\frac{m_{01}^{2}}{m_{00}} \\
\mu_{03} & =\sum_{x} \sum_{y}(x-\bar{x})^{0}(y-\bar{y})^{3} f(x, y) \\
\mu_{21} & =\sum_{x} \sum_{y}\left(x-\bar{y} m_{02}+2 \bar{y}^{2} m_{01}(y-\bar{y})^{1} f(x, y)\right. \\
\mu_{30} & =\sum_{x} \sum_{y}(x-\bar{x})^{3}(y-\bar{y})^{0} f(x, y) \\
& =m_{30}-3 \bar{x} m_{20}+2 \bar{x}^{2} m_{10} \\
\mu_{12} & =\sum_{x} \sum_{y}(x-\bar{x})^{1}(y-\bar{y})^{2} f(x, y) \\
& =m_{12} m_{11}-\bar{x} m_{02}+2 \bar{y}^{2} m_{10} \\
& =\bar{y} m_{20}+2 \bar{x}^{2} m_{01} \\
& =m_{11}(x)
\end{aligned}
$$

Os momentos centrais normalizados, denotados $\eta_{p q}$, são definidos como (GONZALEZ; WOODS, 2007): 


$$
\eta_{p q}=\frac{\mu_{p q}}{\mu_{00}^{\gamma}}
$$

onde

$$
\gamma=\frac{p+q}{2}+1
$$

para $p+q=2,3, \ldots$

Os sete momentos invariantes de $\mathrm{Hu}$, denotados nesta tese por $\phi_{1}$ até $\phi_{7}$, que podem ser derivados dos segundos e terceiros momentos centrais normalizados são:

$$
\begin{aligned}
\phi_{1}= & \eta_{20}+\eta_{02} \\
\phi_{2}= & \left(\eta_{20}-\eta_{02}\right)^{2}+\left(2 \eta_{11}\right)^{2} \\
\phi_{3}= & \left(\eta_{30}-3 \eta_{12}\right)^{2}+\left(3 \eta_{21}-\eta_{03}\right)^{2} \\
\phi_{4}= & \left(\eta_{30}+\eta_{12}\right)^{2}+\left(\eta_{21}+\eta_{03}\right)^{2} \\
\phi_{5}= & \left(\eta_{30}-3 \eta_{12}\right)\left(\eta_{30}+\eta_{12}\right)\left[\left(\eta_{30}+\eta_{12}\right)^{2}-3\left(\eta_{21}+\eta_{03}\right)^{2}\right]+ \\
& \left(3 \eta_{21}-\eta_{03}\right)\left(\eta_{21}+\eta_{03}\right)\left[3\left(\eta_{30}+\eta_{12}\right)^{2}-\left(\eta_{21}+\eta_{03}\right)^{2}\right] \\
\phi_{6}= & \left(\eta_{20}-\eta_{02}\right)\left[\left(\eta_{30}+\eta_{12}\right)^{2}-\left(\eta_{21}+\eta_{03}\right)^{2}\right]+4 \eta_{11}\left(\eta_{30}+\eta_{12}\right)\left(\eta_{21}+\eta_{03}\right) \\
\phi_{7}= & \left(3 \eta_{21}-\eta_{03}\right)\left(\eta_{30}+\eta_{12}\right)\left[\left(\eta_{30}+\eta_{12}\right)^{2}-3\left(\eta_{21}+\eta_{03}\right)^{2}\right]- \\
& \left(\eta_{30}-3 \eta_{12}\right)\left(\eta_{21}+\eta_{03}\right)\left[3\left(\eta_{30}+\eta_{12}\right)^{2}-\left(\eta_{21}+\eta_{03}\right)^{2}\right] .
\end{aligned}
$$

Os momentos de 1 a 6 caracterizam a forma geométrica do objeto da imagem, mantendo robustez à translação, à escala e à rotação. O sétimo momento caracteriza a distorção e o espelhamento da imagem.

Na Figura 3.6 uma imagem de ressonância magnética do crânio é processada para ter rotação em diversos ângulos. Os 7 momentos de Hu são calculados como forma de mostrar a invariância e os resultados estão resumidos na Tabela 3.1. Com este exemplo, pode-se ver a robustez dos momentos de Hu em relação à rotação (GONZALEZ; WOODS, 
2007).

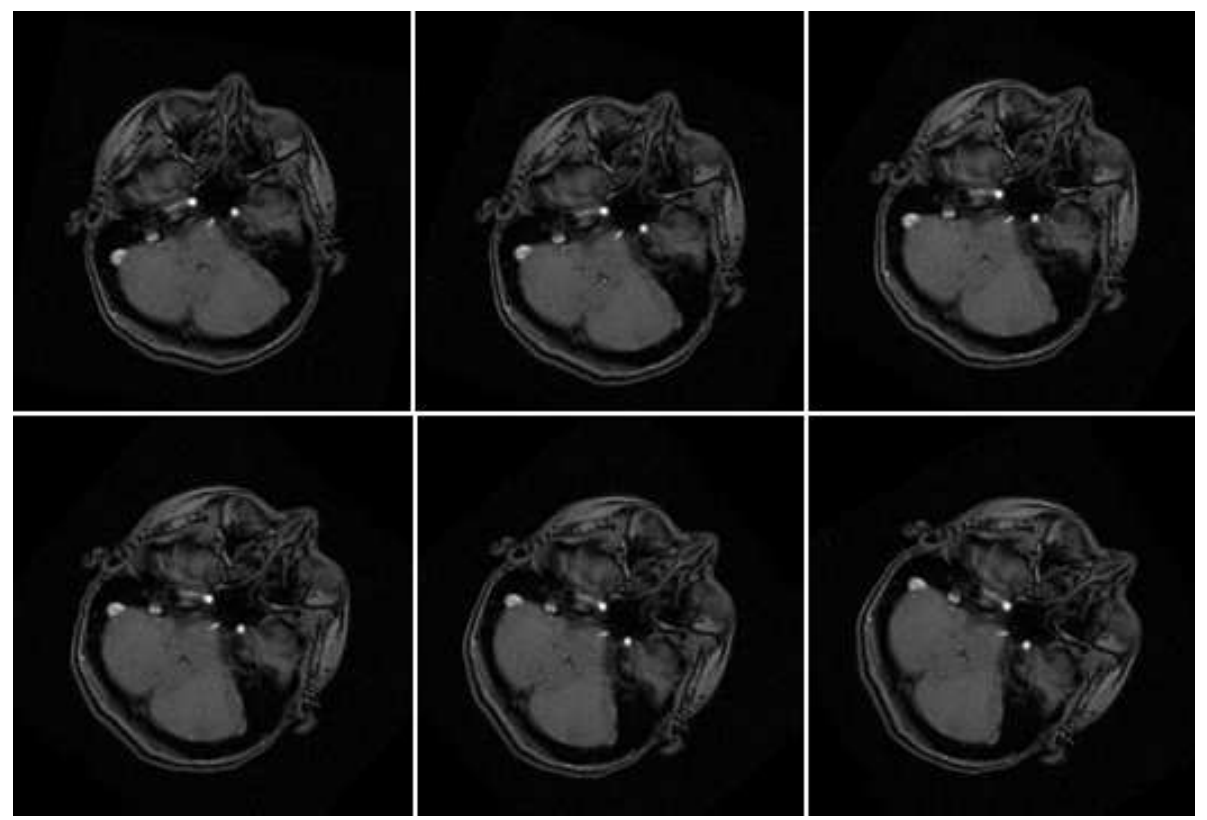

a - Imagens de ressonância magnética rotacionadas de $10^{\circ}$ a $60^{\circ}$ com passo de $10^{\circ}$.

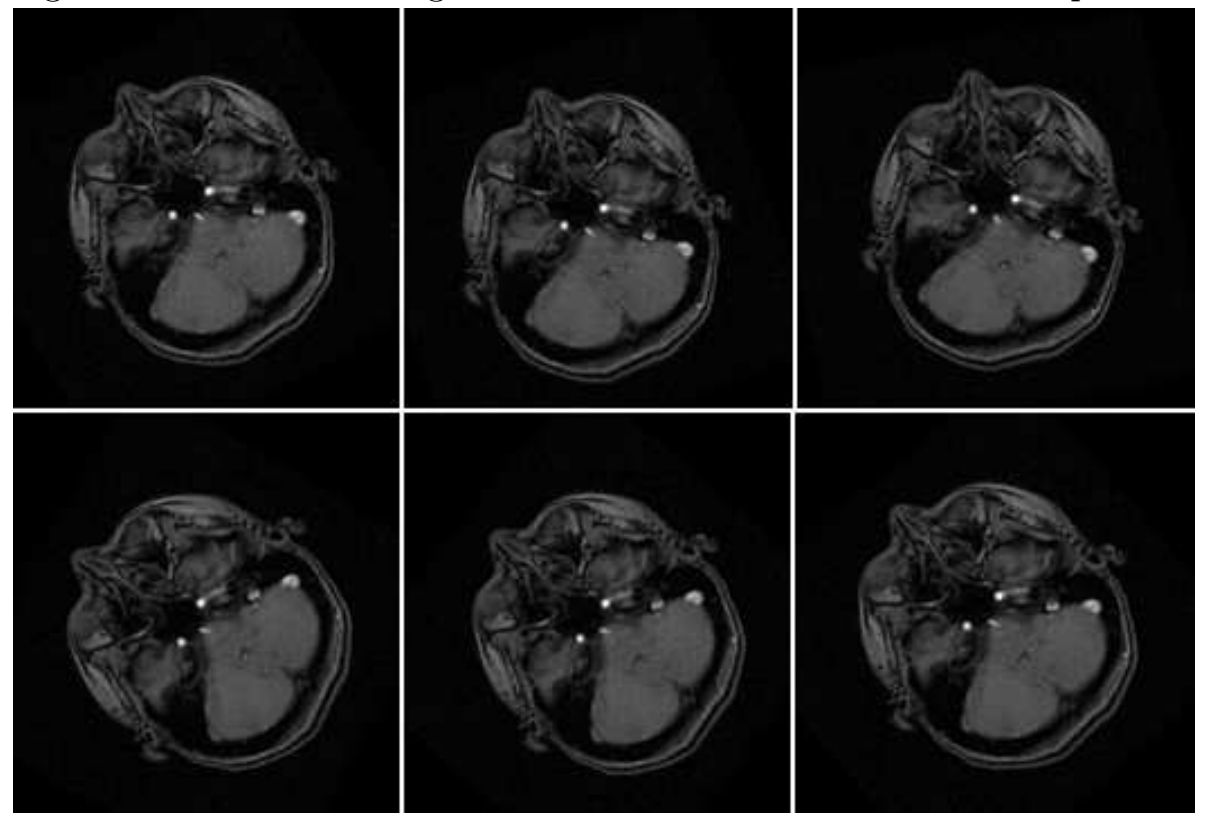

b - Imagens de ressonância magnética rotacionadas de $300^{\circ}$ a $350^{\circ}$ com passo de $10^{\circ}$.

Figura 3.6: Imagens de ressonância magnética rotacionadas para experimentos de momentos de $\mathrm{Hu}$.

O uso de momentos de Hu está restrito à classificação de problemas específicos como, por exemplo, no reconhecimento de letras (CONSEIL; BOURENNANE; MARTIN, 2007). Nesta tese, o seu uso ocorre na tentativa de sintetizar os conjuntos de coeficientes wavelets. Como discutido na seção anterior, haverá uma escolha pelo conjunto de coeficientes com melhor resultado de classificação. Os conjuntos com desempenho de classificação inferior ao esco- 
lhido deveriam ser descartados. Mas, estes conjuntos descartados carregam características da imagem que talvez fossem importantes para a discriminação de classes. A combinação de todos os conjuntos de coeficientes em um único vetor de características causaria um grande aumento no vetor de características. Conseqüentemente, a tarefa de treinamento e classificação acaba sendo prejudicada com este aumento, pois será necessário mais tempo computacional. Os momentos de Hu estão limitados a um vetor de características com dimensão 7. A proposta é sumarizar os conjuntos de coeficientes descartados na forma de momentos de $\mathrm{Hu}$ e, desta forma, a dimensão do vetor de características não sofre um aumento grande e, ainda assim, é possível agregar características que poderiam ser importantes na classificação.

\begin{tabular}{|c|c|c|c|c|c|c|c|}
\hline & $\Phi_{1}$ & Ф2 & Ф3 & $\Phi_{4}$ & Ф5 & Ф6 & Ф7 \\
\hline $0^{\circ}$ & $1,94 \mathrm{E}-03$ & $1,30 \mathrm{E}-04$ & $3,11 \mathrm{E}-04$ & $4,24 \mathrm{E}-04$ & $3,26 \mathrm{E}-04$ & $-1,77 \mathrm{E}-04$ & $3,89 \mathrm{E}-04$ \\
\hline $10^{\circ}$ & ,94E-03 & $1,30 \mathrm{E}-04$ & $3,11 \mathrm{E}-04$ & $4,24 \mathrm{E}-04$ & ,26E-04 & $-1,77 \mathrm{E}-04$ & $3,89 \mathrm{E}-04$ \\
\hline $20^{\circ}$ & $1,94 \mathrm{E}-03$ & $1,30 \mathrm{E}-04$ & $3,11 \mathrm{E}-04$ & & & & $3,89 \mathrm{E}-04$ \\
\hline $30^{\circ}$ & $94 \mathrm{~F}-03$ & & & & & & \\
\hline $40^{\circ}$ & 1 & & & & & & \\
\hline $50^{\circ}$ & & & & & & & \\
\hline $60^{\circ}$ & 1 & & & & & & 3,8 \\
\hline $300^{\circ}$ & $E-03$ & 30 & 04 & 4,2 & 3,26 & $-1,7$ & $3,89 \mathrm{E}-04$ \\
\hline $310^{\circ}$ & $1,94 \mathrm{E}-03$ & $1,30 \mathrm{E}$ & 3,11 & 4,2 & 3,2 & & $3,89 \mathrm{E}-04$ \\
\hline $320^{\circ}$ & $1,94 \mathrm{E}-03$ & $1,30 \mathrm{E}-04$ & $3,11 \mathrm{E}-04$ & $4,24 \mathrm{E}-04$ & $3,26 \mathrm{E}-04$ & $-1,78 \mathrm{E}-04$ & $3,88 \mathrm{E}-04$ \\
\hline $330^{\circ}$ & $1,94 \mathrm{E}-03$ & 1,31E-04 & $3,12 \mathrm{E}-04$ & $4,23 \mathrm{E}-04$ & $3,25 \mathrm{E}-04$ & $-1,76 \mathrm{E}-04$ & $3,89 \mathrm{E}-04$ \\
\hline $340^{\circ}$ & $1,94 \mathrm{E}-03$ & 1,31E-04 & $3,12 \mathrm{E}-04$ & $4,24 \mathrm{E}-04$ & $3,26 \mathrm{E}-04$ & $-1,77 \mathrm{E}-04$ & $3,89 \mathrm{E}-04$ \\
\hline $350^{\circ}$ & $1,94 \mathrm{E}-03$ & $1,30 \mathrm{E}-04$ & $3,11 \mathrm{E}-04$ & $4,24 \mathrm{E}-04$ & $3,26 \mathrm{E}-04$ & $-1,78 \mathrm{E}-04$ & $3,88 \mathrm{E}-04$ \\
\hline
\end{tabular}

Tabela 3.1: Apresentação dos 7 momentos de Hu calculados para cada imagem da Figura 3.6.

No Capítulo 6, será mostrada a diferença nos resultados de classificação usando apenas o conjunto de coeficientes que melhor representa a imagem (avaliado segundo alguns indicadores qualitativos) e usando este mesmo conjunto combinado com os coeficientes que seriam descartados na forma de momentos Hu. Uma explicação mais detalhada dessa combinação será feita a seguir, na Seção 3.5.

Na procura por técnicas de extração de características que garantam boas taxas de classificação, Deselauers (DESELAERS et al., 2006) apresenta uma nova proposta para extração chamada de Histogramas Esparsos, baseados em Patches. De todas as tentativas de extração de características até sua proposta, os Histogramas Esparsos baseados em 
Patches apresentam melhores resultados de classificação. Por essa razão, na Seção 3.4, este método de extração de características será brevemente explicado e serão feitas considerações de sua aplicabilidade.

\subsection{Histogramas Esparsos baseados em Patches}

Modelos baseados em patches vêm se tornando de interesse em visão computacional pelas vantagens como robustez à oclusão e invariância à translação, pois as partes da imagem podem ser modeladas de forma quase independente e, assim, um objeto que está parcialmente ocluído pode ser classificado corretamente enquanto a parte visível puder ser reconhecida.

Nem todas as propostas de extração de características consideram apenas um subconjunto da imagem, pois há perda de informação e, conseqüentemente, as taxas de reconhecimentos são reduzidas, principalmente em aplicações de imagens médicas. A proposta apresentada por Deselaers et. al. (DESELAERS et al., 2006) considera a extração de características de todas as posições da imagem. Neste método, os patches ou subimagens são extraídos da imagem. Os patches que compõem o vetor de características são derivados da redução de dimensionalidade por PCA. Estas características são armazenadas em uma estrutura especial de histograma que permite armazenar vetores em alta-dimensão e usadas por vários métodos de classificação.

Um patch é uma parte da imagem extraída para cada pixel. O tamanho da janela do patch $(l, c)$ é um parâmetro definido experimentalmente. Nos experimentos com imagens médicas descritos em (DESELAERS et al., 2006), l,c foram definidos sendo 15,15. Após a extração dos patches de todas as imagens de treinamento é calculada a transformação por análise de componentes principais (PCA). Usando esta transformação, todos os patches têm sua dimensão reduzida. Ao patch reduzido para as 6 componentes principais, adicionou-se a informação da posição do pixel $(l(i), c(j))$. O esquema completo deste modelo está ilustrado na Figura 3.7 para uma imagem de ressonância magnética.

Este é um método que combina técnicas estatísticas (PCA e histogramas) para carac- 


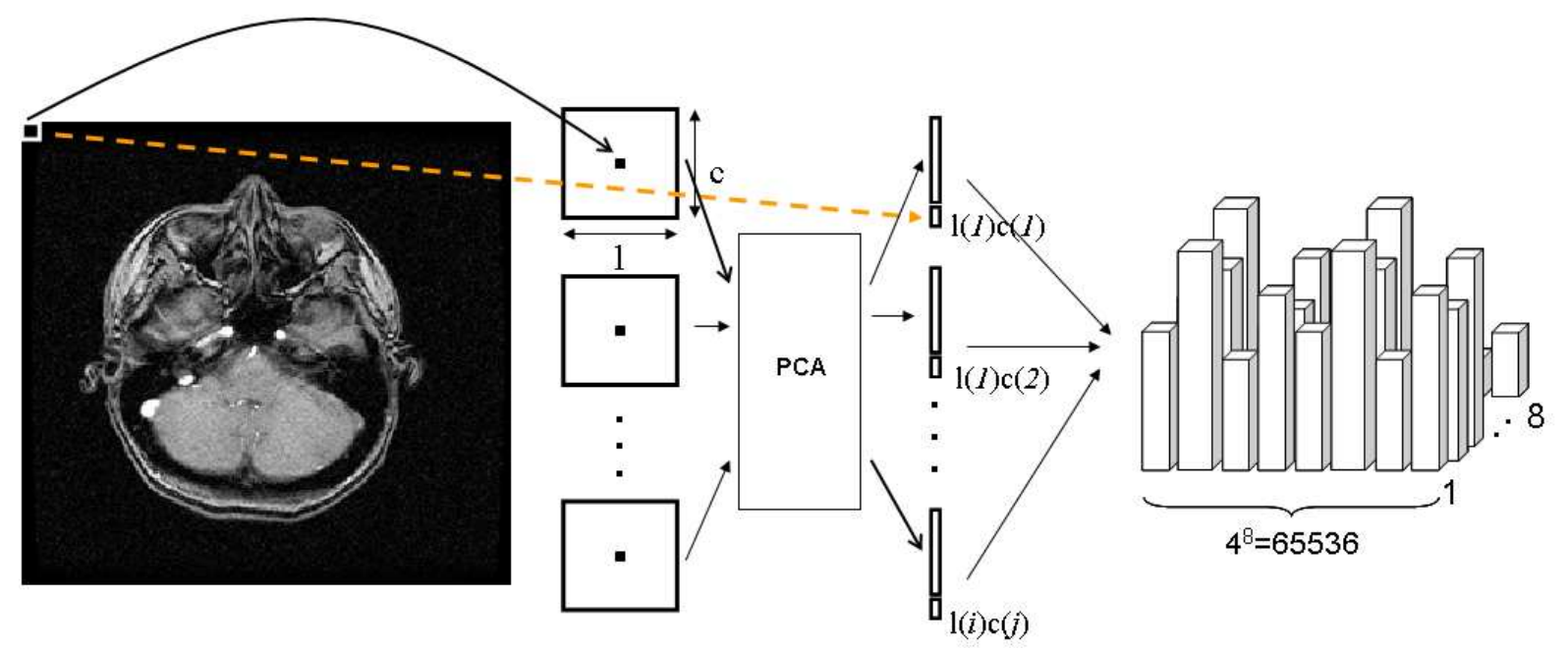

Figura 3.7: Esquema de extração dos Histogramas Esparsos baseados em Patches para uma imagem de ressonância magnética.

terizar imagens. O patch extraído de cada pixel aumenta a correlação de regiões próximas à imagem, mas provoca um grande aumento de dimensão do vetor de características. Para se ter idéia da dimensão do vetor de características, em uma imagem de $256 \times 256$ pixels são gerados 65536 patches de dimensão $15 \times 15$. Para uma base de dados com 9.000 imagens de treino, o vetor resultará em uma dimensão da ordem de $65536 \times(15 \times 15) \times$ 9000 (DESELAERS et al., 2006). Essa nova matriz será usada para o cálculo da PCA. Após este cálculo, cada vetor de características terá a dimensão de $4^{8} \times 8$. Embora este método apresente boas taxas de acerto de classificação, suas desvantagens são o alto custo computacional para seu cálculo e a necessidade de um vetor de características de alta dimensão. A falta de referência na literatura e a não existência de técnicas implementadas também dificultam a reprodução do método.

\subsection{Combinação de técnicas para a extração de caracte- rísticas: Transformada Wavelet e Momentos de $\mathrm{Hu}$}

Este trabalho explora o uso da transformada wavelet para a extração de características. A escolha da melhor família wavelet, nível de decomposição e conjunto de coeficientes é um assunto pouco discutido na literatura, não havendo uma metodologia consolidada para estas escolhas. Aqui, será proposta uma metodologia na qual se aplica a transformada 
wavelet em vários níveis e, com o uso de algumas medidas qualitativas, o melhor nível de decomposição será definido. Após esta definição, algumas famílias wavelets serão escolhidas e, usando-se algumas medidas qualitativas (as mesmas usadas para a escolha do nível de decomposição), será selecionada a família com melhores resultados. Por fim, com as definições do nível de decomposição e da família wavelet, define-se o conjunto de coeficientes, usando as medidas qualitativas das escolhas anteriores, que comporá o vetor de características. Detalhes desta metodologia serão mais bem discutidos no Capítulo 5.

Para os experimentos iniciais, esta abordagem para a composição do vetor de características será feita para efeito de comparação com o método mais convencional da literatura, Imagem Redimensionada, brevemente discutida anteriormente. Porém, ao se escolher um conjunto de coeficientes e descartar os demais conjuntos, alguns detalhes da imagem poderão ser desprezados e, conseqüentemente, a taxa de classificação pode ser reduzida. Contudo, ao se considerar todos os coeficientes, a dimensão do vetor de características será aumentada, o que pode ser uma desvantagem para esta abordagem de classificação. Para fins ilustrativos, pode-se tomar o exemplo anterior da Figura 3.5. Considerando que, pelo método experimental aqui adotado, conclui-se que o melhor nível de decomposição é $n=3$ e o melhor conjunto é o $c A_{3}$. A dimensão desse vetor é de 1.024 . Caso sejam considerados os outros coeficientes, $c D_{3}^{h}, c D_{3}^{v}, c D_{3}^{d}$, a dimensão é aumentada em três vezes, ou seja, para $4.096(1.024+1.024+1.024+1.024)$.

Como proposta deste trabalho, os coeficientes desprezados serão resumidos em momentos de Hu. Desta maneira, ao invés de considerá-los totalmente, por exemplo $c D_{3}^{h}$ (dimensão de 1.024), eles serão resumidos pelos momentos de $\mathrm{Hu}$ denominados por $m\left(c D_{3}^{h}\right)$ (dimensão de 7). Com esta sintetização, os coeficientes podem ser considerados, mas de forma resumida. Além dos coeficientes do mesmo nível, os dos níveis anteriores também podem ser considerados pois, mesmo assim, a dimensão não é muito grande. Ainda com base no exemplo anterior, considerando os coeficientes dos níveis anteriores, a composição do vetor de características $\mathbf{v}$ é a seguinte:

$$
\mathbf{v}=\left[c A_{3}, m\left(c D_{3}^{h}\right), m\left(c D_{3}^{v}\right), m\left(c D_{3}^{d}\right), m\left(c D_{2}^{h}\right), m\left(c D_{2}^{v}\right), m\left(c D_{2}^{d}\right), m\left(c D_{1}^{h}\right), m\left(c D_{1}^{v}\right), m\left(c D_{1}^{d}\right)\right]
$$


resultando em uma dimensão de 1087.

Este método é uma proposta do trabalho e será experimentalmente comparado com os Histogramas Esparsos baseados em Patches no Capítulo 6.

\subsection{Considerações Finais}

Neste Capítulo discutiu-se a extração de características, desde o conceito do assunto até as principais técnicas estudadas na literatura. Discutiram-se aquelas que apresentam melhores resultados na classificação de imagens, Imagem Redimensionada e Histogramas Esparsos baseados em Patches, bem como uma introdução sobre a Transformada Wavelet.

Discutiu-se também sobre o uso de momentos na extração de características, principalmente os de Hu. As vantagens desse método, como invariância à rotação e vetor de características de baixa dimensão, foram experimentalmente mostradas.

Apresentou-se uma proposta de extração de características globais da imagem, a qual combina Transformada Wavelets e momentos de Hu. Esta combinação é feita com o cálculo dos momentos de $\mathrm{Hu}$ sobre os coeficientes de wavelets descartados, segundo a metodologia que será apresentada com mais detalhes no Capítulos 5. Este método é uma maneira de considerar os detalhes desprezados da imagem de forma resumida, sem prejudicar a dimensão do vetor de características.

No capítulo seguinte será discutido o uso de Mapas Auto-Organizáveis ou simplesmente SOM como classificador (na categorização de imagens). Esta é uma arquitetura de Redes Neurais Artificiais amplamente utilizada em mineração de dados e CBIR (KOIKKALAINEN; OJA, 1990), (ZHANG; ZHONG, 1995), (OH; KANEKO; MAKINOUCHI, 1999), (KOSKELA, 2003), (WU; RAHMAN; CHOW, 2005). Neste trabalho, o seu uso ocorre em categorização de imagens. 


\section{O Mapa Auto-Organizável e suas Potencialidades na Categorização de Imagens}

Neste capítulo apresenta-se o Mapa Auto-Organizável SOM (KOHONEN, 2001), bem como sua estrutura, algoritmo de aprendizado e métricas para avaliação de desempenho. Estas descrições teóricas são fundamentais para o entendimento da proposta de aplicação do mapa SOM na categorização de imagens médicas.

\subsection{Classificadores Automáticos}

Existe uma diversidade de classificadores automáticos, sejam estatísticos, como o nãoparamétrico Knn (DUDA; HART; STORK, 2000) ou que envolvam algum tipo de aprendizado (redes neurais artificiais ou aprendizado de máquina) (HAYKIN, 1999). Em grande parte dos trabalhos que focam a categorização de imagens médicas, o classificador usado é o Knn (PIETKA; HUANG, 1992),(BOONE; SESHAGIRI; STEINER, 1992), (PINHAS; GREENSPAN, 2003),(KEYSERS et al., 2003),(LEHMANN et al., 2005).

Há três razões para o freqüente uso deste classificador em problemas de categorização de imagens: os trabalhos estarem focados em recuperação de imagens por conteúdo (CBIR - Content-Based Image Retrieval), a simplicidade de implementação e por ele não ser paramétrico.

O uso do Knn possibilita classificar as imagens com base nas mais próximas. Em sua aplicação como classificador, ao apresentar uma imagem de teste, a comparação com toda a base de dados é feita e a resposta é dada por uma lista de imagens mais semelhantes 
ordenada pelas imagens mais próximas. Assim, é possível se ter idéia do desempenho deste classificador em um sistema CBIR. Por conta disto, Lehmann (LEHMANN et al., 2005) e outros avaliam o resultado de classificação não apenas com base no vizinho mais próximo, mas também analisando os próximos vizinhos até o décimo mais próximo, $\mathrm{k}=1$ até $\mathrm{k}=10$, onde o desempenho é medido com base nos acertos nesta faixa de k. Porém, este tipo de classificador não envolve um aprendizado. Em outras palavras, a cada nova imagem é necessária a comparação desta com toda a base de dados, o que torna a técnica difícil de ser aplicada na prática, mas permite a comparação por ser uma técnica que apresenta bons resultados (benchmark). Por outro lado, o trabalho de Rahmann e colaboradores (RAHMAN; BHATTACHARYA; DESAI, 2007) usou classificador automático com aprendizado de máquina, fuzzy c-mean e Suport Vector Machine (SVM) (EAKINS, 2003). O uso de redes neurais artificiais (RNA) neste contexto de aplicação, classificação, ainda é pouco explorado.

Em aplicação CBIR, a rede neural SOM é a arquitetura neural artificial mais utilizada (ZHANG; ZHONG, 1995), (EAKINS, 2003), (KOIKKALAINEN; OJA, 1990), (ZHANG; ZHONG, 1995), (OH; KANEKO; MAKINOUCHI, 1999), (KOSKELA, 2003), (WU; RAHMAN; CHOW, 2005). As principais vantagens no uso do SOM são a capacidade de aprendizado não-supervisionado, agrupamento e busca por exploração browsing.

Oh e colaboradores (OH; KANEKO; MAKINOUCHI, 1999) propuseram um arcabouço chamado de tabela de índice por similaridade, que é usado para indexar e recuperar imagens a partir de características de cor e textura extraídas com o uso da técnica wavelets.

Diversas aplicações usando SOM foram propostas, principalmente para reduzir o número de imagens candidatas antes de uma exaustiva medida de similaridade ser aplicada, e para propósitos de visualização de dados (KOSKELA, 2003).

Outras aplicações usando SOM estendido foram propostas para acelerar o tempo de processamento do mapa SOM tradicional e também para implementar a relevância da resposta, como TS-SOMs (Tree Structured Self-Organizing Map) (KOIKKALAINEN; OJA, 1990), PicSOM (Picture Self-Organizing Map) (KOIKKALAINEN et al., 2000) e GHSOQM 
(Growing Hirerachical Self-Organizing Quadtree Map) (WU; RAHMAN; CHOW, 2005).

Contudo, o uso do SOM como classificador de imagens é assunto pouco explorado na literatura. Antes de continuar este assunto, a seguir será brevemente exposto SOM em termos de arquitetura, algoritmo, medidas de desempenho e aplicação.

\subsection{Mapa Auto-Organizável}

O Mapa Auto-Organizável (Self-Organizing Map), também conhecido como rede de Kohonen ou simplesmente SOM, é uma arquitetura de rede neural artificial com aprendizado do tipo não-supervisionado (HAYKIN, 1999),(KOHONEN, 2001). As principais aplicações de SOM estão nas tarefas de agrupamento (BOSCARIOLI; SILVA; DEL-MORAL-HERNANDEZ, 2006b),(BOSCARIOLI; SILVA; DEL-MORAL-HERNANDEZ, 2006a), classificação (SILVA et al., 2006),(SASSI; SILVA; DEL-MORAL-HERNANDEZ, 2006),(SILVA et al., 2007) e visualização de dados (VESANTO; ALHONIEMI, 2000),(BOSCARIOLI; SILVA; DEL-MORAL-HERNANDEZ, 2008). SOM faz uma projeção não-linear de dados de alta dimensão em um mapa discreto usualmente de duas dimensões, preservando a topologia dos dados de entrada tão fielmente quanto possível. Assim, padrões de entrada similares serão mapeados em regiões espacialmente próximas do mapa de saída. Como conseqüência, a relação entre dados de entrada é espelhada em termos de distância das respectivas representações no espaço de saída. Desta forma, SOM é uma ferramenta adequada para visualização e exploração de dados em alta dimensão.

\subsection{Arquitetura}

SOM é uma rede em duas camadas, entrada (vetores de características) e saída (mapa de neurônios), como ilustrado na Figura 4.1.

Na figura, o vetor de entrada é representado por vetores $d$-dimensionais $\mathbf{x}_{i} \in \Re^{d}$, por exemplo, $\mathbf{x}_{i}=\left(x_{i 1}, x_{i 2}, \ldots, x_{i d}\right)$ são descritos por $d$ características no espaço de entrada. O conjunto de vetores de características $\mathbf{x}_{i}$ para o SOM será denotado como $X$. Ao 
apresentar um padrão na camada de entrada do SOM, este será propagado em paralelo para o mapa de neurônios (ou unidades) na camada de saída, a qual deve ser organizada em uma malha retangular ou hexagonal, como ilustrado na Figura 4.2.

Uma unidade $u$ é associada a um vetor de pesos $\mathbf{w}_{u}=\left(w_{u 1}, w_{u 2}, \ldots, w_{u d}\right)$, que é de dimensionalidade $d$, como o padrão de entrada. Estes vetores de pesos devem ser inicializados aleatoriamente, com escolhas randômicas no domínio dos padrões de entrada ou por outros métodos mais sofisticados como proposto em (KOHONEN, 2001).

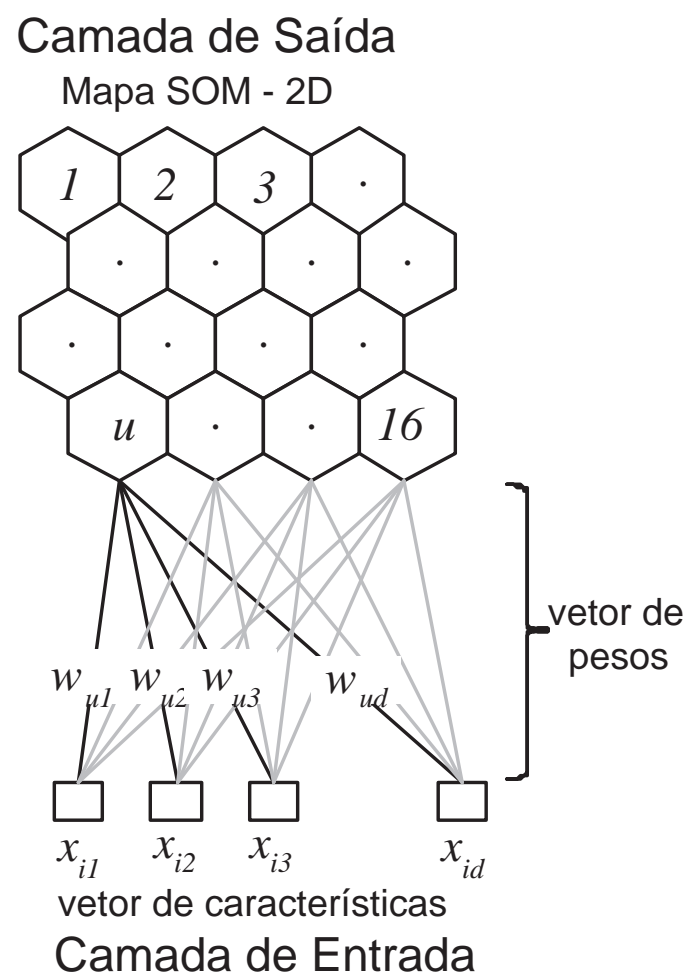

Figura 4.1: Exemplo de arquitetura SOM com 16 neurônios na camada de saída (mapa $4 \times 4)$.

\subsection{Algoritmo de Aprendizado}

Nas próximas equações será usada a notação de tempo discreto, com $t$ denotando a iteração de treinamento atual. O treinamento se inicia com a seleção aleatória de um vetor de características do conjunto de treinamento, $\mathbf{x}_{i}$. Cada unidade $u$ com a menor distância entre seu vetor de pesos $\mathbf{w}_{u}$ e $\mathbf{x}_{i}$ no espaço euclidiano é, então, selecionada como a unidade com melhor casamento (ou simplesmente BMU de best-matching unit), chamada 


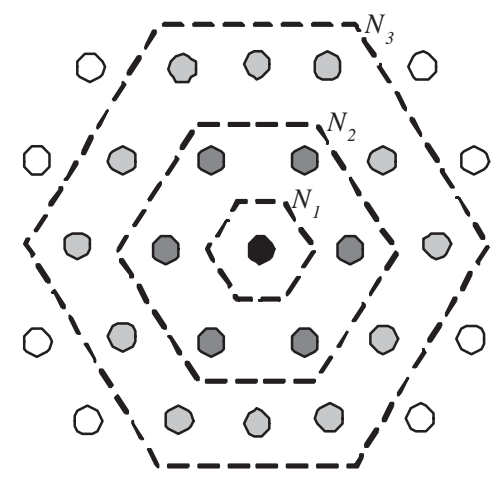

a) Hexagonal

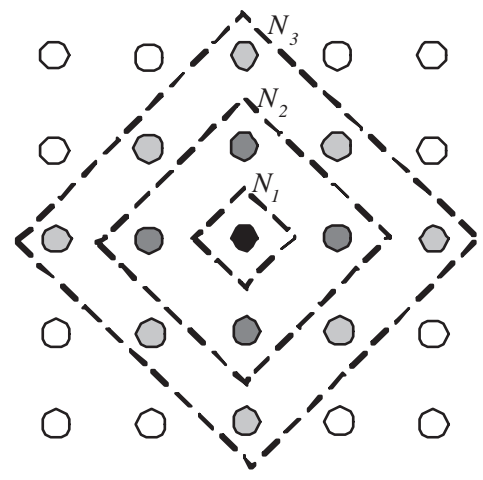

b) Retangular

Figura 4.2: Exemplos de vizinhanças no mapa SOM. A relação entre os neurônios define a vizinhança que pode ser retangular (4 neurônios) ou hexagonal (6 neurônios).

de neurônio vencedor e denotada como $c$, de acordo com a Equação 4.1. A distância euclidiana é denotada como $\|$.$\| .$

$$
c=\underset{u}{\operatorname{argmin}}\left(\left\|\mathbf{x}_{i}-\mathbf{w}_{u}\right\|\right)
$$

Em outras palavras, a unidade $c$ é o melhor representante de $\mathbf{x}_{i}$. Para aumentar a probabilidade de esta unidade ser escolhida como vencedora, caso o mesmo vetor de características seja selecionado nas interações subseqüentes do treinamento, a diferença entre o vetor de pesos da unidade vencedora $\mathbf{w}_{c}$ e $\mathbf{x}_{i}$ será diminuída. Esta adaptação gradual do vetor de pesos é controlada pelo parâmetro de taxa de aprendizado $\alpha(t) \in[0,1]$. Usualmente, este parâmetro diminui em função do tempo com $\lim _{t \rightarrow \infty} \alpha(t)=0$. Assim, o vetor de pesos será adaptado mais fortemente no início do treinamento. Valores baixos de $\alpha(t)$ no final do processo de treinamento definem a fase de ajuste fino.

Para garantir a preservação topológica do mapeamento, ou seja, preservar as relações de similaridade entre os vetores de características e as unidades do mapa, não apenas o vetor de pesos do neurônio vencedor $c$ será atualizado, mas também os vetores de pesos das unidades vizinhas. Quando uma relação de vizinhança é definida, as unidades vizinhas são também definidas. Na Figura 4.2, as linhas tracejadas e os diferentes tons de cinza indicam a relação entre o neurônio vencedor e seus vizinhos. Desta forma, os 
neurônios que fazem vizinhança ao neurônio vencedor também são atualizados. Assim, na próxima iteração $(t+1)$, vetores de características semelhantes a $\mathbf{x}_{i}$ serão mapeados em regiões vizinhas do mapa SOM. A força da adaptação das unidades vizinhas, $h_{c i}(t)$ é determinada pela distância de grade entre a unidade $c$ e os neurônios do mapa. Esta é uma função decrementada com o tempo, como mostra a Equação 4.2 (função de vizinhança gaussiana).

$$
h_{c i}(t)=\exp ^{-\frac{\left\|r_{c}-r_{i}\right\|^{2}}{2 \sigma^{2}(t)}}
$$

onde $r_{c}$ é a coordenada do neurônio vencedor $c, r_{i}$ é a coordenada de um neurônio vizinho $i$ no mapa de saída. O parâmetro $\sigma(t)$ define o tamanho do raio da vizinhança e é um fator dependente do tempo. Pode-se perceber na Equação 4.2 que unidades próximas ao vencedor são atualizadas mais fortemente que as unidades mais distantes do vencedor. Um valor alto de $h_{c i}$ para um grande volume de vizinhos no início do processo de treinamento levará os vetores de pesos das unidades a uma organização global. Assim, unidades vizinhas terão vetores de pesos similares. Com o decremento da função de vizinhança sucessivamente em função do tempo, as adaptações se tornarão mais locais.

Uma função de vizinhança mais simples pode ser implementada, definindo um conjunto de unidades $N_{c}(t)$ (janela de vizinhança) ao redor do vencedor $c$ no tempo $t$. Desta maneira, apenas os vetores de pesos das unidades vizinhas, dentro da janela de vizinhança, são adaptados. Com este método, o tempo computacional é reduzido, pois apenas um subconjunto de unidades requer a adaptação do vetor de pesos, visto que, com a função gaussiana (Equação 4.2), todos os vetores de pesos das unidades são atualizados em cada iteração.

Definida a taxa de aprendizado $\alpha(t)$ e a função de vizinhança $h_{c i}(t)$, o vetor de pesos $\mathbf{w}_{u}(t+1)$ da unidade $u$ é adaptado pela adição de uma parcela $\alpha(t) \cdot h_{c i}(t)$ do vetor diferença $\left[\mathbf{x}_{i}(t)-\mathbf{w}_{u}(t)\right]$ ao $\mathbf{w}_{u}(t)$, de acordo com a Equação 4.3. O $\mathbf{x}_{i}(t)$ denota o vetor de características corrente no tempo $t$, pertencente ao conjunto de padrões de treinamento, $\mathbf{x}_{i} \in X$

$$
\mathbf{w}_{u}(t+1)=\mathbf{w}_{u}(t)+\alpha(t) h_{c i}(t)\left\|\mathbf{x}_{i}-\mathbf{w}_{u}\right\|
$$


Como conseqüência da Equação 4.3, o vetor de pesos do neurônio vencedor e os pesos das unidades vizinhas são "movidos" em direção ao vetor de características corrente, de forma que, o vetor de características e os padrões semelhantes tendem a ser mapeados dentro de regiões muito próximas do mapa nas próximas iterações do aprendizado.

A Figura 4.3 ilustra um mapa SOM com uma representação gráfica da função de vizinhança gaussiana. À esquerda, é apresentado o espaço de entrada $\Re^{d}$, o vetor de pesos do neurônio vencedor $\mathbf{w}_{c}(t)$ no tempo $t$ e o atual vetor de características $\mathbf{x}_{i}$ no espaço de entrada. Observa-se que o vetor de pesos do neurônio vencedor $\mathbf{w}_{c}(t+1)$, depois da adaptação no tempo $t+1$, se aproxima do vetor de características $\mathbf{x}_{i}$. O movimento é representado pela seta sólida.

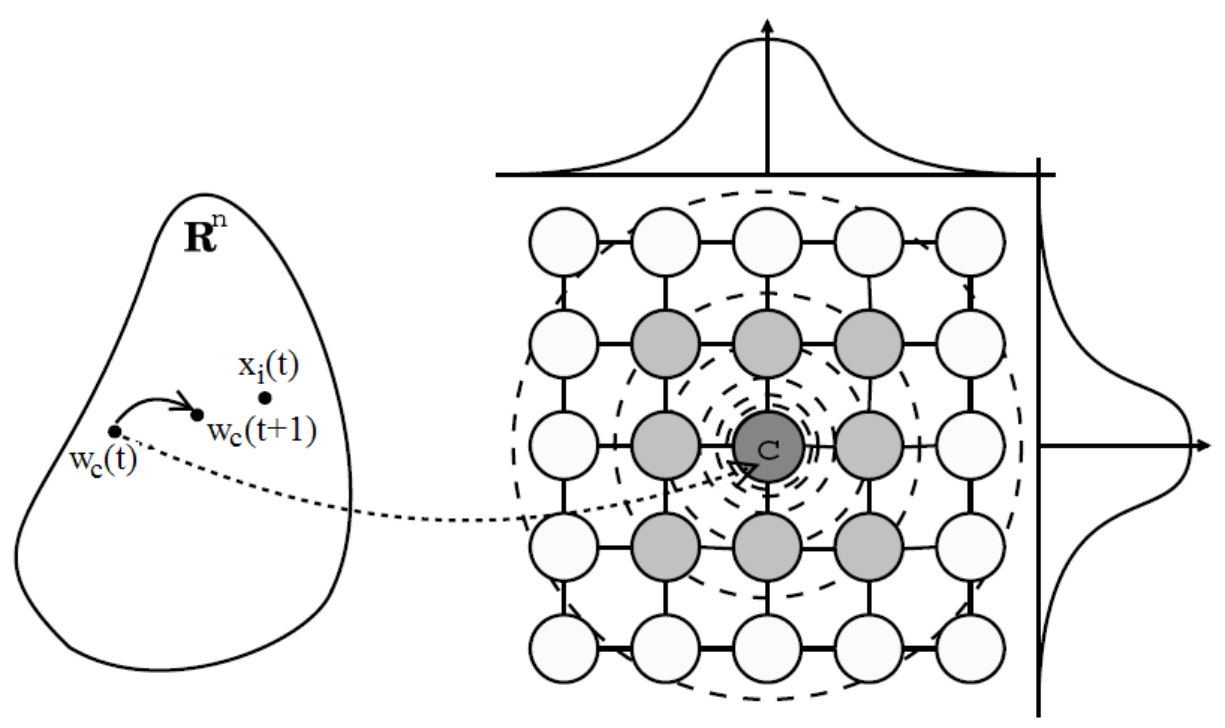

Figura 4.3: A intensidade de adaptação das unidades individuais é indicada pelos diferentes círculos em tons de cinza e pelas gaussianas na horizontal e na vertical. Adaptado de (WU; RAHMAN; CHOW, 2005).

No lado direito da Figura 4.3, o SOM é representado por uma seqüência de círculos pontilhados. A seta pontilhada mostra a relação entre a unidade vencedora $c$ e seu vetor de pesos no espaço de entrada. Os diferentes tamanhos de círculos representam as diferentes adaptações, de acordo com a distância do neurônio vencedor. A unidade mais escura terá a maior adaptação.

De forma resumida, uma iteração do algoritmo de aprendizado SOM pode ser descrita 
como:

1. seleção aleatória de um vetor de características $\mathbf{x}_{i}$ do conjunto de treinamento;

2. busca pela unidade vencedora (Equação 4.1);

3. adaptação do vetor de pesos do vencedor e de seus vizinhos (Equação 4.3);

4. modificação da taxa de aprendizado e da faixa de vizinhança.

Em seguida ao final de cada iteração, o processo de treinamento é continuado com a seleção aleatória do próximo vetor de características, a ser considerado na nova iteração de treinamento. O processo continua até um número pré-definido de iterações ou até que um critério de parada adequadamente escolhido seja alcançado. Por exemplo, um treinamento poderia ser interrompido se uma organização estável dos vetores de características do conjunto de treinamento dentro da grade de duas dimensões fosse alcançada.

Na Figura 4.4, é mostrada uma base de dados artificialmente gerada, os vetores de pesos depois do treinamento (Figura 4.4a) e o mapa SOM 2D após o treinamento (Figura 4.4b). Neste exemplo, o que se pretende destacar é a dimensionalidade dos vetores de características e dos vetores de pesos (3D), e a representação destes no mapa SOM (2D). Neste exemplo, é possível também verificar a manutenção topológica de um mapa SOM, ou seja, a relação da vizinhança no espaço de características (Figura 4.4a) é preservada no espaço do mapa (Figura 4.4b). As letras são as classes dos vetores de características que tiveram um dado neurônio como melhor casamento (neurônio vencedor) e, o valor em parênteses, o número de vetores de características que estão sendo representados pelo neurônio (histograma).

Em aplicações de data mining, o resultado final é a visualização dos dados multidimensionais (dimensão muito maior que 4). Neste exemplo, pode ser verificada a potencialidade do uso do mapa SOM na visualização de dados multidimensionais. Esta propriedade do SOM é considerada por alguns pesquisadores como uma generalização do PCA (HAYKIN, 1999) e que pode ser melhorada com a construção 3D do mapa (COSTA; ANDRADE-NETTO, 
2007) ou exploração do mapa em volume (globo) (MATSUMOTO; UMANO; INUIGUCHI, 2008).

Na Seção seguinte, serão apresentadas as medidas de desempenho usualmente aplicadas a um mapa SOM para averiguar a qualidade do mapeamento obtido.

\subsection{Medidas de Desempenho do Mapa Auto-Organizável}

As medidas usadas para calcular o desempenho do SOM são: erro médio de quantização (mqe), erro médio final de quantização (MQE) e erro topográfico (TE) (KIVILUOTO, 1995).

O erro médio de quantização (mqe) mede a distância média entre os vetores de características com seu respectivo vetor de pesos com melhor casamento $\mathbf{w}_{c}$. O cálculo dessa medida é:

$$
m q e_{c}=\frac{1}{n} \sum_{\mathbf{x}_{i} \in X}\left\|\mathbf{x}_{i}-\mathbf{w}_{c}\right\|
$$

onde $n$ é o número de $x_{i}$ que teve o neurônio $c$ como vencedor.

O erro médio final de quantização (MQE) do mapa é calculado a partir dos mqe de cada neurônio vencedor (BMU):

$$
M Q E=\frac{1}{U} \sum_{c=1}^{u} m q e_{c}
$$

sendo $U$ o número total de neurônios do mapa.

A segunda medida de qualidade é o erro topográfico (TE) que quantifica a capacidade do mapa em representar a topologia dos vetores de características de entrada. Para cada $\mathbf{x}_{i}$ calcula-se o primeiro BMU, $\mathbf{w}_{c}$ e o segundo BMU, $\mathbf{w}_{d}$, e então é calculado o TE, Equação 4.6, definida por (KIVILUOTO, 1995):

$$
T E=\frac{1}{U} \sum_{i=1}^{X} u\left(\mathbf{x}_{i}\right)
$$

onde $u\left(\mathbf{x}_{i}\right)=1$, caso $\mathbf{w}_{c}$ e $\mathbf{w}_{d}$ não sejam adjacentes e $u\left(\mathbf{x}_{i}\right)=0$, caso $\mathbf{w}_{c}$ e $\mathbf{w}_{d}$ sejam adjacentes. 


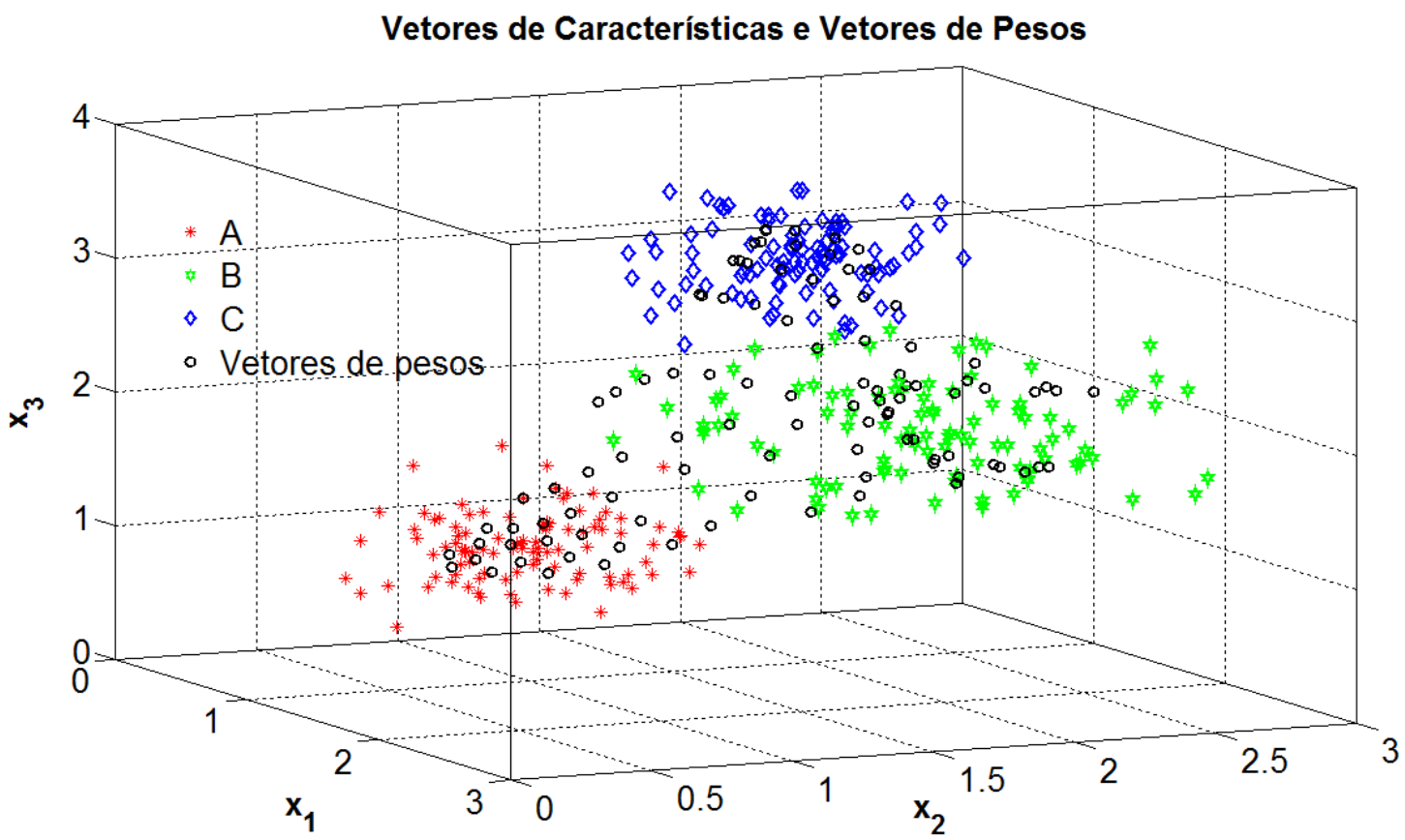

a - Base de dados com vetores de características gerados artificialmente com os vetores de pesos já treinados.

\section{Mapa SOM 2D Rotulado}

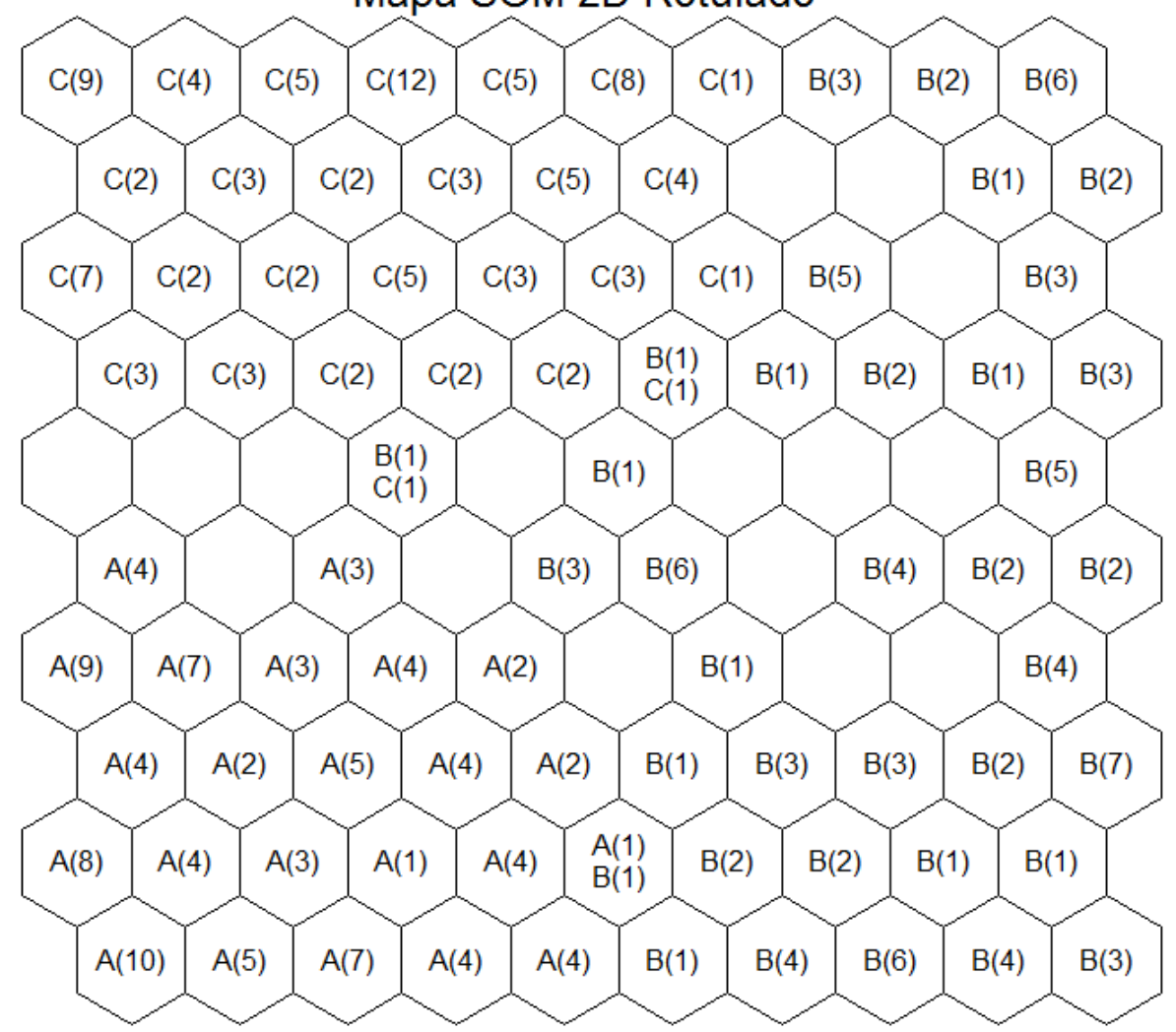

b - Mapa do SOM rotulado.

Figura 4.4: A partir da base de dados artificial (a) treina-se o SOM, o qual organiza os dados da base em um mapa rotulado (b). 


\subsection{Aplicação do Mapa SOM em Problemas de Cate- gorização}

Após o treinamento do mapa SOM, todas as imagens envolvidas no treinamento e suas respectivas categorias são associadas aos respectivos neurônios vencedores, como ilustra a Figura 4.5, a partir do cálculo da distância Euclidiana entre os vetores de características das imagens de treinamento da base de dados e os vetores de pesos do mapa. Isto definirá os melhores casamentos - neurônios vencedores, ou simplesmente BMU (de Best Match Unit) para cada vetor de características - que podem ser ordenados crescentemente $\left(1^{o}\right.$ (1BMU), $2^{\circ}(2 \mathrm{BMU}) \ldots$ último (UBMU)).

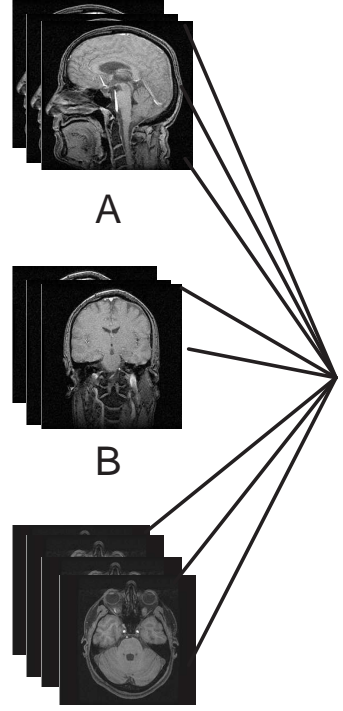

C

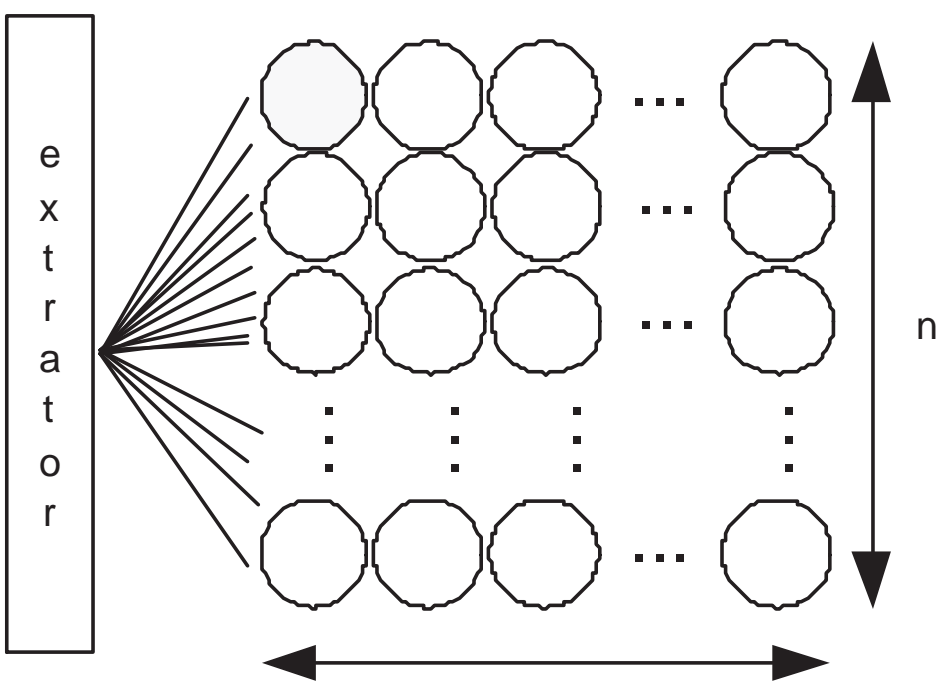

$\mathrm{m}$

Figura 4.5: As imagens de entrada de diferentes classes $(A, B$ e $C$ ) passam pelo extrator e os vetores de características assim produzidos são usados para gerar o mapa (treinamento SOM).

Se os vetores de características, os $x_{i}$ de uma base de treinamento, estão organizados em uma tabela, com as definições dos neurônios vencedores é possível acrescentar colunas em tal base de treinamento, com os dados dos neurônios vencedores, como está representado na Figura 4.6. Caso o neurônio do mapa SOM esteja rotulado, como discutido acima na Figura 4.4, também é possível acrescentar esta informação em colunas.

As estratégias para se fazer rotulação no mapa SOM também podem ser observadas na Figura 4.4b, onde cada neurônio está rotulado com a classe e o número de vetores 


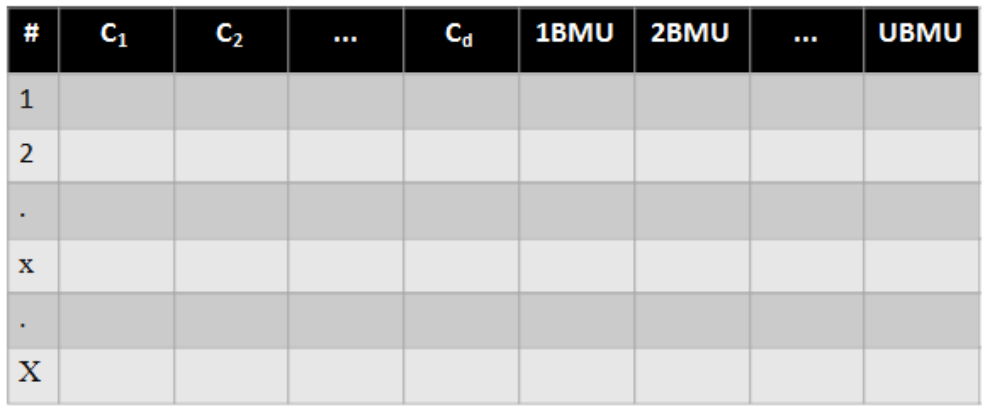

Figura 4.6: Ilustração esquemática de como ficaria a tabela com os vetores de características da base de treinamento com os neurônios vencedores.

de características desta classe (histograma), mas poderia estar rotulado apenas com a classe de maior freqüência (votação máxima). No Capítulo 6, a discussão será retomada, apresentando estes conceitos em função de resultados experimentais.

A classificação usando diferentes estratégias de SOM é um assunto pouco discutido na literatura. A seguir, serão apresentadas quatro diferentes estratégias para uso de SOM na classificação.

O primeiro processo na tarefa de classificação é que ao receber uma imagem de teste o seu vetor de características é extraído, como na Figura 4.7. A maneira mais simples de usar o mapa SOM na classificação é associar o vetor extraído da imagem ao neurônio vencedor. O rótulo do neurônio, em termos de histograma ou de máxima votação, pode ser usado para classificar uma imagem.

Uma outra abordagem, explorada nesta tese, é usar o neurônio vencedor para se definir a região onde as imagens com características semelhantes estão concentradas e, depois, procurar pelas imagens mais próximas para a classificação. Enquanto nas duas abordagens de classificação, histograma ou máxima votação, não se podia ter a liberdade de definir um número de imagens para comparação, agora, com tal abordagem, é possível deixar para o médico-usuário ou para o estudante-usuário a definição deste parâmetro.

Com o parâmetro para a escolha do número de imagens a serem comparadas, pode acontecer de o neurônio vencedor não representar esta quantidade de imagens. Como discutido em parágrafos acima, o SOM tem como uma das suas características a manutenção topológica dos dados, ou seja, neurônios vizinhos tendem a representar padrões semelhan- 
tes. Esta propriedade do SOM pode ser usada para compor a quantidade de imagens, caso o número delas não seja garantido apenas pelo neurônio vencedor. Assim, no momento da associação da imagem nova ao mapa, além do neurônio vencedor é importante saber também quais são o $2^{\circ}, 3^{\circ}$ e etc neurônios vencedores, como ilustrado na Figura 4.8.

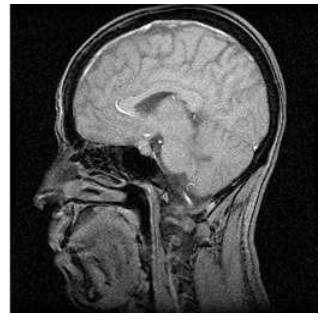

Imagem de teste

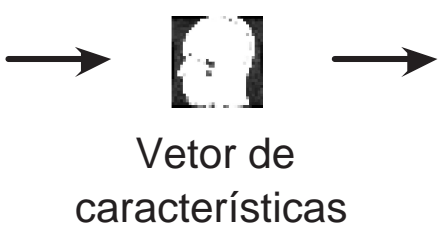
características

\section{Rótulo do neurônio}

Vencedor

$1 \mathrm{BMU}$

2BMU

3BMU

\section{por máxima votação}

A

A

B

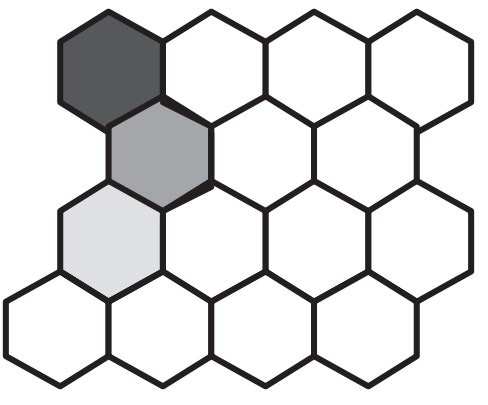

Mapa SOM

$(4 \times 4)$

\section{Rótulo do neurônio \\ por histograma}

$A(2)$

$A(10)$

$A(2), B(6)$

Figura 4.7: Esquema da metodologia de classificação considerando a máxima freqüência de categorias em cada neurônio vencedor (BMU) ou o histograma de classes.

Além de não permitir a liberdade no número de imagens a ser comparada, a proposta de classificação usando o rótulo atribuído ao neurônio pode dar uma falsa classificação, uma vez que ele representa uma coleção de imagens. Este problema é ainda maior se o vetor de pesos do neurônio estiver em uma região de classes diferentes (região de fronteira). Por outro lado, se o vetor de pesos do neurônio vencedor é considerado como um indicador da região onde há imagens semelhantes, a comparação permitirá uma melhor classificação.

Outra abordagem que poderia ser interessante, quarta maneira considerada aqui de usar o SOM na classificação, é produzir uma resposta em termos de graus de pertinência, 
como forma de entregar ao médico-usuário ou estudante-usuário mais informações para a tomada de decisão. Para tanto, o FuzzyKNN, que é um método de calcular graus de pertinência com base em um repertório dos $k$ padrões comparados, poderia ser empregado (KELLER; GRAY; GIVENS, 1995).

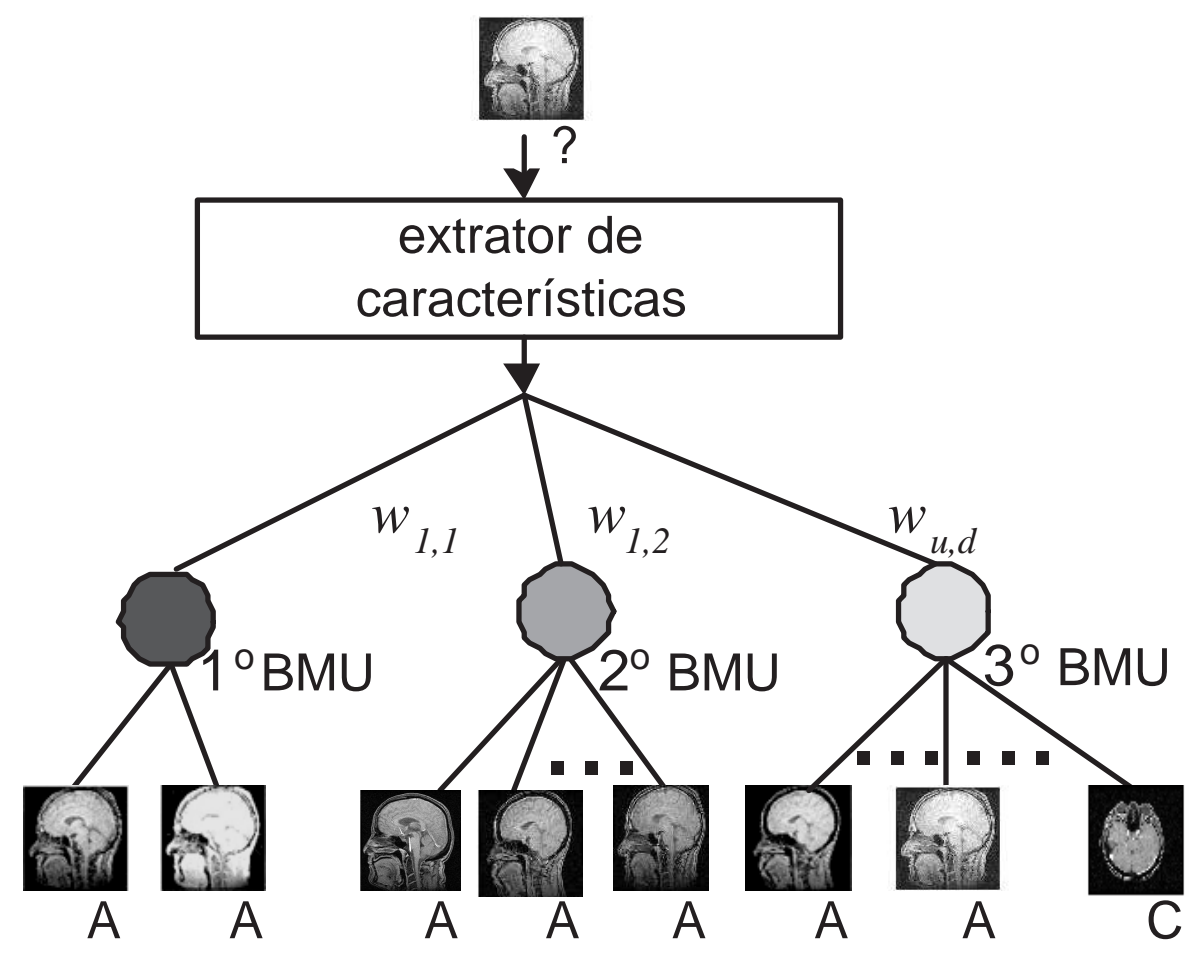

Figura 4.8: Ao apresentar uma imagem para a classificação, o vetor de características é extraído e então comparado com os vetores de pesos. De acordo com a similaridade, as imagens do neurônio vencedor são recuperadas.

\subsection{Considerações Finais}

Neste capítulo foi feita uma revisão geral sobre os métodos de classificação usados na literatura e sobre as diferentes formas de utilizar SOM estruturado para aplicações em CBIR. O algoritmo de treinamento do mapa SOM foi apresentado de forma introdutória, como também as suas características de quantização vetorial e manutenção topológica e as principais medidas de desempenho.

Apresentaram-se, também, as quatro formas de uso do mapa SOM como classificador. As duas primeiras técnicas convencionais (votação máxima e histograma) foram usando o rótulo do mapa para classificação e as outras, propostas no trabalho, através do vetor de 
pesos como índice da região com imagens semelhantes; cuja classificação se obteve pelo rótulo do vetor de características com maior freqüência, ou ainda, usando o rótulo dos vetores de características, mas com respostas em grau de pertinência. As duas últimas formas de classificação, apesar de apresentarem resultados mais confiáveis porque evitam problema de região de fronteira, ainda carecem de algumas adaptações para seu uso. No Capítulo seguinte, serão discutidos os problemas envolvidos nessa forma de classificação e uma proposta de como resolvê-los. 


\section{Proposta para uso do SOM na categorização de imagens}

Neste capítulo será discutida a proposta do presente trabalho para classificação que usa os vetores de pesos para indicar a região do mapa SOM com imagens semelhantes àquelas que se deseja categorizar. Após o treinamento do mapa SOM, os vetores de pesos dos neurônios vencedores representarão os vetores de características da base de treinamento, conforme discutido no capítulo anterior. Porém, dois problemas podem ocorrer: o neurônio vencedor pode representar padrões de classes diferentes (fronteira) ou a posição final do neurônio vencedor pode não permitir a comparação com as imagens mais parecidas. Será usada uma base com dados artificialmente gerados para auxiliar o entendimento e a explicação da proposta de solução.

Discute-se, também, sobre as duas bases de dados que serão usadas nos experimentos de exploração e de validação e a metodologia experimental adotada.

\subsection{Categorizando imagens com Mapa SOM}

Para uma melhor discussão da metodologia proposta em problemas de categorização usando o mapa SOM, será gerada artificialmente uma base de dados com 90 padrões, distribuídos em três grupos de diferentes classes e com 30 padrões para cada classe.

Um mapa SOM de tamanho $5 \times 5$ será utilizado. A base de dados e os resultados em diferentes épocas do treinamento do SOM estão ilustrados na Figura 5.1, na qual pode-se perceber que inicialmente (em $t=0)$ os vetores de pesos de cada neurônio estão todos desorganizados, mas com o processo iterativo de atualização (treinamento), eles vão se 

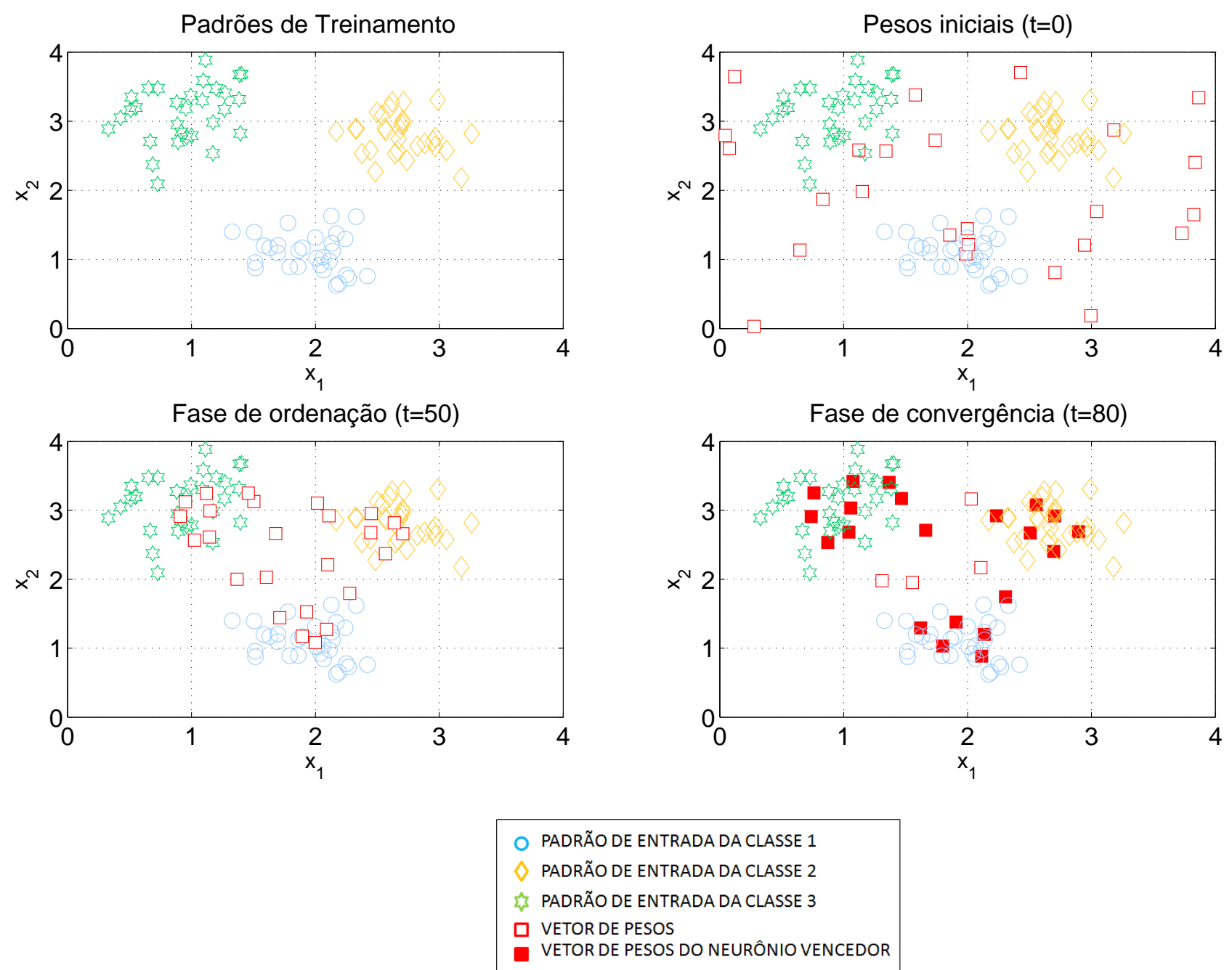

Figura 5.1: Resultados de treino em diferentes épocas $(t=0, t=50$ e $t=80)$ para uma base de dados gerada artificialmente.

organizando e ordenando-se $(t=50)$ e, no final do processo $(t=80)$, os vetores de pesos que foram vencedores (BMUs), após o treinamento, se tornam representantes dos padrões de entrada, estimando a densidade de probabilidade dos grupos.

Abstraindo que os vetores de entrada sejam vetores de características em uma tarefa de classificação usando o conhecido Knn, ao se apresentar um novo vetor de características (uma imagem nova), a comparação deste novo vetor com todos os vetores de pesos definirá uma relação de similaridade, da menor à maior distância euclidiana, podendo tal informação ser usada para a classificação, tanto considerando o valor de K igual a 1 como deixando esta escolha como um parâmetro livre. No caso do classificador SOM, se a relação entre a imagem original e o respectivo vetor de características é mantida na base 
de dados de treinamento ou mesmo em uma tabela, como ilustrada na Figura 4.6, em uma tarefa de classificação, é feito o cálculo para a definição dos neurônios vendedores após a extração do vetor de características da imagem que está sendo classificada.

O número de comparações feitas entre o vetor de características e os vetores de pesos pelo SOM é menor que o número de comparações entre o vetor de características da imagem a ser classificada e os vetores de características das imagens de treinamento pelo Knn. No exemplo acima, o número de comparações feito pelo Knn foi de 90 vezes, enquanto o número de comparações feito pelo classificador SOM foi de 21 vezes (tamanho do mapa SOM menos o número de neurônios que não representam vetores de características da base de treinamento, $5 \times 5$ ou $25-4)$.

O pré-processamento se inicia com a associação dos vetores de características aos neurônios do mapa. Cada neurônio do mapa pode ser identificado com um rótulo que, nesta proposta, não é, necessariamente, a classe da imagem de treinamento, mas outro qualquer, o qual, neste caso, foi definido como sendo A, B, C, ... Z. O rótulo gerado para cada neurônio do mapa será atribuído ao vetor de características. Na Figura 5.2 está ilustrado o mapa SOM, onde cada cruzamento do reticulado é um neurônio, identificado com o rótulo gerado e com a freqüência com que ele foi vencedor.

O resultado da associação dos vetores de características com os rótulos do mapa está ilustrado na Figura 5.3. Nela fica claro que, definindo a associação com os vetores de pesos, o acesso aos vetores de características é imediato, isto é, dado um novo vetor de características e estabelecendo qual seu neurônio vencedor, a busca pelos vetores de características mais semelhantes seria feita procurando, na coluna de 1BMU, quais os outros vetores de características que também tiveram o mesmo neurônio como vencedor, como explicado na Figura 4.6 do capítulo anterior.

Analisando este experimento, podem ser feitas as seguintes considerações:

1. O número de vetores de características que cada neurônio representa não é o mesmo, 


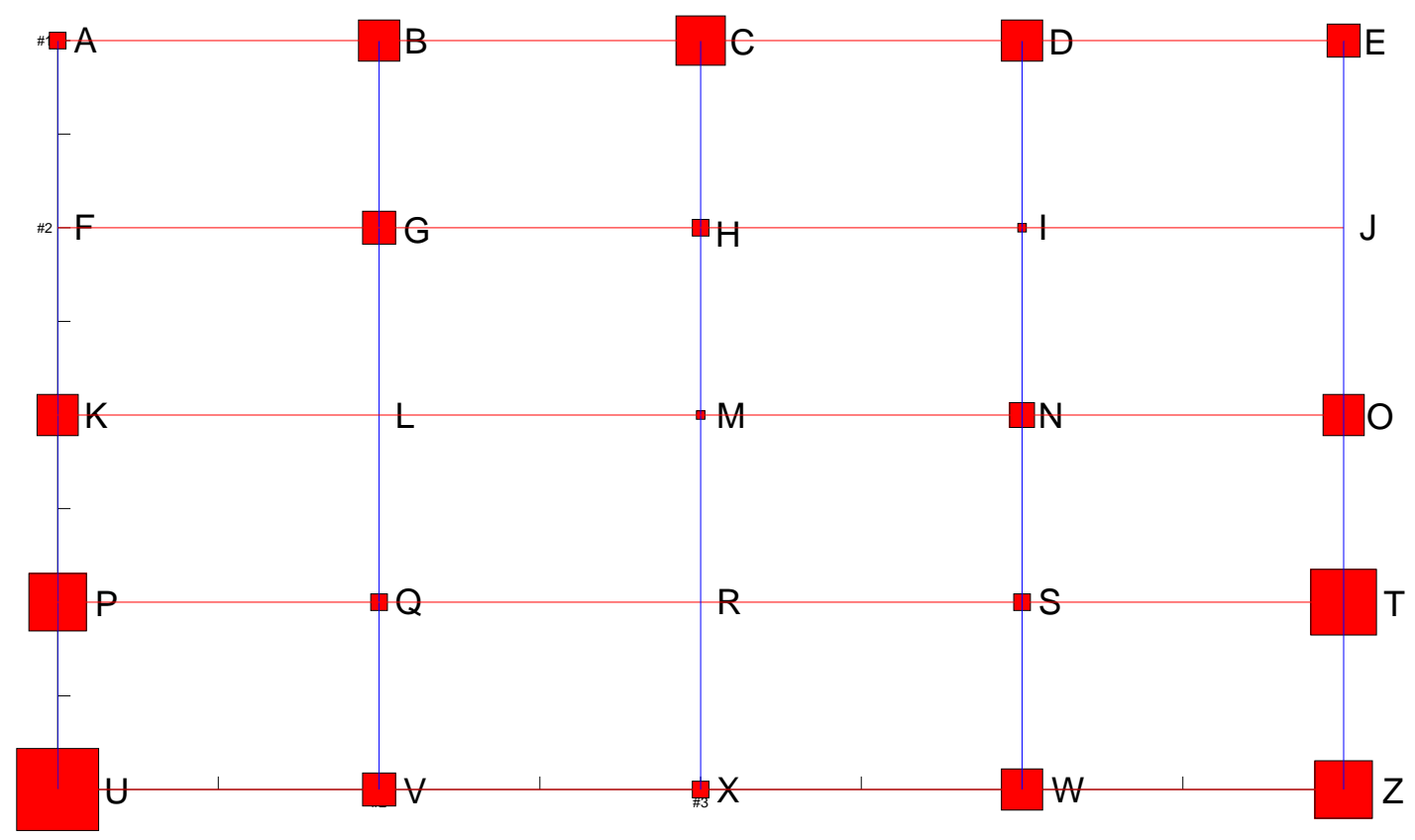

Figura 5.2: Mapa com histograma de vencimentos.

como visto no mapa de histograma (Figura 5.2). Isto afeta a classificação porque considerar os rótulos individuais dos vetores de características não garantirá, para cada neurônio, a decisão por um número mínimo de padrões, representados por cada neurônio vencedor do mapa SOM, como um parâmetro pré-estabelecido pelo usuário. Conclusão: desta maneira não se pode permitir que o número de padrões comparados para a decisão possa ser parametrizado pelo usuário.

2. Os vetores de pesos nem sempre são os centros dos vetores de entrada. Neste sentido, caso o novo vetor de características esteja em uma região de fronteira, não se pode garantir que as imagens comparadas na classificação sejam as mais parecidas ou, ainda, não se pode garantir que o resultado de classificação foi decidido pelos padrões de características mais próximos. Uma mostra deste problema é contemplada no exemplo da Figura 5.4, que é uma ampliação localizada da Figura 5.3. Nele, o novo padrão de características no espaço euclidiano está mais próximo do neurônio C, que representa padrões mais distantes do neurônio B ou mesmo do neurônio H. Conclusão: a decisão de classificação baseada nos vetores de características mais próximos acaba sendo feita em função da posição dos neurônios de seus vetores de 
pesos e não dos padrões de características mais próximos.

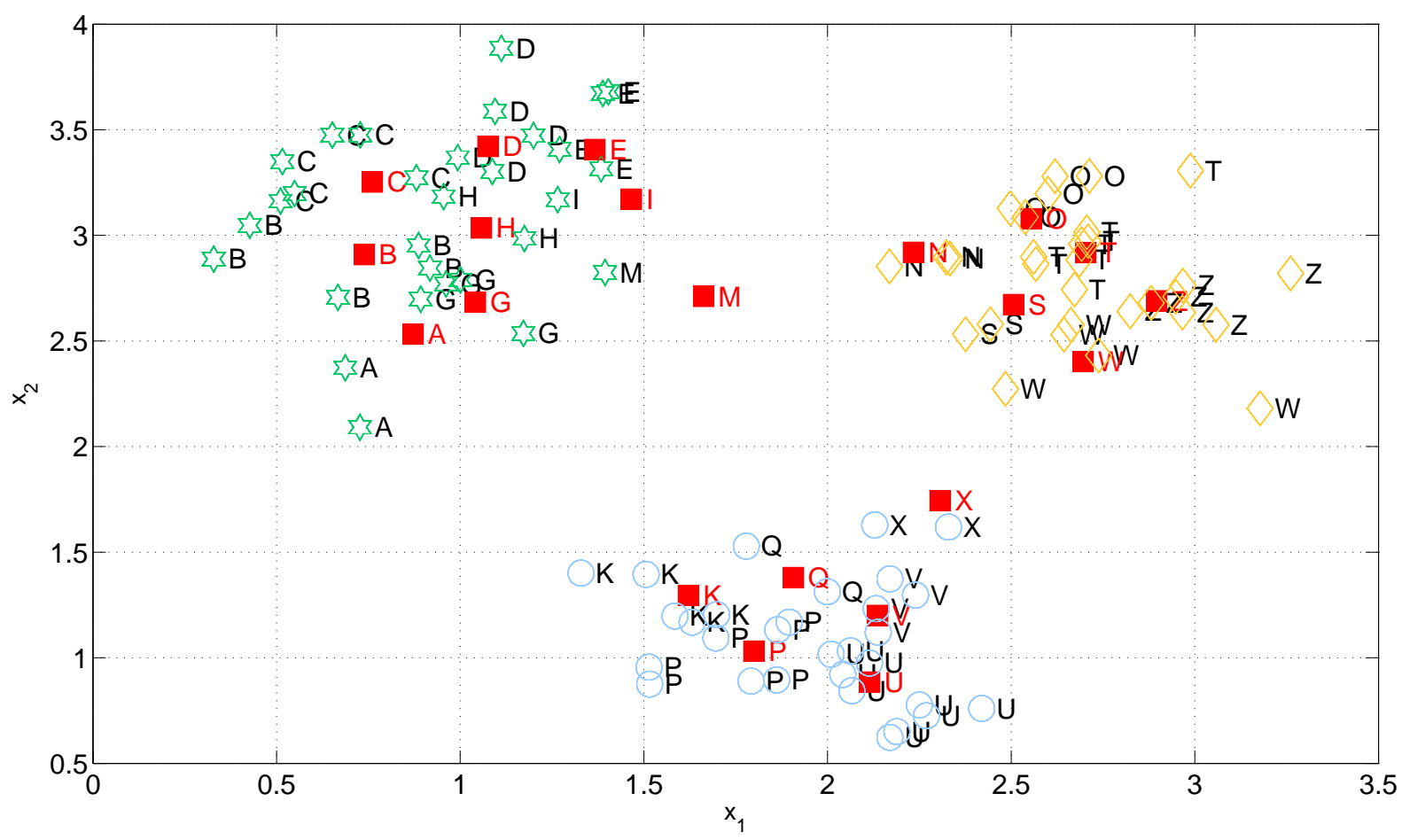

O PADRÃO DE ENTRADA DA CLASSE 1

PADRÃO DE ENTRADA DA CLASSE 2

PADRÃO DE ENTRADA DA CLASSE 3

VETOR DE PESOS DO NEURÔNIO VENCEDOR

Figura 5.3: Padrões de entrada e neurônios vencedores com rótulos atribuídos a cada unidade do mapa e a cada padrão de entrada.

Será discutida a seguir, a proposta de solução para garantir que a classificação seja feita considerando os vetores de características será discutida a seguir.

\subsection{Resolvendo os problemas de fronteira para a clas- sificação}

Considerando o exemplo da Seção 5.1, os neurônios B, C, H são vizinhos no mapa (veja a Figura 5.2) e também são vizinhos no espaço de características, veja Figura 5.3 ou Figura 5.4, o que indica a manutenção topológica do mapa SOM, onde neurônios vizinhos tendem a representar padrões semelhantes, assunto discutido no Capítulo 4. 
Isto significa que a ordem de similaridade entre o novo vetor de características e os vetores de pesos (Figura 5.4) traz como mais próximo C, B e H, respectivamente. Esta é a ordem dos melhores casamentos, ou a ordem dos neurônios vencedores (1BMU, 2BMU e 3BMU). Desta maneira, caso o usuário peça que a decisão seja tomada com um número de imagens maior que aquelas que o neurônio vencedor representa, os próximos neurônios vencedores podem ser consultados para garantir o número escolhido pelo usuário. Entretanto, isso ainda não resolve completamente o problema dos padrões novos na região de fronteira. Ainda com uso o auxílio do exemplo anterior, Figura 5.4, caso o usuário requeresse a decisão com base em três padrões semelhantes, o neurônio 'C' representa seis padrões, ou seja, os outros vetores de características que são mais similares a este novo vetor de características não seriam comparados.

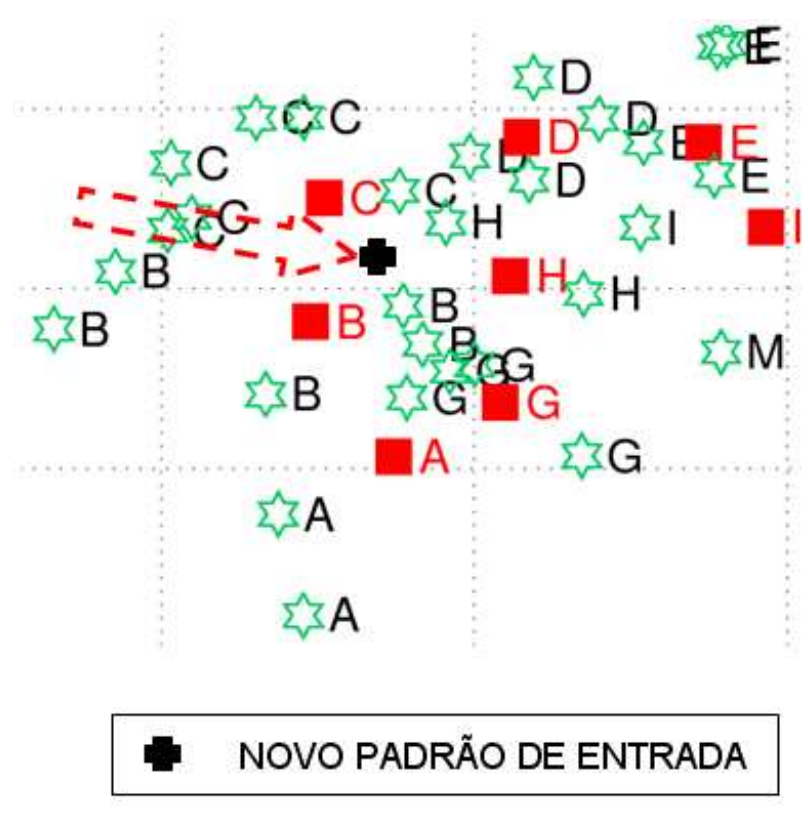

Figura 5.4: Ampliação de uma parte da Figura 5.3, considerando a apresentação de um novo padrão de entrada para ser classificado.

Para resolver o problema de parametrização do número de imagens escolhido pelo usuário e também o de padrões na região de fronteira será feita uma investigação para saber o maior número de padrões que um único neurônio representa e, assim, será definido, experimentalmente, o número de padrões a serem comparados de forma que a consulta aos neurônios vizinhos sempre seja necessária, independente da escolha do usuário. Assim, a parametrização é feita de forma que, para qualquer classificação, pelo menos os neurônios 
vizinhos sejam consultados, independentemente de o primeiro neurônio vencedor representar um número de padrões previamente definido pelo usuário. O algoritmo para a seleção das imagens que o neurônio vencedor representa e das imagens que os neurônios vizinhos representam é o seguinte:

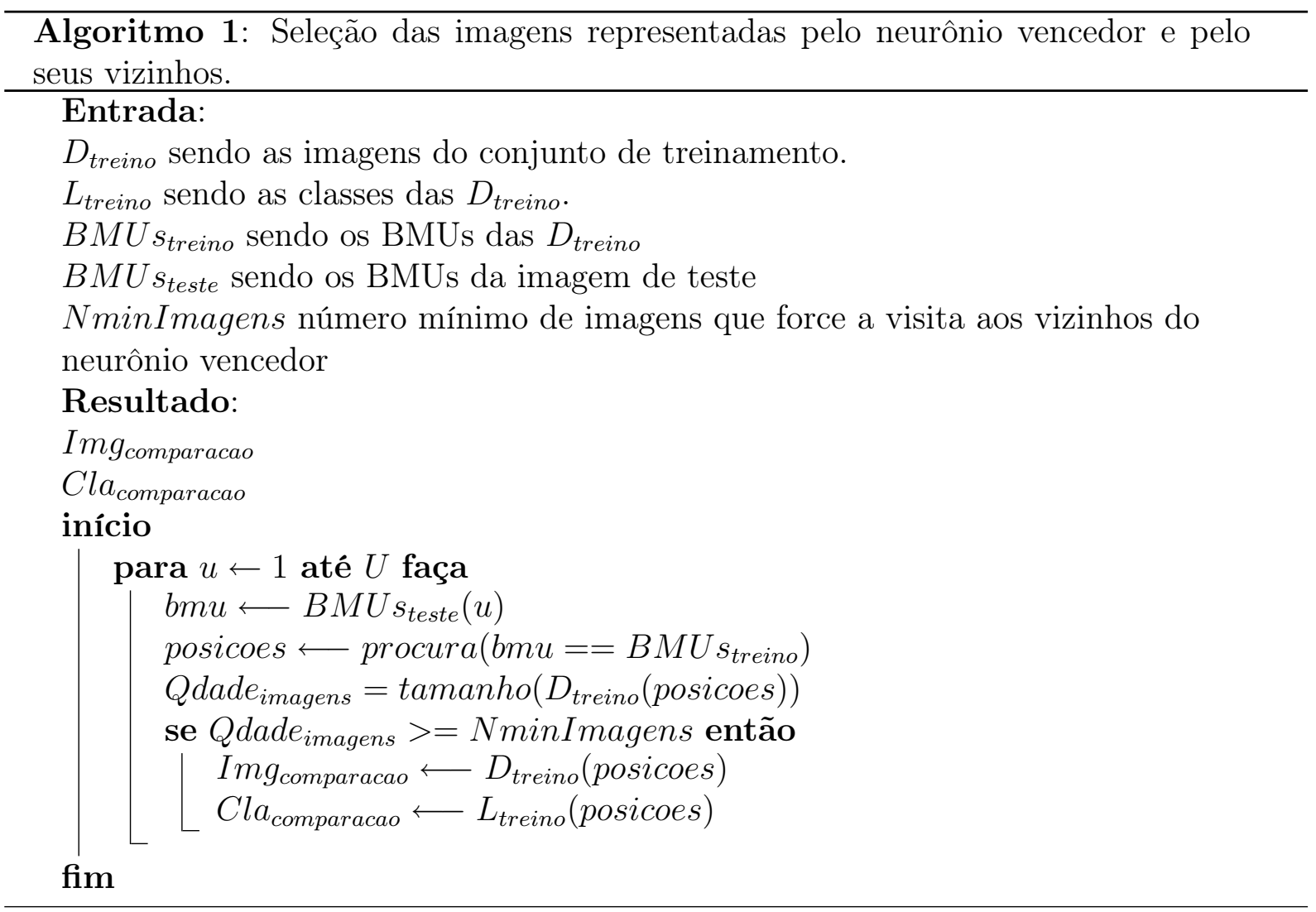

Para validar a proposta do uso do mapa SOM na categorização de imagens serão utilizadas duas bases de imagens médicas, uma para confirmação de viabilidade do método, em que serão discutidas todas as definições do modelo proposto e apresentados os resultados de classificação. Ainda com a utilização desta base de dados, serão apresentados experimentos para investigar a propriedade do modelo em função da sensibilidade de rotação, translação ou rotação e translação. A segunda base de dados é pública e disponível para teste de modelos de classificação e de recuperação de imagens médicas, a qual já foi usada com outros modelos de classificação e recuperação de imagens (LEHMANN et al., 2005), (DESELAERS et al., 2006). Nesta base, o modelo será validado e comparado com o melhor resultado já conseguido com seu uso. Serão discutidos, nas seções seguintes, as informações como modalidade de imagens médicas, quantidade de imagens, número de 
classes e método de avaliar a classificação.

\subsection{Bases de dados para os experimentos de categori- zação}

Para análise experimental da metodologia proposta e confirmação de viabilidade na categorização de imagens, utilizaram-se as duas bases de dados reais, brevemente introduzidas na seção anterior. As bases serão separadas de acordo com seus detalhes e dificuldade de classificação. A primeira base, que será chamada de exploração, tem imagens em formato DICOM e foi retirada da rotina do Instituto do Coração (InCor), hospital-escola da Faculdade de Medicina da Universidade de São Paulo. Os experimentos com a base de exploração serão chamados de exploratórios, pois tratam de casos reais, porém, com número de imagens e de categorias reduzido. As imagens são de ressonância magnética (RM) categorizadas pela vista da aquisição e todas em formato DICOM. Um total de 397 imagens foi selecionado conforme a vista de aquisição e estão distribuídas em 125 imagens de vista transversal (MR1), 120 imagens de vista sagital (MR2), 121 imagens de vista coronal (MR3) e 31 imagens de vista coronal com profundidade diferente (MR4). Uma amostra de cada conjunto de imagens pode ser vista na Figura 5.5. As categorias (MR1 MR4) não seguem uma padronização por vocabulário médico, apenas foram assim definidas para fins de confirmação de viabilidade do modelo. Esta base tem algumas qualidades importantes para avaliação do mapa SOM como classificador. Uma delas é que como a característica principal das classes é a forma, o mapa SOM indicará a proximidade topológica desta característica, alocando em regiões vizinhas do mapa as imagens com forma similar. Outra característica interessante é a similaridade entre MR3 e MR4. Elas têm forma parecida, mas se diferenciam na textura. Esta diferença permitirá a verificação da sensibilidade do extrator de características usando o mapa SOM para visualizar se as classes estão sendo separadas.

No segundo experimento, chamado validatório, serão testadas imagens disponíveis para fins acadêmicos (CLOUGH; MüLLER; SANDERSON, 2004), também usadas por outro 

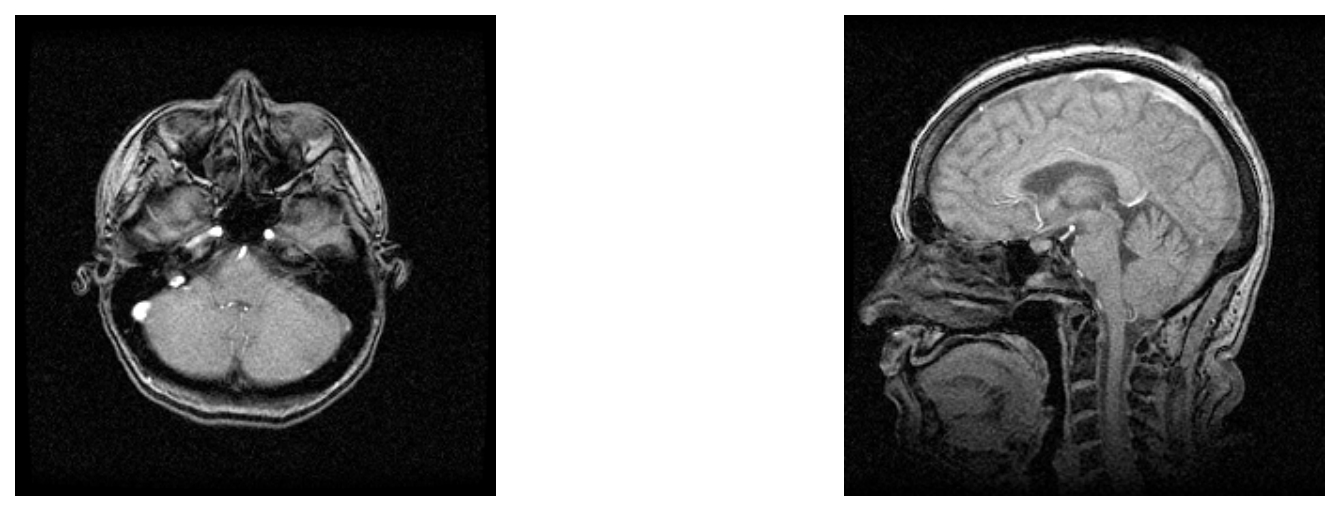

MR1

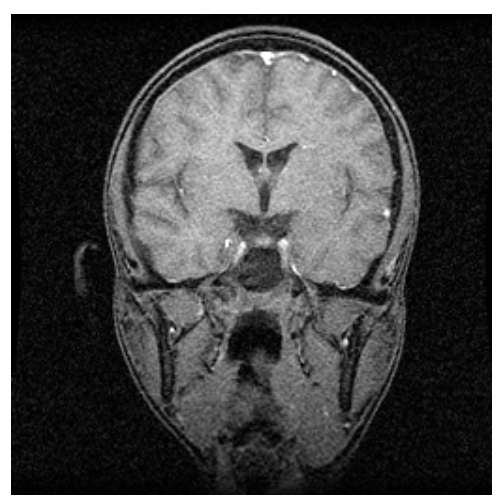

MR2

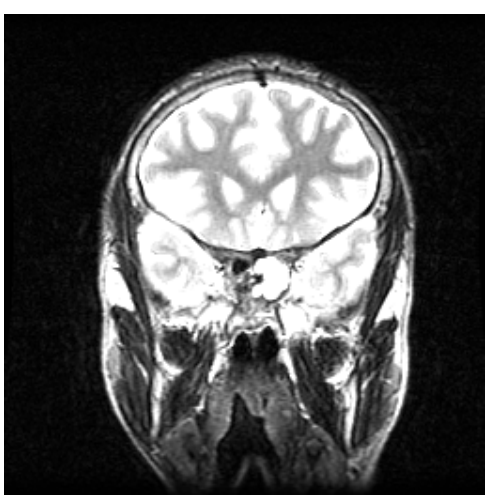

MR3

$\mathrm{MR} 4$

Figura 5.5: Amostra de cada categoria da base de imagens.

grupo de pesquisa (LEHMANN et al., 2005), (DESELAERS et al., 2006). Esta base, que será chamada de validação, permite a comparação dos resultados alcançados neste trabalho aos melhores resultados apresentados na literatura. Nesta base de dados, o número de imagens e o número de categorias são maiores em relação à base de exploração e a categoria de cada imagem segue a codificação IRMA (Image Retrieval in Medical Applications) (LEHMANN et al., 2005).

Os quatro eixos que compõem o código IRMA são: a técnica de imagem e modalidade (T-eixo, quatro níveis de detalhes), a posição relativa entre o equipamento de imagem e o paciente (D-eixo, três níveis de detalhes) e o sistema biológico que está sendo investigado (B-eixo, três níveis de detalhes). Assim, cada imagem codificada tem a forma TTTT- 
DDD-AAA-BBB, com 797 categorias únicas disponíveis nos quatro eixos.

Atualmente, 10000 imagens são selecionadas da rotina clínica da Universidade de Medicina de Aachen, Aachen, Alemanha e manualmente codificadas com o IRMA, resultando em mais de 400 códigos utilizados.

A categorização das imagens foi feita por radiologistas experientes. Pela dificuldade de se reunir radiologistas para categorizar um número extenso de imagens, as categorias foram organizadas em 2,1,2 e 1 nível de detalhes em T-,D-,A- e B-eixos respectivamente, ao invés de TTTT-DDD-AAA-BBB. Isto é possível porque o código IRMA é mono-hierárquico, ou seja, sem ciclos, o que permite formar subgrupos únicos. Assim, o número de códigos IRMA únicos utilizados é de 135 dentro do esquema TT**-D*-AA*-B*. Adicionalmente, um limiar pode ser aplicado para números mínimos de imagens em cada categoria e todas as imagens de categoria abaixo do limiar são descartadas. Isto resulta em 10000 imagens de 116 categorias usando um mínimo de cinco imagens por categoria. Um exemplo do código IRMA está ilustrado na Tabela 5.1.

As imagens estão separadas em 2 conjuntos, 9.000 para treinamento e 1.000 para teste. Os histogramas de imagens por classe para o conjunto de treinamento e para o conjunto de teste estão ilustrados na Figura 5.6. Por estes histogramas, percebe-se que não há uma uniformidade no número de imagens por classe, o que dificulta o processo de classificação, principalmente quando se utilizam classificadores com aprendizado.

\begin{tabular}{|lc|}
\hline Índice da Categoria & Código IRMA \\
\hline 1 & $11^{* *} 1^{* *}-50^{*} 0^{* *}$ \\
\hline 2 & $11^{* *} 2^{* *}-50^{*} 0^{* *}$ \\
\hline 3 & $11^{* *} 1^{* *}-41^{*} 7_{-}^{* *}$ \\
\hline$\ldots$ & $* * * *_{-} * * *_{-} * * *_{-} * * *$ \\
\hline 116 & $11^{* *} 2^{* *}-45^{*} 7^{* *}$ \\
\hline
\end{tabular}

Tabela 5.1: Exemplos de categoria das imagens usadas nos experimentos. O código IRMA está explicado na Tabela 5.2

Além da distribuição de imagens por classe não ser uniforme, outra dificuldade do uso desta base de dados está na variabilidade intra-classe e inter-classe. A aparência visual de imagens em algumas categorias varia significantemente. Isto ocorre também para imagens 


\begin{tabular}{|c|c|}
\hline Técnica & \\
\hline $11^{* *}$ & Radiografia plana \\
\hline $12^{* *}$ & Fluoroscopia \\
\hline $13^{* *}$ & Angiografia \\
\hline $14^{* *}$ & Tomografia Computadorizada \\
\hline $31^{* *}$ & Ressonância Magnética \\
\hline Direção & \\
\hline $1 * *$ & Coronal \\
\hline $2^{* *}$ & Sagita l \\
\hline $3^{* *}$ & Axial \\
\hline $4^{* *}$ & Outra \\
\hline Anatomia & \\
\hline $20^{*}$ & Crânio, não especificado \\
\hline $21^{*}$ & Crânio facial \\
\hline $22^{*}$ & Crânio base \\
\hline $23^{*}$ & Crânio neural \\
\hline $30^{*}$ & Espinha, não especificada \\
\hline $31^{*}$ & Espinha cervical \\
\hline $32^{*}$ & Espinha torácica \\
\hline $33^{*}$ & Espinha lombar \\
\hline $41^{*}$ & Mão \\
\hline $42^{*}$ & Junção radiocarpal \\
\hline $43^{*}$ & Antebraço \\
\hline $44^{*}$ & Cotovelo \\
\hline $45^{*}$ & Braço \\
\hline $46^{*}$ & Ombro \\
\hline $50^{*}$ & Peito, não especificado \\
\hline $51^{*}$ & Peito, osso \\
\hline $52^{*}$ & Pulmão \\
\hline $53^{*}$ & Hilo \\
\hline $61^{*}$ & Mama direita \\
\hline $62^{*}$ & Mama esquerda \\
\hline $70^{*}$ & Abdome, não especificado \\
\hline $71^{*}$ & Abdome superior, \\
\hline $72^{*}$ & Abdome meio \\
\hline $73^{*}$ & Abdome inferior \\
\hline $80^{*}$ & Pélvis, não especificado \\
\hline $91^{*}$ & Pé \\
\hline $92^{*}$ & Articulação do tornozelo \\
\hline $93^{*}$ & Perna \\
\hline $94^{*}$ & Joelho \\
\hline $95^{*}$ & Coxa \\
\hline $96^{*}$ & Anca \\
\hline Biosistema & \\
\hline $0 * *$ & Não especificado \\
\hline $1^{* *}$ & Sistema cérebro-espinhal \\
\hline $2^{* *}$ & Sistema cardiovascular \\
\hline $3^{* *}$ & Sistema respiratório \\
\hline $4^{* *}$ & Sistema gastrointestinal \\
\hline $5^{* *}$ & Sistema uropoietic \\
\hline $6^{* *}$ & Sistema reprodutivo \\
\hline $7 * *$ & Sistema muscular \\
\hline
\end{tabular}

Tabela 5.2: Detalhamento dos códigos IRMA. 


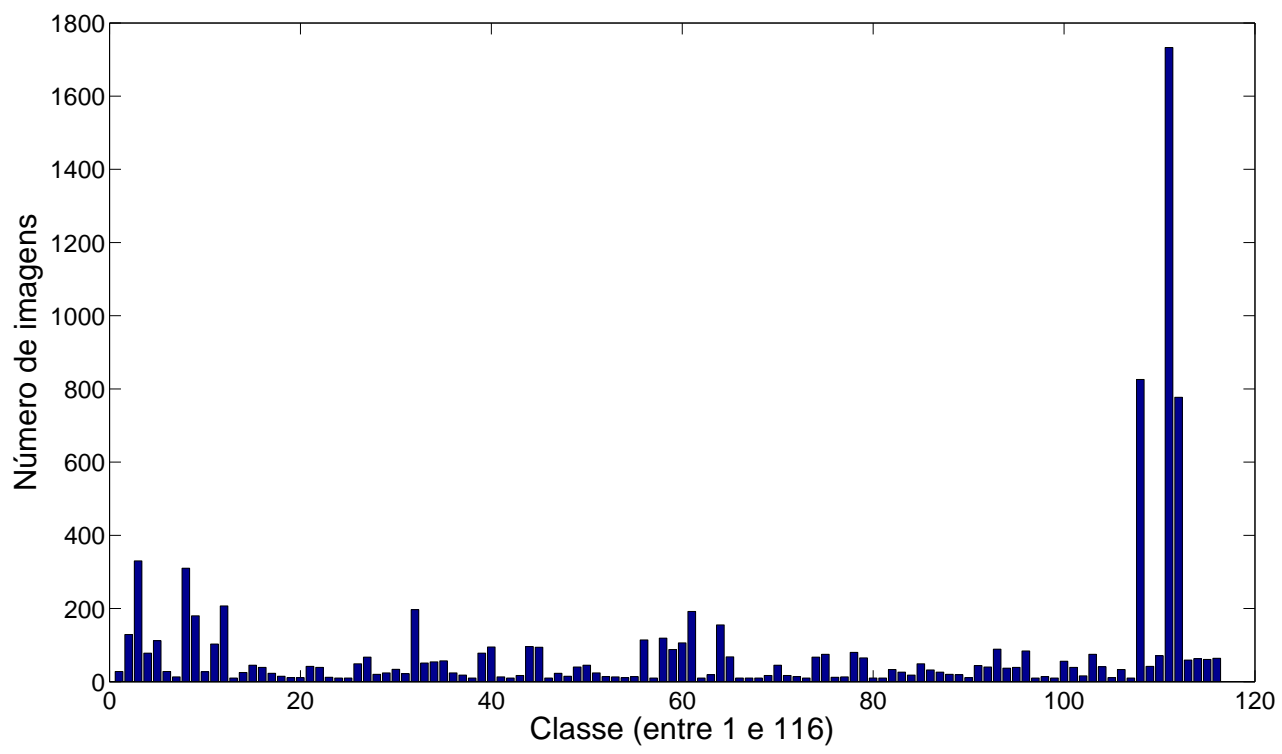

imagens de treinamento

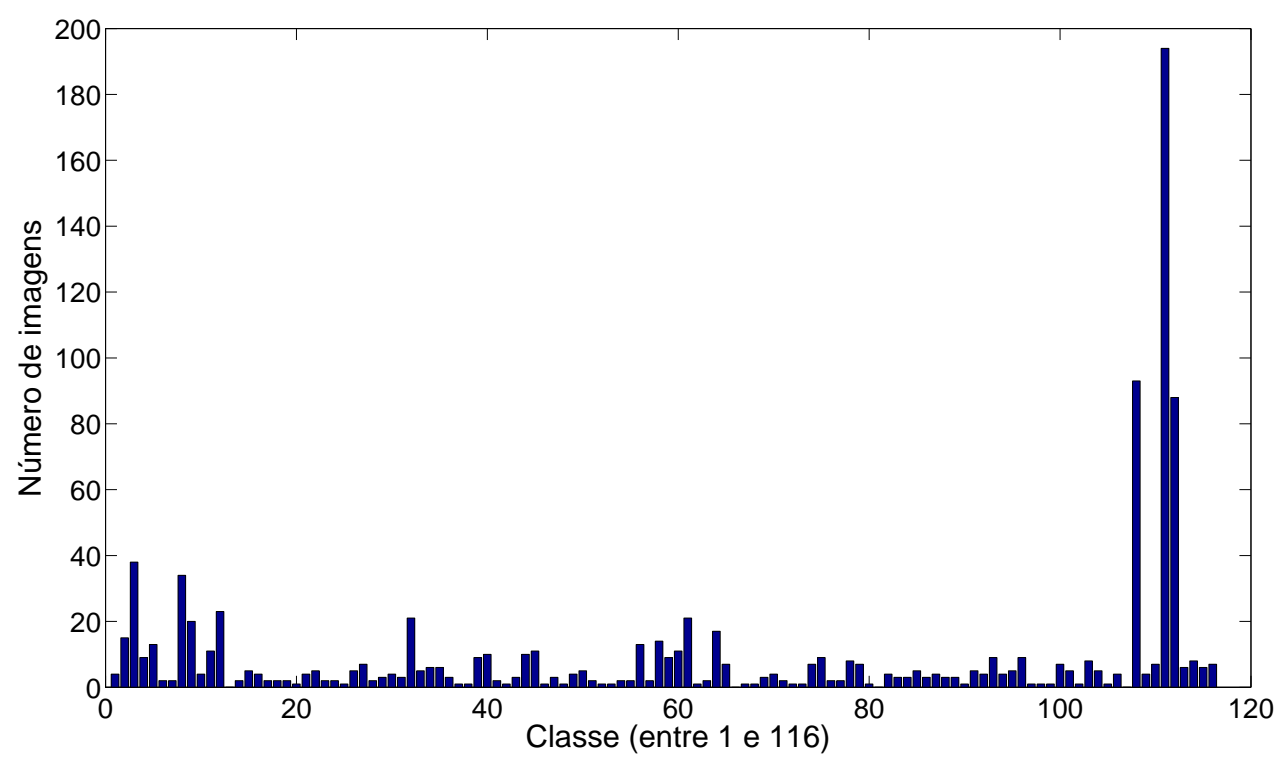

imagens de teste

Figura 5.6: Histograma da base de validação. 
com o mesmo código. Por exemplo, a Figura 5.7. Todas as radiografias são identicamente codificadas (IRMA 1121-120-800-700). As categorias com agrupamentos esparsos dentro de um mesmo grupo comprometem a tarefa de classificação. Outra situação que dificulta a extração de características e, conseqüentemente, a classificação é quando as imagens têm códigos IRMA diferentes, mas com similar aparência visual. A Figura 5.8 ilustra este problema para imagens de mamografia que foram adquiridas em orientação craniocaudal e oblíqua.
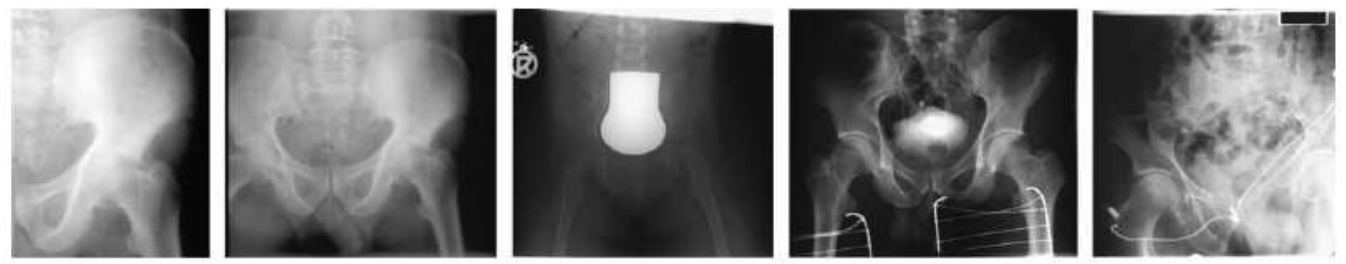

Figura 5.7: Variabilidade Intra-classe. Todas as radiografias têm a mesma codificação (IRMA 1121-120-800-700). Adaptado de (LEHMANN et al., 2005).
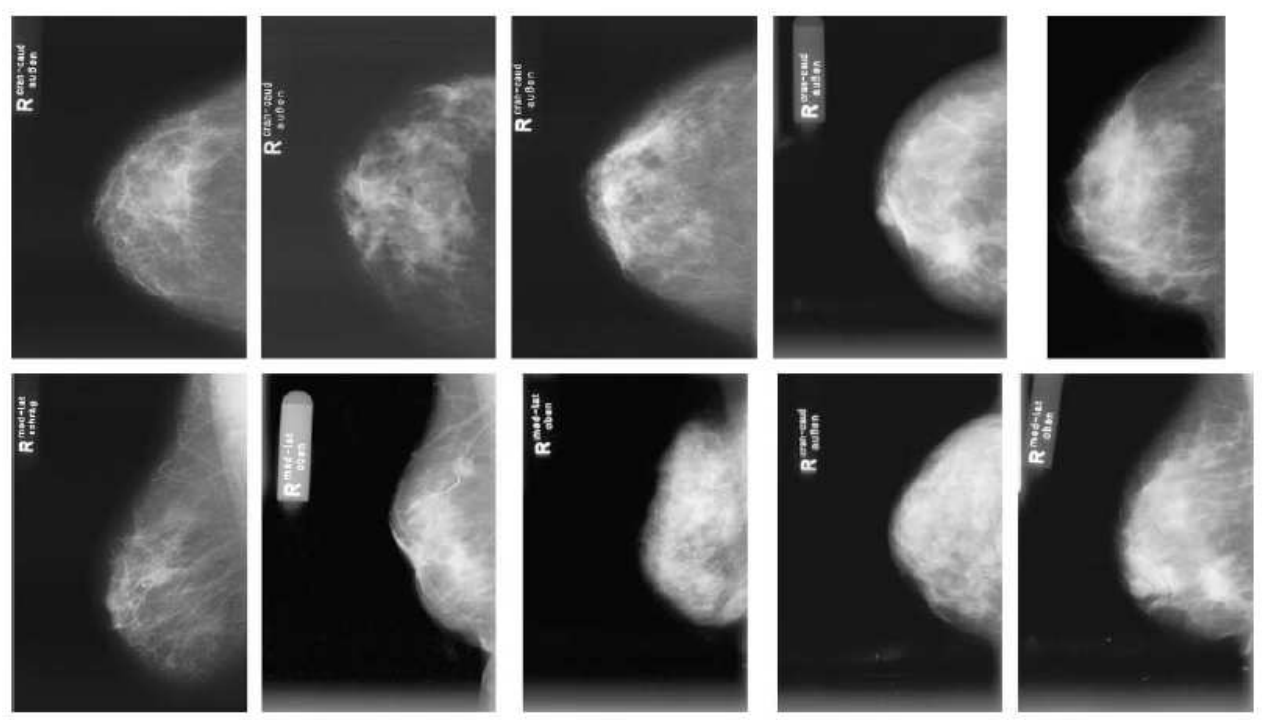

Figura 5.8: Similaridade Inter-Classe. Todas as mamografias em vista axial/craniocaudal são codificadas como $11^{* *}-3^{* *}-61^{*}-6^{* *}$ (linha superior), enquanto em outras orientações têm codificações $11^{* *}-4^{* *}-61^{*}-6^{* *}$ (linha inferior). Adaptado de (LEHMANN et al., 2005).

A seguir, um maior detalhamento sobre os experimentos realizados será conduzido. 


\title{
5.4 Métodos Experimentais para validação da proposta de categorização
}

\begin{abstract}
Abaixo, será discutida, em detalhes, a metodologia envolvida nos experimentos do trabalho. A discussão será feita tanto para a fase de extração de coeficientes quanto para a fase de classificação. Ressaltando que não existe uma metodologia consolidada para definição da melhor família wavelet, nível de decomposição e conjunto de coeficientes a ser utilizada. Apresenta-se aqui uma metodologia para tais definições que pode não ser necessariamente a melhor, mas permite justificar as escolhas.
\end{abstract}

\subsubsection{Metodologia para Extração dos Coeficientes Wavelets mais Representativos}

Como já destacado desde o Capítulo 1, a proposta do trabalho é uma máquina classificadora para categorizar imagens médicas, a qual envolve um extrator de características e um classificador, sendo estes transformada wavelet e mapas auto-organizáveis, respectivamente.

Para a extração de características, discutiu-se no Capítulo 3 que no uso da AMR (Análise em Multi-Resolução), da qual wavelets é um tipo, uma imagem é decomposta para cada nível de decomposição, em quatro diferentes conjuntos de coeficientes como está representado na Figura 5.9.

Primeiramente, é preciso definir o nível de decomposição; em seguida, é necessário definir o tipo de wavelet mãe e, por fim, qual conjunto de coeficientes utilizar.

Para todas as definições, a avaliação será feita usando as medidas $M Q E, T E, I D B$ e Taxa de Acerto com base no resultado de classificação por SOM de tamanho $10 \times 10$. Para as caracterizações do extrator de características, o tamanho do mapa foi fixo, mas para os experimentos de classificação serão feitas investigações com outros tamanhos do mapa. As medidas MQE (Equação 4.5) e TE (Equação 4.6) são usuais na avaliação do SOM e foram definidas no Capítulo 4. A medida IDB (Índice de Davies-Bouldin) é bem conhecida na avaliação de técnicas de agrupamento de dados, pois mede a relação 


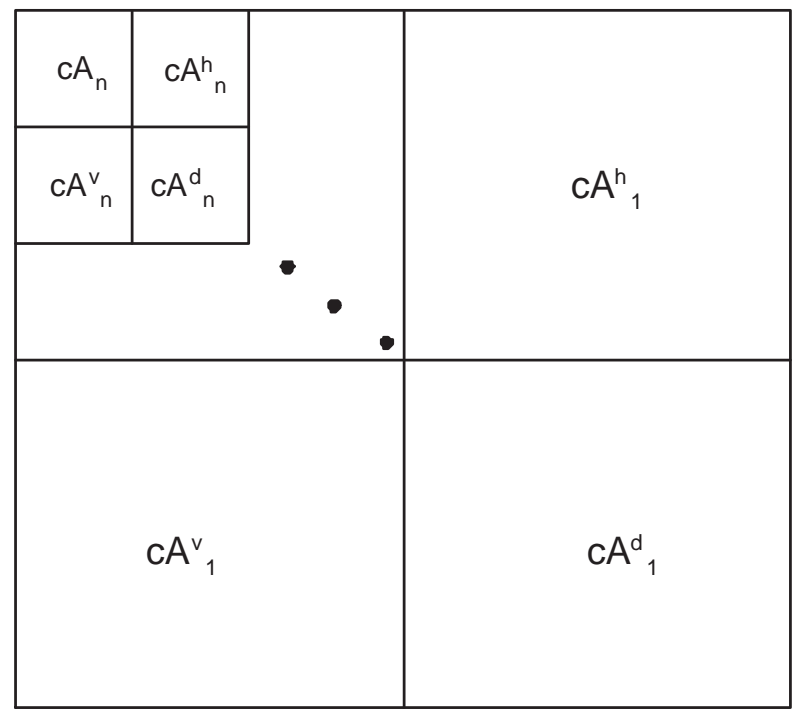

Figura 5.9: Esquema de decomposição por AMR (Análise em Multi-Resolução).

inter-grupo e intra-grupo. Mais detalhes sobre esta métrica podem ser encontrados no Apêndice A. Contudo, ela é explorada aqui com uma medida alternativa às usualmente utilizadas.

Para a definição do número de decomposições, utilizou-se a metodologia ilustrada no esquema da Figura 5.10, na qual para cada nível de decomposição, com início em $n=2$, o conjunto de coeficientes de aproximação, $c A_{n}$, das imagens para treinamento do mapa SOM e das imagens para testes do mapa SOM é extraído e são calculadas as medidas MQE, TE, IDB e Taxa de Acerto.

Como o experimento é para definição da decomposição, usou-se apenas a wavelet Haar. Ao definir o nível de decomposição, são conduzidos experimentos usando outras duas wavelets mãe, que satisfaçam as condições admissíveis - a função ter média zero, decaimento abrupto e estar localizada tanto no espaço de tempo como no de freqüência definidas no Capítulo 3, como Daubechies (DB) e Reverse biorthogonal wavelets (RBIO).

Após a definição do número de coeficientes e do tipo de wavelet mãe, as características das imagens de treinamento são extraídas para o treinamento do classificador. 


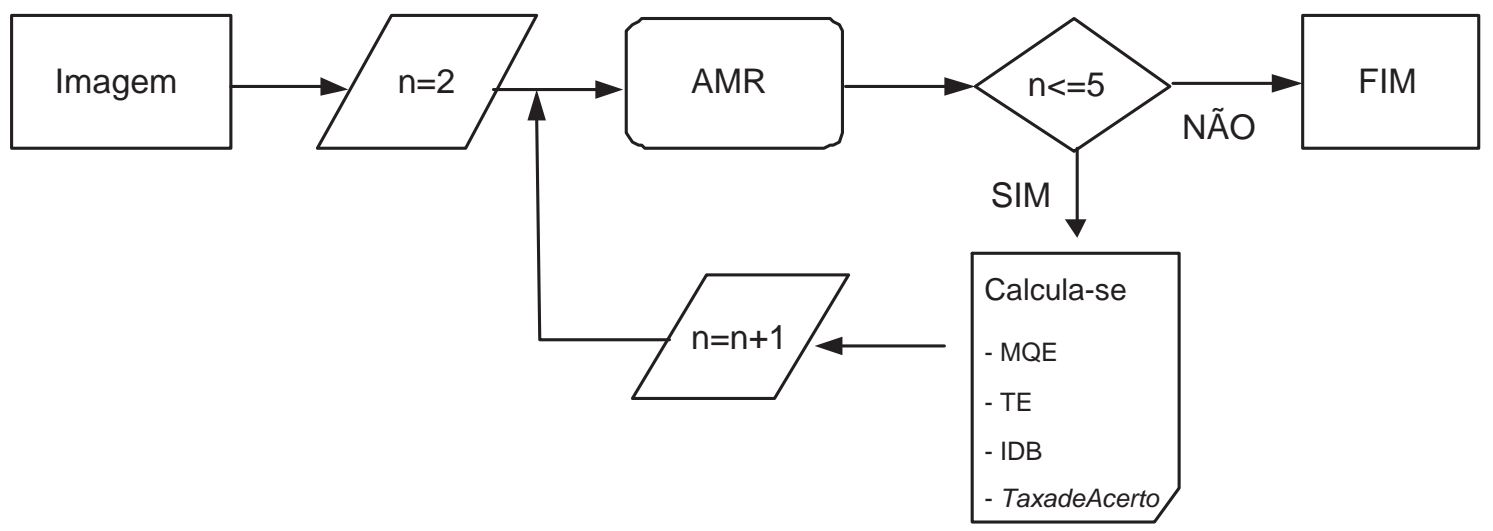

Figura 5.10: Esquema de avaliação do conjunto de coeficientes $c A_{n}$, onde $n$ é o nível de decomposição.

\subsubsection{Metodologia para Categorização}

Antes dos experimentos de classificação é preciso definir o tamanho do mapa do SOM. Para tanto, usam-se as mesmas medidas utilizadas na definição de características $M Q E$, TE, IDB e Taxa de Acerto para diferentes tamanhos de mapa $(4 \times 4,6 \times 6,8 \times 8,10 \times 10$, $12 \times 12)$.

As medidas $M Q E$ e TE são bastante usuais para medida de qualidade do mapa SOM. No entanto, neste trabalho é proposto o uso de outra medida, empregada para qualidade de agrupamento e apresentada anteriormente: o Índice de Davies-Bouldin (IDB) (DAVIES; BOULDIN, 1979). Para tanto, o mapa SOM deve estar segmentado em grupos. Para a segmentação, será adaptada a metodologia de Vesanto e Alhoniemi (VESANTO; ALHONIEMI, 2000) para descobrir o número de grupos em uma base de dados, a qual utiliza o classificador $K$-médias para agrupar os vetores de pesos do mapa e o IDB para medir a qualidade do agrupamento. Em (VESANTO; ALHONIEMI, 2000), o valor de $K$ inicial é $2(k=2)$ e o menor valor de $I D B$ para os diferentes valores deste parâmetro indicará o número de grupos existentes em uma base de dados. Como nesta tese o número de classes é sempre conhecido, não é necessário variar o valor de $K$. Logo, o IDB é apenas calculado para um único valor de $K$. No Anexo B, a metodologia de Vesanto e Alhoniemi (VESAnto; AlHONIEMI, 2000) é discutida em detalhes. Com esta maneira de medir o $I D B$, consegue-se verificar a formação de bordas do mapa sobre as classes. Entretanto, as medidas $M Q E, T E, I D B$ são bem empregadas para medir a qualidade do mapa. Como 
o foco do trabalho é a classificação, a taxa de acerto terá uma importância maior por quantificar o uso do mapa.

Para os experimentos exploratórios, o método de classificação empregado é o "leaveone-out" (DUDA; HART; STORK, 2000). Como a própria tradução do nome do método sugere, deixe um de fora, este método é usado para separar o conjunto de treinamento e o conjunto de teste em diversas combinações, das quais, a cada passo, tira-se um padrão para usá-lo como teste e o restante dos padrões é usado para o treinamento. Um exemplo esquemático deste método está ilustrado na Figura 5.11.

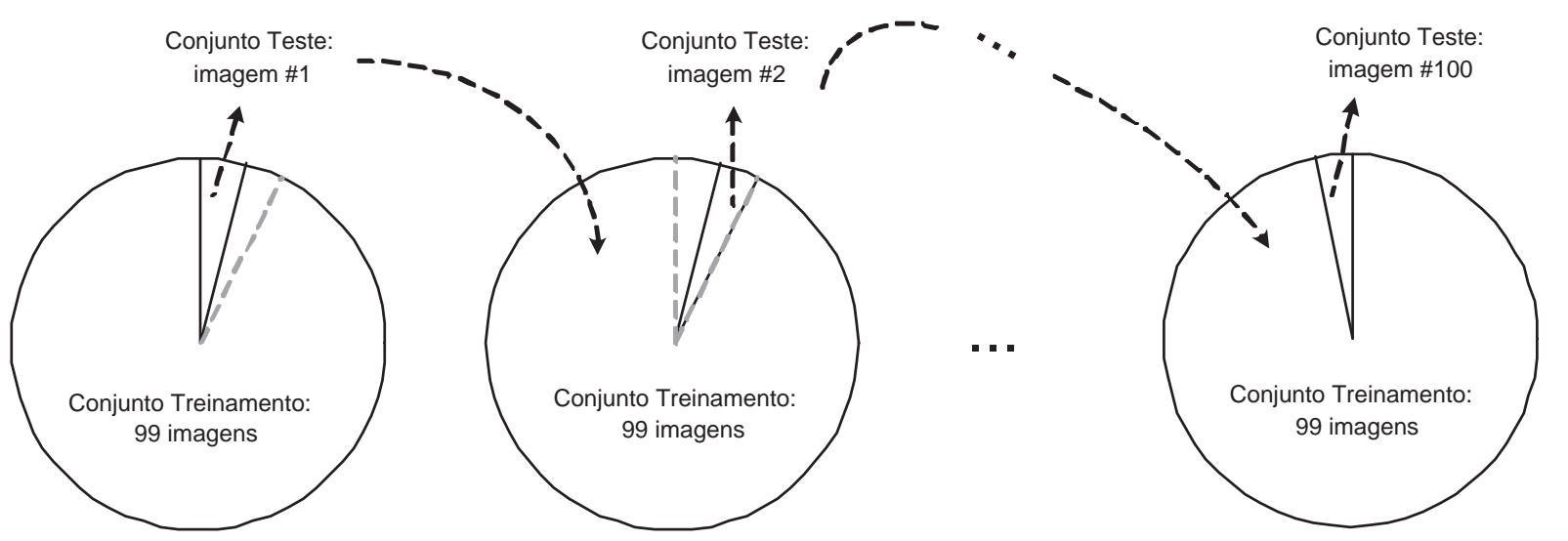

Figura 5.11: Esquema de uso do método leave-one-out para uma base de dados com 100 imagens.

A cada passo do processo, contabiliza-se o acerto ou o erro do classificador e, ao final, é computada a porcentagem de acertos que o classificador atingiu.

A segunda base de dados tem seu próprio conjunto de teste. Para fins de comparação, o teste do classificador será feito com o uso do conjunto de teste.

Por fim, as características das imagens serão representadas pelos coeficientes que resultaram nas melhores medidas ( $M Q E, T E, I D B$ e Taxa de Acerto) e com a melhor família wavelet. O mapa SOM que apresenta melhores medidas qualitativas será treinado com as características das imagens.

Para avaliar a sensibilidade do modelo, extrator de características e classificador, quanto à rotação e à translação, serão geradas 200 novas imagens, 50 de cada classe. A geração procederá da seguinte forma: 
- escolhem-se 5 imagens aleatoriamente para cada classe das imagens de treinamento.

- a cada imagem aplicam-se diferentes escalas de rotação, translação, e rotação e translação.

- a escala varia de 10 a 35. No caso de translação, a unidade da escala é pixel, deslocado para cima, direita, baixo e esquerda. Na rotação, a escala é graus: positivo.

\subsection{Considerações Finais}

A classificação em SOM pode ser feita a partir dos rótulos dos neurônios, definidos por votação ou frequência. Uma maneira alternativa de se fazer a classificação, proposta neste trabalho, é usar o neurônio como uma referência para a região do espaço de características com padrões mais semelhantes.

Discutiram-se os problemas com este método para classificação e, conseqüentemente, para a recuperação de imagens para o caso em que o usuário defina livremente o parâmetro número de padrões a serem comparados. A proposta de solução pode não ser ótima, mas força um mínimo de neurônios a ser consultado, ou seja, amplia a área da região a ser explorada. Com isto, o resultado pode ser exato (crisp), ou então pode ser estendido em termos de pertinência (fuzzy) (KELLER; GRAY; GIVENS, 1995).

Apresentaram-se também, as duas bases de dados utilizadas nos experimentos. A primeira delas trata de uma base real, mas com poucos casos e com categorias definidas para exploração do modelo de classificação proposto, a fim de investigar seus resultados de comparação com outro de melhor resultado da literatura, bem como explorar suas propriedades quando utilizada em imagens reais, as quais apresentam invariância de rotação, translação e ambos. Por fim, apresentou-se uma segunda base de dados usada nos experimentos realizados, com imagens da rotina de um hospital que está disponível publicamente para fins de pesquisa e já foi utilizada em outros estudos.

Para avaliação dos resultados usando a base de exploração, discutiu-se sobre o uso do método leave-one-out. Por outro lado, para a base de validação, discutiu-se sobre o uso 
da base de teste para fins de comparação de resultados.

No Capítulo seguinte, serão abordados os resultados experimentais. 


\section{Avaliação experimental do categorizador de imagens}

Este capítulo apresenta os resultados experimentais da proposta. Todos os experimentos foram feitos com o uso do software MATLAB usando o pacote SOMToolbox (SOMToolbox, 2007), com alterações para os experimentos específicos da tese. O SOMToolbox é um pacote desenvolvido pelo grupo de pesquisa do Teuvo Kohonen (KOHONEN, 2001) e largamente usado pela comunidade científica que aplica SOM em suas pesquisas (KASKI, 1998), (OJA; KASKI; KOHONEN, 2003).

O computador utilizado foi um PC desktop com processador Athlon XP $2.2 \mathrm{GHz}$, com 1GByte de memória RAM.

\subsection{Experimentos de definições usando a base de ex- ploração}

Os resultados apresentados a seguir serão da base de exploração, discutida no capítulo anterior, para preparação do modelo. Os objetivos destes experimentos são:

- definição dos níveis de decomposição wavelets;

- definição da melhor família de wavelets;

- definição do melhor conjunto de coeficientes (de aproximação ou de detalhamentos);

- validação do modelo quanto à sensibilidade a rotação, translação, e rotação e translação; 
- comparação do modelo obtido com aquele proposto de Lehmann et. al. (LEHMANN et al., 2005).

Entre os experimentos apresentados a seguir para caraterizar a máquina classificadora, o primeiro foi realizado para a definição dos níveis de decomposição (na análise wavelets). Os resultados obtidos estão sintetizados na Tabela 6.1. Para estes experimentos, as 397 imagens foram decompostas, por análise wavelets, em 4 diferentes níveis, iniciando com $n=2$ até com $n=5\left(c A_{2}\right.$ até $\left.c A_{5}\right)$. A cada nível, o coeficiente de aproximação, $c A_{n}$, foi extraído, um SOM de tamanho $10 \times 10$ foi treinado e as medidas MQE (erro médio final de quantização), TE (erro topográfico), IDB e taxa de acerto foram calculados. O tempo de treinamento também foi medido.

\begin{tabular}{|l|c|c|c|c|}
\hline & $\boldsymbol{c A}_{\mathbf{2}}$ & $\boldsymbol{c A}_{\mathbf{3}}$ & $\boldsymbol{c A _ { 4 }}$ & $\boldsymbol{c A _ { 5 }}$ \\
\hline MQE & 16,63 & 13,87 & 10,79 & 8,07 \\
\hline TE & 0,02 & 0,03 & 0,03 & 0,04 \\
\hline IDB & 1,08 & 1,01 & 1,05 & 1,07 \\
\hline Taxa de Acerto (\%) & 91 & 95 & 92 & 90 \\
\hline Tempo de Treinamento & 129 & 29 & 6 & 1 \\
\hline
\end{tabular}

Tabela 6.1: Resultados experimentais usando o coeficiente de aproximação em diferentes níveis de decomposição wavelets.

Os resultados das medidas para a escolha dos níveis de decomposição indicam que o nível a ser utilizado é $3,\left(c A_{3}\right)$. Em relação à medida $M Q E$, o resultado apresentado não garante qualidade e percebe-se que a medida é sensível à mudança de dimensão do vetor de características (dimensão para $c A_{2}$ é muito maior que para $c A_{5}$, os resultados de $M Q E$ foram respectivamente 16,53 e 8,07). Por outro lado, TE indica o quanto o mapa consegue representar a topologia das imagens, que se manteve estável para todos os conjuntos $(0,03)$. O IDB também foi menor para $c A_{3}, 1,01$, melhor resultado confirmado pela Taxa de Acerto, 95\%. O tempo de treinamento em $c A_{3}, 29$ segundos, é aceitável para esta aplicação.

Com o uso do conjunto de coeficientes $c A_{3}$, três diferentes famílias wavelets foram comparadas (Haar, Db2 e RBIO) em termos de Taxa de acerto. Os resultados estão resumidos na Tabela 6.2 . 


\begin{tabular}{|c|c|c|c|}
\hline & Haar & DB2 & RBIO \\
\hline Acerto & $95 \%$ & $66 \%$ & $95 \%$ \\
\hline
\end{tabular}

Tabela 6.2: Resultados de classificação do SOM usando diferentes famílias wavelets.

Duas famílias tiveram taxa de $95 \%$ de acerto. A escolha se deu pela Haar por manter a morfologia da imagem original, o que permite sua utilização como ícone e permite a busca browser no SOM, mostrado a seguir.

Por fim, experimentos para definir o conjunto de coeficientes como vetor de características das imagens foram conduzidos e sintetizados na Tabela 6.3.

\begin{tabular}{|l|c|c|c|c|}
\hline & $\boldsymbol{c A}_{\mathbf{3}}$ & $\boldsymbol{c D}_{\mathbf{3}}^{\boldsymbol{h}}$ & $\boldsymbol{c D}_{\mathbf{3}}^{\boldsymbol{v}}$ & $\boldsymbol{c D}_{\mathbf{3}}^{\boldsymbol{d}}$ \\
\hline MQE & 13,87 & 5,56 & 5,85 & 3,64 \\
\hline TE & 0,03 & 0,03 & 0,03 & 0,00 \\
\hline IDB & 1,05 & 1,59 & 1,54 & 1,88 \\
\hline Taxa de Acerto (\%) & 95 & 66 & 72 & 40 \\
\hline
\end{tabular}

Tabela 6.3: Resultados experimentais usando o coefiente de aproximação e os coeficientes de detalhamento com nível 3 de decomposição.

Estes experimentos possibilitam algumas análises importantes relativas à qual medida de desempenho utilizar. Como já dito, serão utilizadas as medidas, $M Q E, T E, I D B$ e Taxa de Acerto. Cada uma mede, respectivamente, quantização do mapa, representação topológica, qualidade de agrupamento e taxa de acerto. O interesse para o trabalho é maximizar a taxa de acerto e, por isso, esta medida terá um peso maior na decisão de qual conjunto de coeficientes escolher. Sendo assim, as medidas que acompanham a taxa de acerto deverão também ter uma relevância maior. Neste sentido, o $I D B$ dos resultados experimentais, Tabela 6.3, converge para a melhor medida de taxa. O conjunto de coeficiente que apresentou melhor taxa também apresentou o menor $I D B$. Por outro lado, o $T E$ se manteve quase sempre constante. O $M Q E$ se mostrou uma medida sensível à intensidade dos coeficientes (valores de $c A_{3}$ são mais altos que os valores de $c D_{3}^{h}, c D_{3}^{v}$ e $c D_{3}^{d}$ ). Diante desses aspectos, define-se que o conjunto $c A_{3}$ é a melhor escolha, uma vez que sua taxa de acerto é melhor que a dos demais, bem como o seu $I D B$. Uma outra observação interessante é em relação ao $C D_{3}^{h}$ que produziu erros pequenos de $M Q E$ e 
$I D B$. Zuchini (ZUCHINI, 2003) mostrou experimentalmente que, se as medidas $M Q E$ e $T E$ derem resultados baixos, significa que o mapa tem baixa capacidade de generalização. Isto também pode ser verificado nos resultados dos experimentos aqui apresentados, dado que a taxa de acerto foi muito baixa.

Após a definição do nível de decomposição e do conjunto de coeficientes a ser utilizado é preciso, agora, considerar os experimentos para a escolha do tamanho do mapa. A Tabela 6.4 mostra os diferentes tamanhos de mapa a ser escolhido, os respectivos resultados $M Q E, T E, I D B$ e o tempo gasto no treinamento (em segundos).

Foi considerado o uso das medidas $M Q E$, TE e $I D B$ porque havia uma hipótese de que seria possível estabelecer alguma correlação entre elas. Desde que o $M Q E$ quantifica a resolução do mapa ou quantos neurônios são necessários para representar os dados, mas, ao mesmo tempo, não é uma medida apropriada para a escolha do tamanho do mapa porque ao, aumentar o número de neurônios, o $M Q E$ é automaticamente reduzido (há aumento do número de vetores de pesos para quantização), porém começa-se a perder a capacidade de representação topológica. Este efeito é detectado pelo resultado da medida TE, que indica a capacidade do mapa representar a topologia dos dados. Por outro lado, a medida $I D B$ verifica a qualidade de agrupamento, avaliando quatro grupos sendo formados no mapa. Como está mostrado na Tabela 6.4, não há uma clareza com respeito ao uso destas medidas em relação à escolha do melhor tamanho do mapa. Por esta razão, os experimentos de classificação são conduzidos para os três diferentes tamanhos de mapa. Com este resultado de classificação, as medidas realizadas anteriormente $M Q E, T E$ e $I D B$ servem agora como apoio à escolha de qual tamanho do mapa deve ser usado.

\begin{tabular}{|l|c|c|c|}
\hline Tamanho do mapa & $6 \times 6$ & $10 \times 10$ & $12 \times 12$ \\
\hline MQE & 15,25 & 13,87 & 13,39 \\
\hline TE & 0,04 & 0,03 & 0,02 \\
\hline IDB & 0,91 & 1,01 & 1,12 \\
\hline Taxa de Acerto (\%) & 92 & 95 & 91 \\
\hline Tempo de treinamento (s) & 90 & 100 & 110 \\
\hline
\end{tabular}

Tabela 6.4: Resultados experimentais que comparam as diferentes medidas de desempenho para os diferentes tamanhos de mapa SOM. 
Analisando a Tabela 6.4 pelo processo da quantização, à proporção que o mapa aumenta a medida $M Q E$ sempre melhora, como era de se esperar. O TE é praticamente o mesmo nos 3 diferentes mapas, variando em um ponto na terceira casa decimal. O IDB, que se mostrou robusto para os outros experimentos de definição de características, não manteve esta propriedade para a variação do tamanho do mapa. Isso ocorre porque, a cada cálculo do $I D B$, o tamanho do mapa é maior, o número de vetores de pesos aumenta e, conseqüentemente, o valor do $I D B$ será maior. Contudo, a única medida válida para a escolha do tamanho do mapa, segundo os critérios aqui propostos, é a taxa de acerto e, por este critério, o mapa de tamanho $10 \times 10$ é o escolhido para os experimentos exploratórios.

Para esta base de dados, ou outra com as características semelhantes, tem-se uma máquina classificadora, configurada com um extrator de características baseado em transformada discreta wavelets com a função de base Haar para extrair os coeficientes de aproximação para três níveis de decomposição. O classificador treinado é o SOM, configurado com 100 neurônios em um mapa de $10 \times 10$. Este modelo será agora testado com detalhes para se saber quais as suas propriedades de desempenho. O ensaio da máquina classificadora será feito quanto à rotação, translação ou rotação e translação. Os resultados estão resumidos na Figura 6.1.

Este experimento demonstra que o modelo é bastante robusto quando as variações são aplicadas separadamente, rotação e translação, com variação até de 35 graus (para rotação) e 35 pixels (para translação), pois a taxa de acertos ainda se mantém em 90\%. Entretanto, na aplicação conjunta de rotação e translação, a taxa de acerto de até $90 \%$ é mantida quando a variação é até 25 (graus e pixels). É fato que estas taxas por variações podem mudar quando as características da base de dados são alteradas (modalidade, número de classes e etc).

Como forma de legitimar a qualidade das características extraídas por wavelets, $c A_{3}$, se fez uma comparação com o melhor extrator de características usado por Lehmann et. al. (LEHMANN et al., 2005), Imagem Redimensionada (IR). A base de dados a ser utilizada 
é a de validação. A comparação será feita usando dois diferentes classificadores, SOM e Knn.

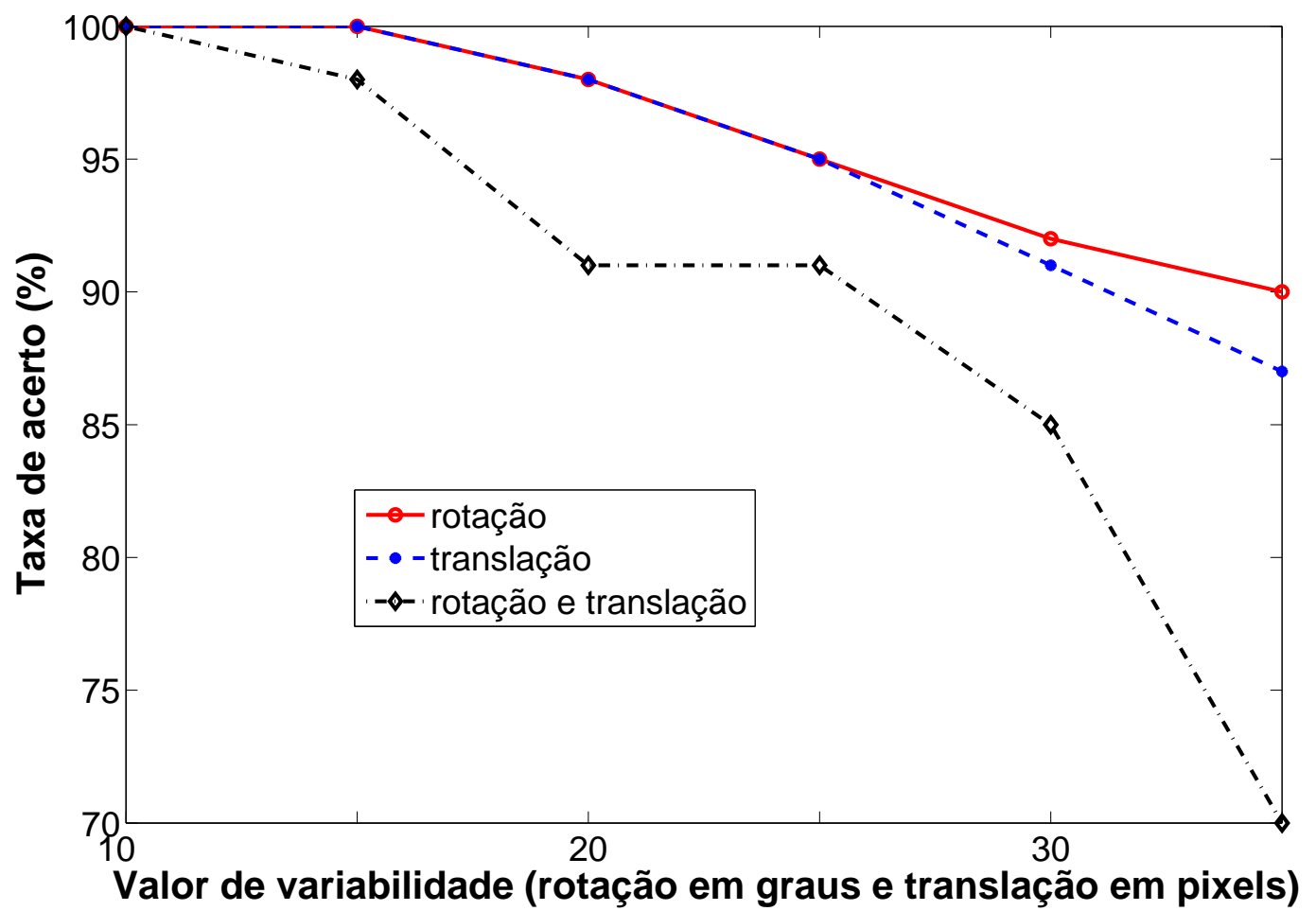

Figura 6.1: Experimentos de Robustez

Após os experimentos de definição do tamanho do mapa, o classificador SOM com tamanho $10 \times 10$ é comparado ao classificador Knn. Para isto, o classificador SOM é treinado com $c A_{3}$ e com IR, assim como o classificador Knn. Os resultados desta comparação estão resumidos na Tabela 6.5.

\begin{tabular}{|c|c|c|}
\hline & $\boldsymbol{c A}_{\mathbf{3}}$ & IR \\
\hline SOM & $95,0 \%$ & $91,0 \%$ \\
\hline $\boldsymbol{K n n}$ & $95,2 \%$ & $93,8 \%$ \\
\hline
\end{tabular}

Tabela 6.5: Resultado do classificador SOM treinado com o coeficiente de aproximação no terceiro nível de decomposição, $c A_{3}$, e com a Imagem Redimensionada, IR, e resultado do classificador $K n n$ para um vizinho mais próximo com $c A_{3}$ e com IR.

Os resultados desta tabela indicam dois pontos importantes: O primeiro é que os resultados de classificação usando $c A_{3}$ foram superiores aos resultaos obtidos usando IR. O segundo ponto é que os resultados apresentados pelo classificador SOM são competitivos 
aos resultados apresentados pelo classificador $K n n$.

Como já visto no Capítulo 5, a classificação com SOM é feita em termos do padrão mais semelhante, vizinho direto mais próximo. Contudo, discutiram-se as diferentes formas de rotulação do mapa, histograma e máxima votação. Aproveitou-se dos experimentos de validação para ilustrar estas duas formas de rotulação, com o uso de um dos mapas gerados no treinamento. Os resultados do mapa rotulado estão ilustrados na Figura 6.2, tanto por histograma como por máxima votação. Estes mapas poderiam ser usados para inferir a classe de uma nova imagem.

Existem outras formas de rotular o mapa, o que permite sua busca por padrões mais semelhantes, através da exploração do mapa (browsing). Uma delas é a partir da rotulação de cada neurônio com a imagem que possui a característica $\left(c A_{3}\right)$ mais semelhante ao neurônio vencedor, Figura 6.3a. Outra é a transformação do vetor de pesos de cada neurônio em uma matriz. O resultado é uma imagem suavizada, mas que mantém as características principais da imagem original, como na Figura 6.3b. Entretanto, esta última forma de visualização só é possível se o vetor de características mantiver a morfologia da imagem, ou seja, ela não seria possível no caso do uso dos coeficientes decompostos usando uma outra família wavalets como características da imagem. As regiões sem imagens são de neurônios que não representam vetores de características ou, simplesmente, são de neurônios que não foram vencedores.

\subsection{Experimentos usando a base de validação}

Para os resultados a seguir, utilizou-se a base de dados de validação, cujos detalhes foram descritos no capítulo anterior. Para verificar se as definições anteriores são válidas para esta base, repetiram-se os experimentos de definições, usando para isso a metodologia apresentada no esquema da Figura 5.10. Os resultados confirmaram aquelas melhores escolhas. Assim, considerou-se para a extração de características a família wavelet Haar, o nível de decomposição igual a 3 e coeficientes de aproximação.

Para não descartar totalmente os coeficientes de detalhamento, em um segundo ex- 


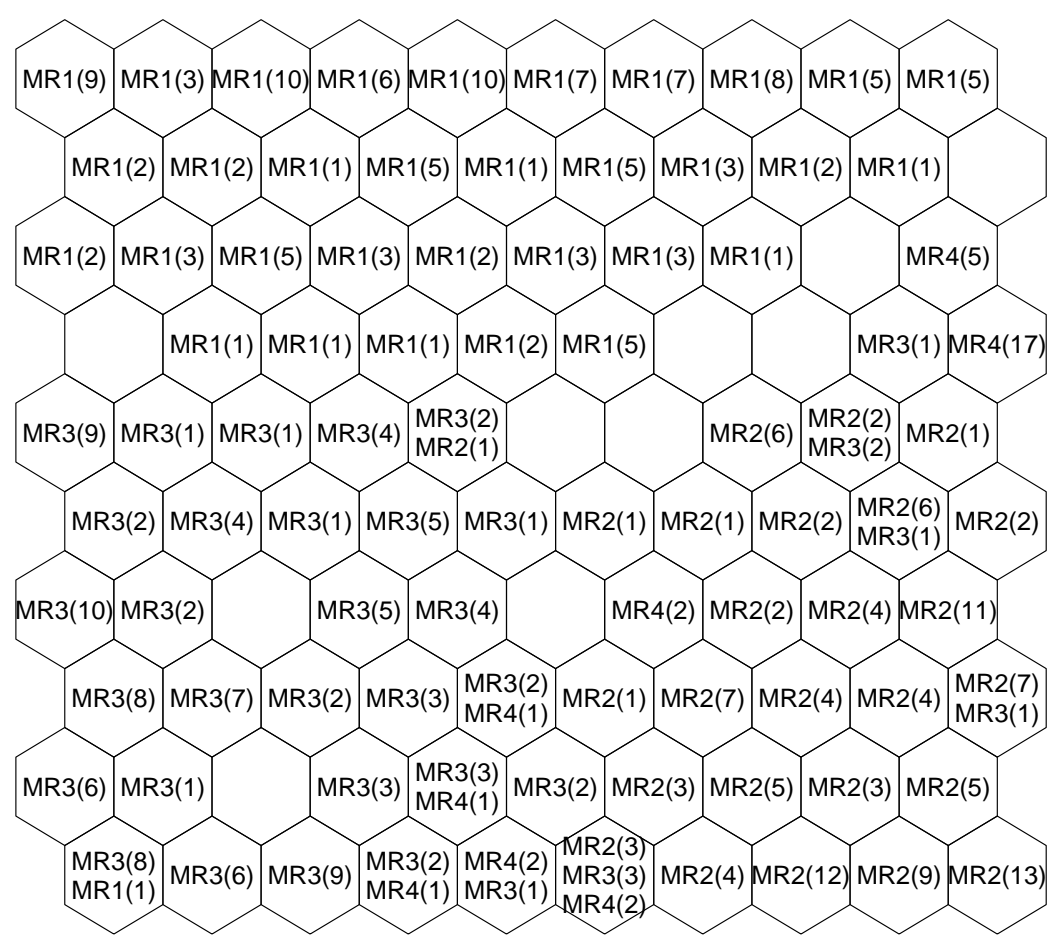

a - Mapa rotulado por histograma.

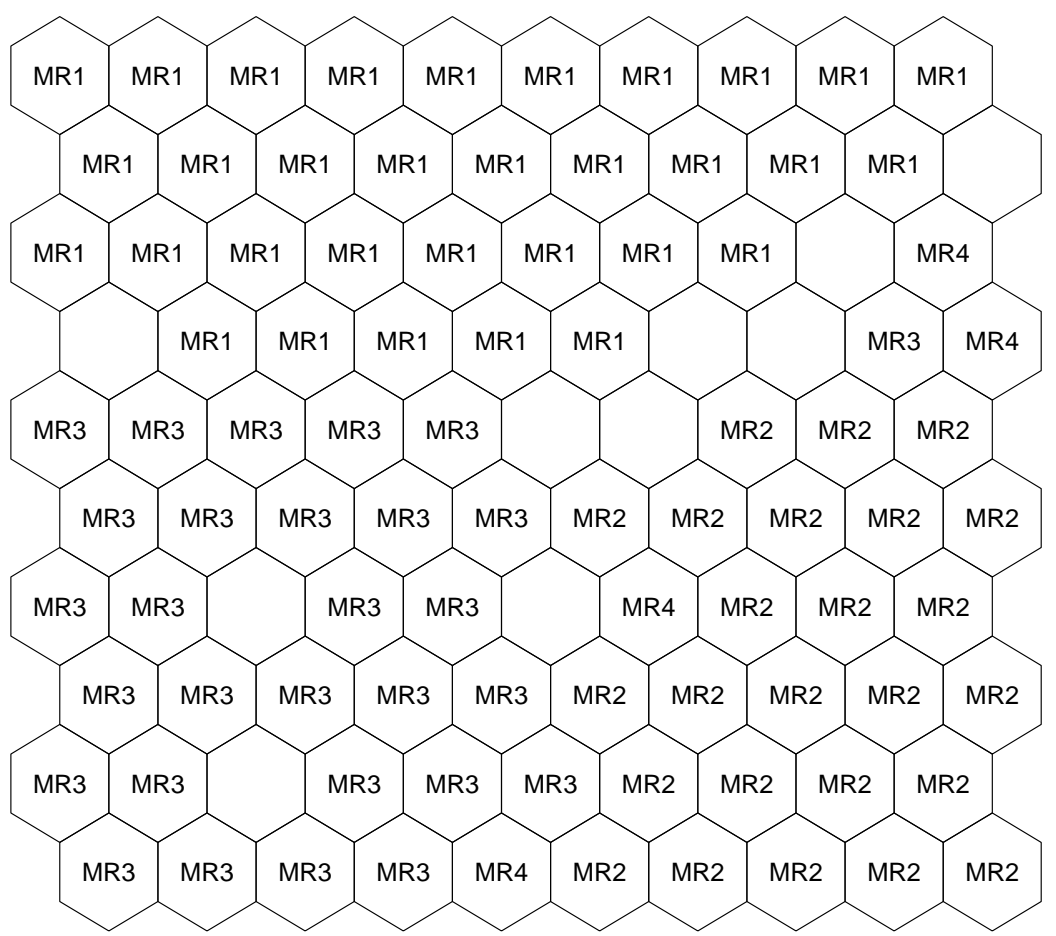

b - Mapa rotulado por máxima votação.

Figura 6.2: Exemplo de rotulação do mapa SOM por histograma e por máxima votação. 


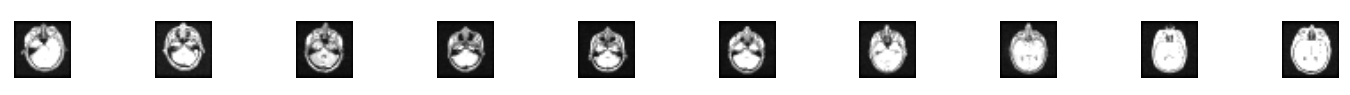

○

- 00 圈

- 00000

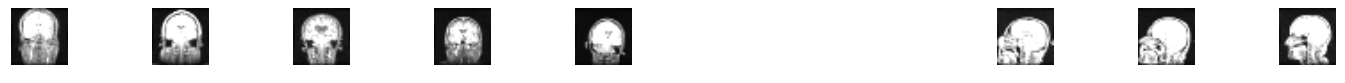

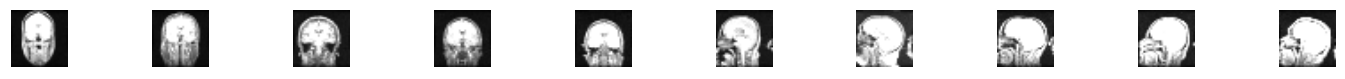

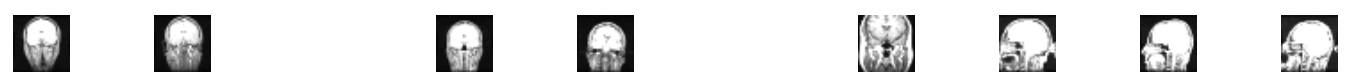

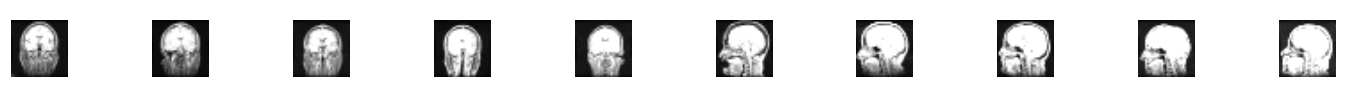

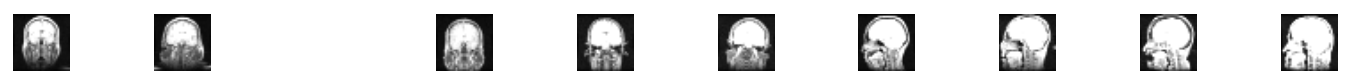

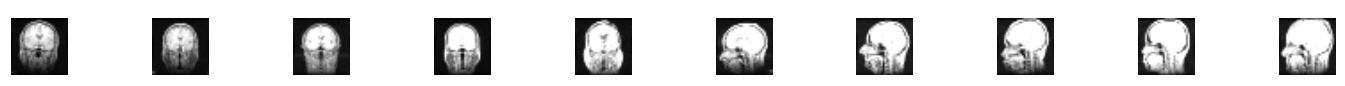

a - Mapa SOM rotulado com a imagem mais próxima do neurônio vencedor (melhor representante).

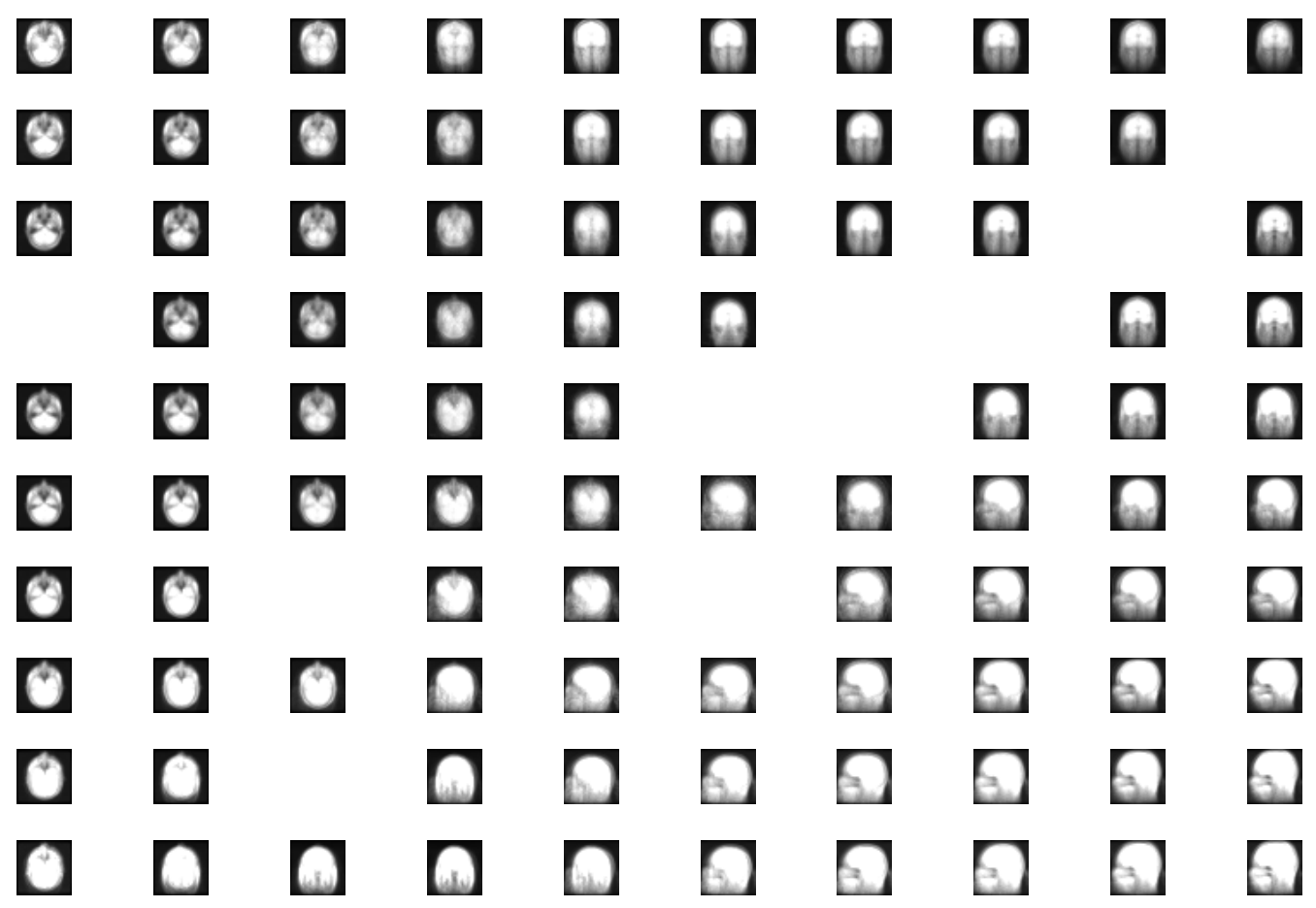

b - Visualização dos vetores de pesos em forma de matriz. Pode ser usado para busca por exploração (browsing)

Figura 6.3: Exploração do mapa SOM para visualização das imagens cujos vetores de características são os mais próximos dos respectivos vetores de pesos e visualização dos vetores de pesos. 
perimento, estes serão representados na forma de momentos de $\mathrm{Hu}$ e serão combinados aos coeficientes de aproximação. Para definir o melhor tamanho do mapa, foram feitos experimentos considerando alguns tamanhos, mas calculando apenas a taxa de acerto e tempo de processamento, uma vez que as medidas MQE, TE e IDB não foram robustas para estas escolhas, de acordo com os experimentos anteriores. Foram considerados 3 diferentes tamanhos de mapa, $20 \times 20$, $40 \times 40$ e $60 \times 60$, pois o número de classes e o número de imagens são maiores que os da base de exploração. Para a classificação, considerou-se que, no mínimo, os quatro neurônios vencedores fossem consultados ou que, ao mínimo, 50 imagens fossem comparadas. A categorização será feita considerando a classe da imagem mais próxima. Os resultados estão na Tabela 6.6. O mapa $60 \times 60$ foi utilizado nos experimentos porque apresentou a melhor taxa de acerto.

\begin{tabular}{|l|c|c|c|}
\hline Tamanho do mapa & $20 \times 20$ & $40 \times 40$ & $60 \times 60$ \\
\hline Taxa de Acerto (\%) & 58,3 & 65,1 & 72,3 \\
\hline Tempo de treinamento (s) x $\mathbf{1 0}^{\mathbf{3}}$ & 90 & 155 & 180 \\
\hline
\end{tabular}

Tabela 6.6: Resultado de classificação e tempo de treinamento para os diferentes tamanhos de mapa SOM usando a base de dados de validação.

Com as características extraídas das imagens e o tamanho de mapa configurado, experimentos de classificação foram feitos comparando o combinado de características (wavelets e momentos de $\mathrm{Hu}$ ) e classificador SOM com o combinado de características e o classificador vizinho mais próximo - Knn.

Para efeitos de comparação dos resultados apresentados nesta tese, a Tabela 6.7 traz os melhores resultados para o problema em questão, que foram obtidos usando imagens redimensionadas (IR) e o conceito recente proposto por Deselaer et. al. (DESELAERS et al., 2006), chamado de Histogramas Esparsos baseados em Patches (brevemente discutido no Capítulo 3). Pelas características da base de dados, imagens da rotina clínica, grande variabilidade de imagens da mesma classe e distribuição de imagens por classe não-linear, o resultado de 83,8 de acerto é bastante otimista.

Os resultados apresentados na Tabela 6.8 são os obtidos nesta tese. Usando o $c A_{3}$ como características e o SOM como classificador, obtiveram-se resultados melhores do que 


\begin{tabular}{|l|c|}
\hline & Knn \\
\hline IR & 67,9 \\
\hline Patch-based & 83,8 \\
\hline
\end{tabular}

Tabela 6.7: Resultados de classificação usando o classificador Knn com IR e Patch-based apresentados por Deselaers et. al. (DESELAERS et al., 2006).

com IR e Knn, mas não melhores do que quando comparados a Histogramas Esparsos baseados em Patches e Knn. Contudo, quando se faz a decomposição em wavelets, apenas as componentes de alta-frequência são consideradas, descartando as componentes de baixa-frequência, como já discutido no Capítulo 3. Agora, estes coeficientes descartados serão resumidos em momentos de $\mathrm{Hu}$ e serão combinados com o $c A_{3}$, como explicado no Capítulo 3. Com essa combinação, $c A_{3}$ e $H u$, os resultados são bem próximos aos 83,8 obtidos por Deselaers et al., com diferença de $1.5 \%$ para o Knn e de $2 \%$ para o SOM. A grande diferença dos resultados aqui alcançados está no baixo custo computacional para a extração das características e na simplicidade de implementação das técnicas aqui abordadas (assuntos facilmente encontrados na literatura). No capítulo seguinte, será feita uma discussão completa dos resultados.

\begin{tabular}{|l|c|c|}
\hline & Knn & SOM \\
\hline $\boldsymbol{c} \boldsymbol{A}_{\mathbf{3}}$ & 72,5 & 72,3 \\
\hline $\boldsymbol{c} \boldsymbol{A}_{\mathbf{3}}$ e $\boldsymbol{H u}$ & 83,1 & 82,8 \\
\hline
\end{tabular}

Tabela 6.8: Resultados de classificação com o classificador $K n n$ e com o classificador SOM considerando como vetores de características $c A_{3}$ e $c A_{3}$ combinado com os coeficientes descartados sumarizados na forma de momentos $\mathrm{Hu}$.

Knn é um classificador de referência, que apresenta melhor resultado, mas o custo para seu uso é algo a ser questionado. Por essa razão, experimentos considerando, imagem de teste, acerto ou erro e tempo de resposta foram feitos comparando o Knn e o SOM, Figura 6.4 e Figura 6.5, respectivamente.

A grandeza de tempo do Knn, Figura 6.4a e do SOM, Figura 6.5a, está em minutos. Enquanto o Knn usa em média 1,8 minutos, o SOM gasta em média 0,018 minutos, aproximadamente 1 segundo. Por outro lado, a taxa de acertos usando o Knn, considerando um vizinho mais próximo (1nn), foi de $83,1 \%$, Figura $6.4 \mathrm{~b}$, e o SOM com taxa de acerto 
de $82,8 \%$, Figura $6.5 b$, uma diferença de $0,3 \%$, ou seja, menos de $1 \%$. Vale ressaltar que em um hospital, centenas de imagens são produzidas diariamente, isto é, para uso prático SOM é uma proposta bastante competitiva, dado que o tempo para classificação é muito menor que o apresentado pelo Knn e a taxa de acerto entre eles é praticamente a mesma.

Para um melhor conhecimento dos resultados e para avaliar a potencialidade da proposta, considerou-se, além da taxa de acerto em termos do vizinho mais próximo, a classificação até o décimo mais próximo $(K=1$ até $K=10)$ com intervalo de 1 , veja Figura 6.4a e Figura 6.5b. Em ambos, Knn e SOM, as taxas de acerto mostraram variações equivalentes, visto que, até o quarto vizinho mais próximo, ambos ainda mantiveram a taxa na casa dos $80 \%$ e, para os 10 vizinhos mais próximo, a taxa de ambos se manteve na casa dos $75 \%$.

Após os experimentos de caracterização da máquina classificadora, foram apresentados experimentos de comparação envolvendo os principais resultados da literatura e os resultados da combinação do $c A_{3}$ com momentos de Hu e SOM. A seguir, serão apresentados dois protótipos, Categorizador de Imagens Médicas (CATIME) e Recuperador de Imagens Médicas (RECIMME), que usam a máquina classificadora abordada nesta proposta em duas diferentes interfaces.

\subsection{Categorizador de imagens médicas: CATIMME e RECIMME}

Pensando que esta metodologia possa se tornar uma ferramenta para o ensino, no qual o médico estudante deverá treinar sua capacidade de diagnóstico; uma ferramenta para o auxílio ao diagnóstico, para o qual o médico terá casos anteriores como referência para tomar uma decisão, ou mesmo, uma ferramenta que auxilia na categorização automática de exames da rotina clínica, foram desenvolvidas duas interfaces que implementam a máquina classificadora proposta nesta tese.

A primeira interface, chamada de CATIME (Categorizador de Imagens Médicas) foi desenvolvida no MatLab, Figura 6.6 e contempla as duas bases de dados, de exploração 


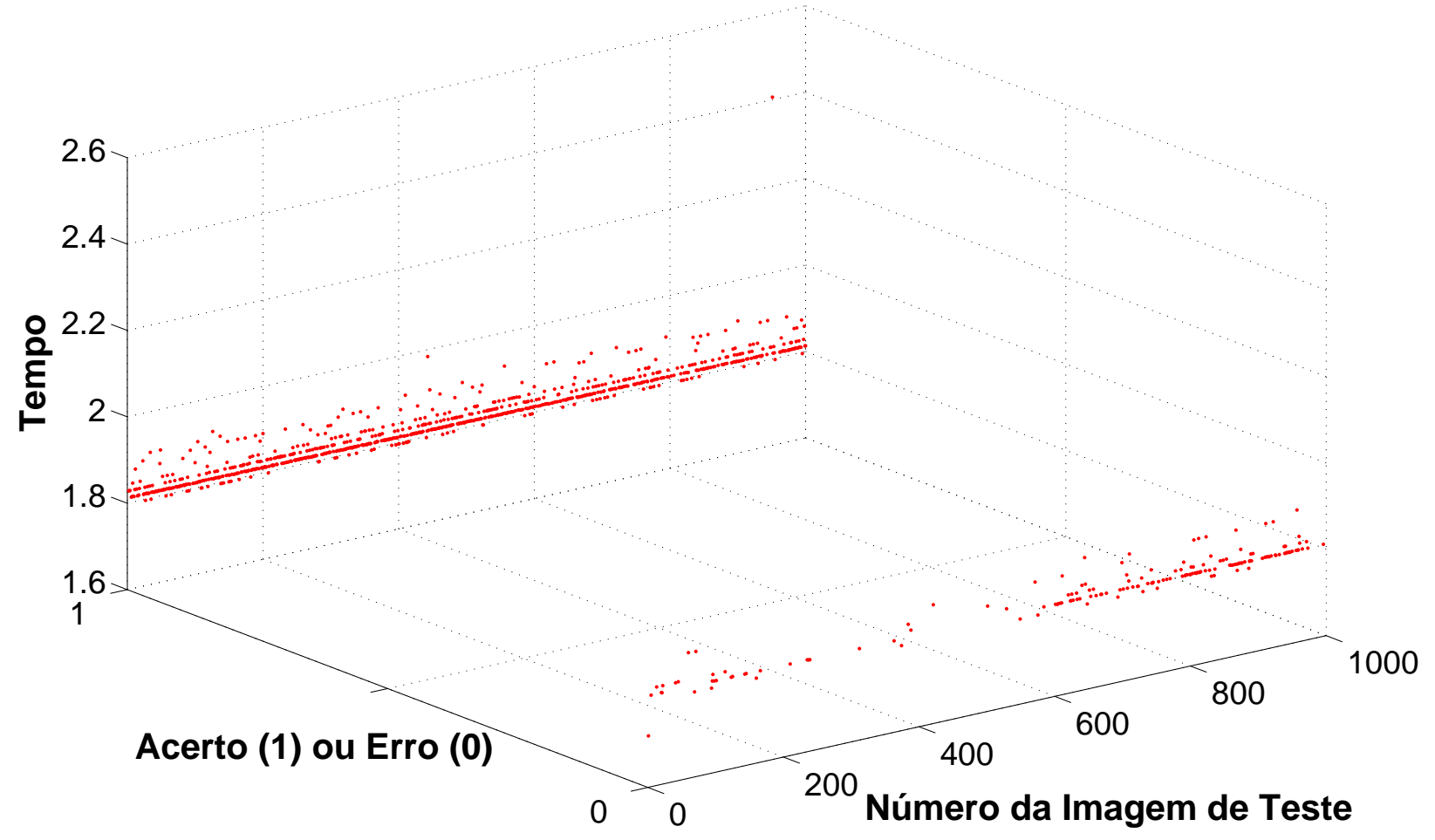

a - Análise de tempo de classificação e acerto ou erro para cada imagem de teste usando o classificador Knn.

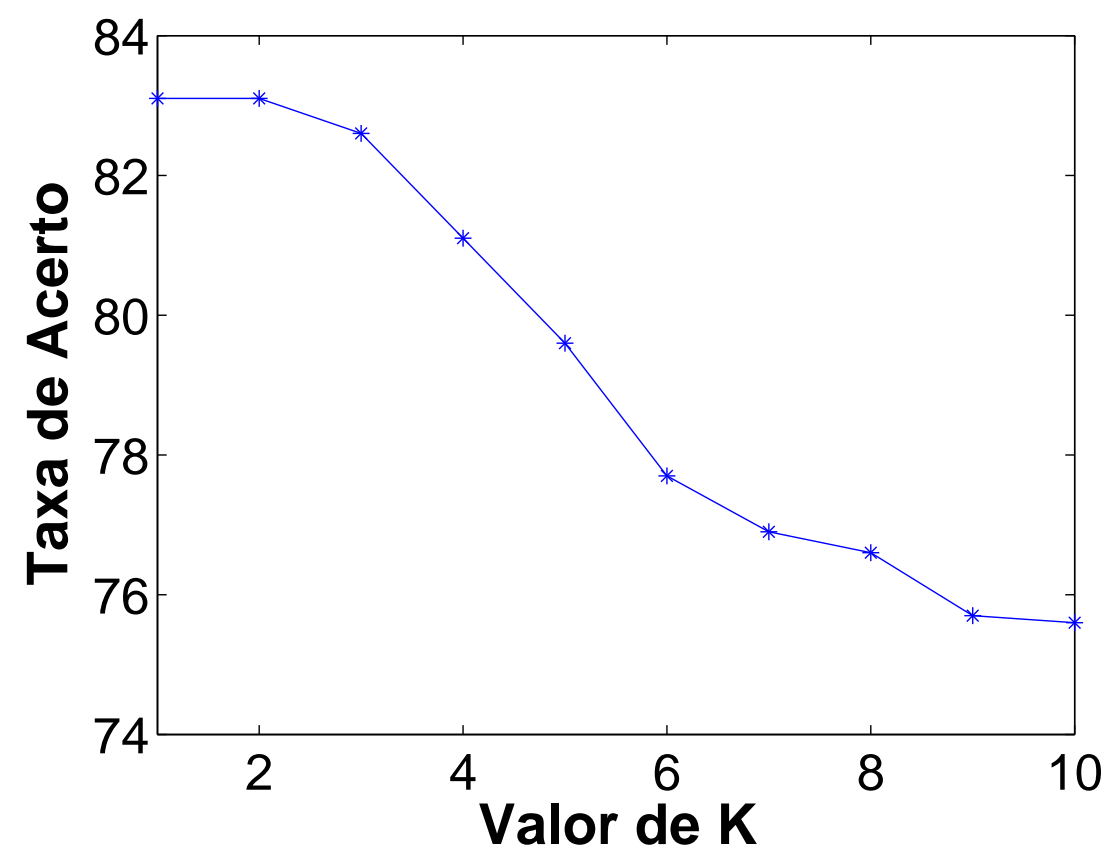

b - Análise de taxas de acerto em classificação para diferentes números de $K$.

Figura 6.4: Análises de tempo de classificação (a) e acerto de classificação (b) para o classificador Knn. 


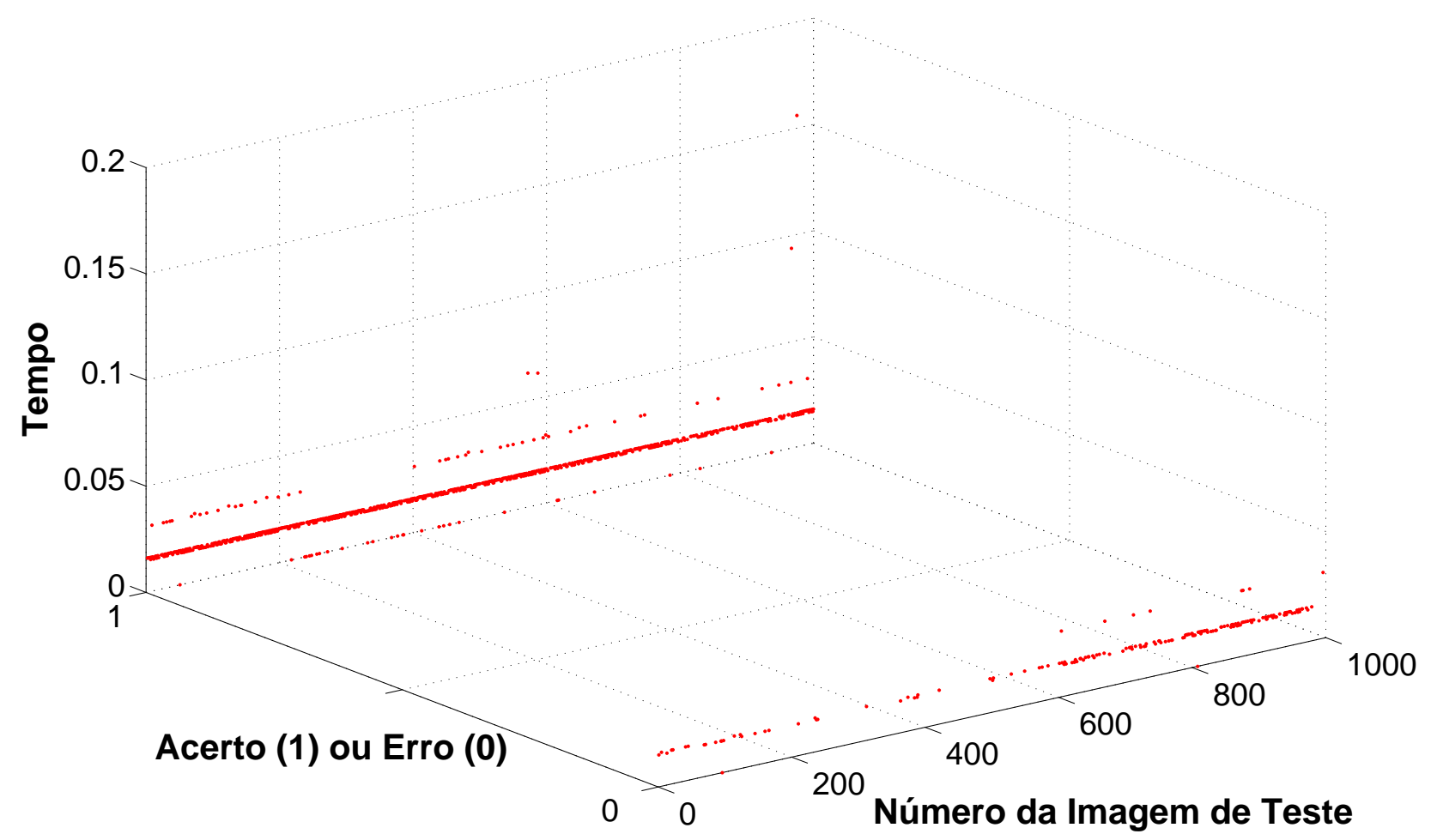

a - Análise de tempo de classificação e acerto ou erro para cada imagem de teste usando o classificador SOM.

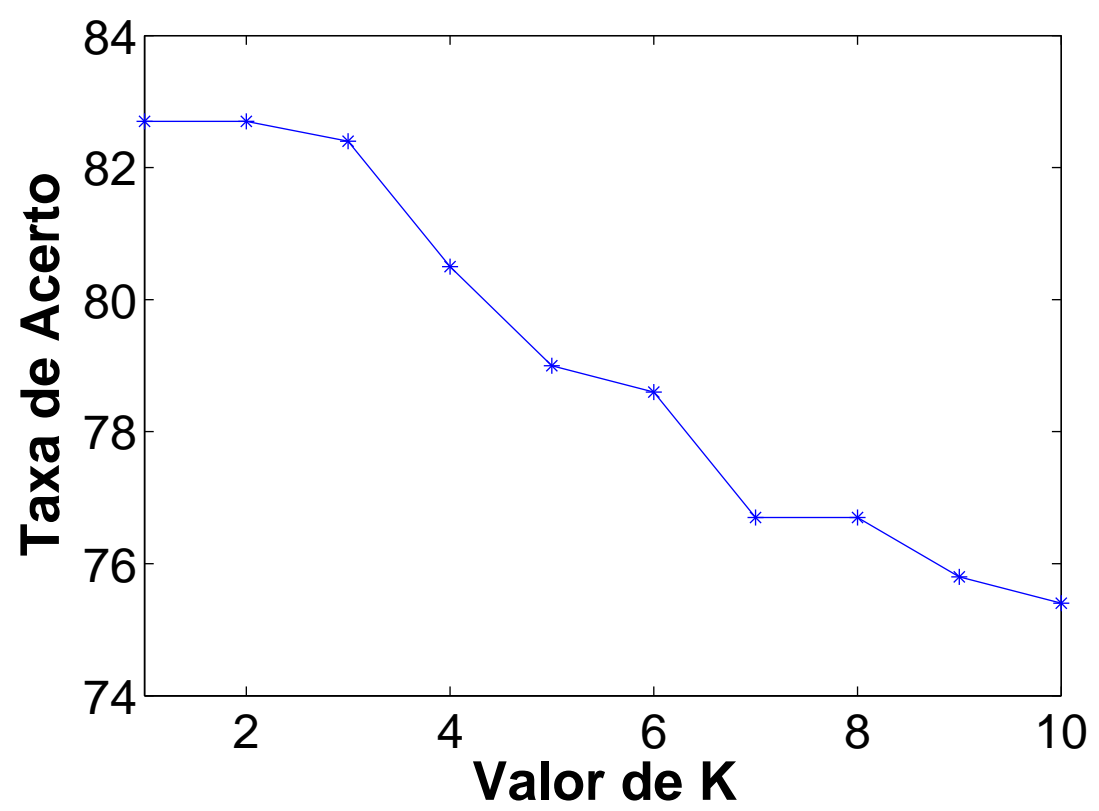

b - Análise de taxas de acerto em classificação para diferentes números de $K$.

Figura 6.5: Análises de tempo de classificação (a) e acerto de classificação (b) para o classificador SOM. 
e de validação. Ela permite abrir novas imagens em qualquer formato (DICOM e PNG), permite escolher o classificador (há possibilidade de inserir outros classificadores) e tem, como resultado, as 10 imagens mais semelhantes, a taxa de acerto do classificador e o tempo para processar. Mais detalhes sobre a interface estão descritos no Apêndice B. Por coincidência, na tela escolhida para ilustração, é possível verificar a dificuldade de um classificador automático fazer inferências. Note-se que a terceira imagem de resposta tem aparência muito parecida com a imagem de teste, porém, é de outra classe.

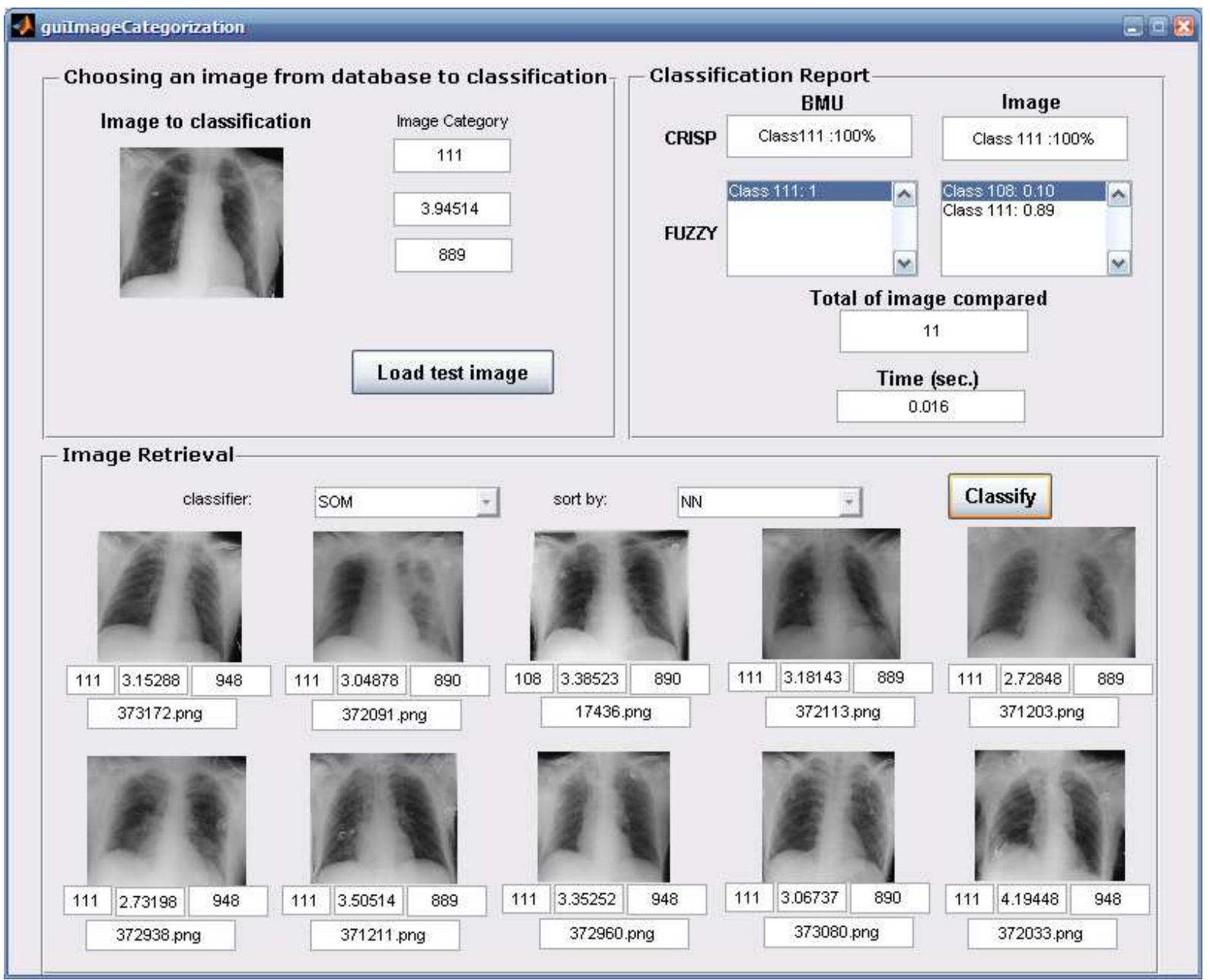

Figura 6.6: Interface do CATIME (Categorizador de Imagens Médicas).

Na segunda interface, chamada de RECIMME (Recuperador de Imagens Médicas ), Figura 6.7, além de estar visível na web, junto às imagens mais parecidas são exibidas também algumas informações do paciente, como sexo, idade, peso, descrição, etc, o que pode ser interessante na tomada de decisão. Maiores detalhes estão discutidos no Anexo B. 


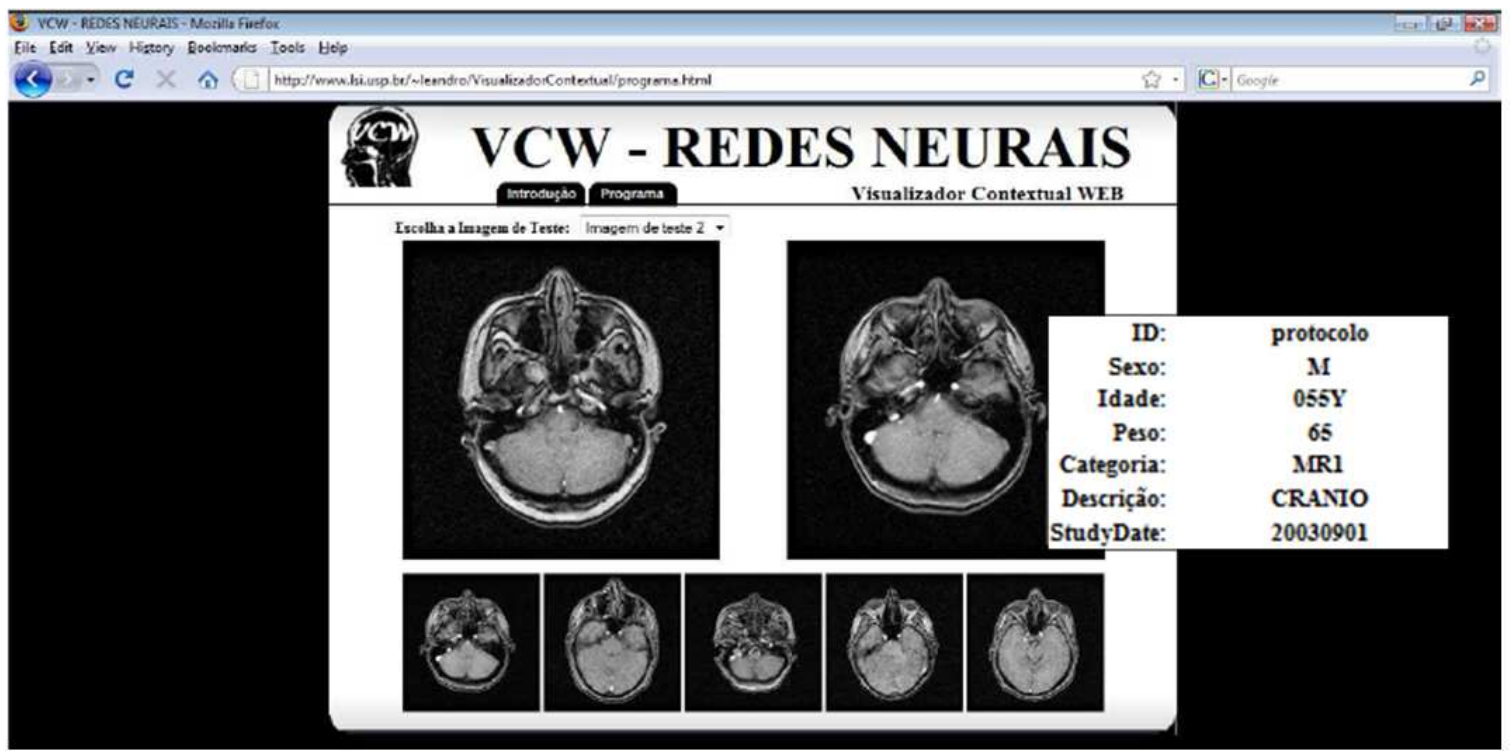

Figura 6.7: Interface do RECIMME (Recuperador de Imagens Médicas).

Para verificar a viabilidade de uso das duas interfaces como uma ferramenta de apoio ao ensino, na tomada de decisão ou na categorização automática, foram realizados experimentos para avaliar se os métodos propostos respondiam frente a uma nova imagem de teste e, dentre as 10 mais semelhantes, para ao menos uma imagem da mesma classe.

Verificou que, da seleção de 10 imagens mineradas de uma base de dados com 9.000 imagens, pelo menos uma delas pertence à mesma classe da imagem consultada. Os resultados do SOM para a classificação, que antes tinham como taxa de acerto 82,8\%, passam agora para 94,1\% (Tabela 6.9), verificando-se se, em um conjunto de 10 imagens, pelo menos uma é da mesma classe. Esta nova taxa apresentada pelo SOM foi melhor que a apresentada pelo Knn 93,4\%, usando a mesma estratégia de classificação que o do SOM, ou seja, quase $1 \%$ melhor $(0,7 \%)$. Estes resultados podem ser interessantes para treinamento de especialistas, por exemplo, podendo servir como uma forma de sortear as respostas em um teste para estudantes. Contudo, podem úteis também no auxílio ao diagnóstico, pois, de 10 referências, pelo menos uma é relevante.

Por fim, vale destacar também uma forma de ajudar no armazenamento categorizado das imagens, como usar as imagens mais parecidas como opções para classificação e deixar o especialista decidir pela classe mais adequada. No caso de trabalhos de extensão para 
usar o CATIME ou o RECIMME em CBIR, o resultado apresentado também é interessante, pois uma imagem semelhante pode ser usada para o refinamento de buscas futuras (termo conhecido como relevance feedback, leia mais em (S.DEB; Y.ZHANG, 2004)).

\begin{tabular}{|l|c|c|}
\hline Tamanho do mapa & $K n n$ & $\mathrm{SOM}$ \\
\hline Taxa de Acerto (\%) & 93,4 & 94,1 \\
\hline
\end{tabular}

Tabela 6.9: Resultados de classificação considerando como acerto ao menos uma imagem da mesma classe para um conjunto de dez mais parecidas.

\subsection{Considerações Finais}

Apresentaram-se neste capítulo os resultados experimentais obtidos nesta pesquisa. Apresentou-se, também, a aplicação da metodologia para a definição do nível de decomposição wavelets, para a escolha da família wavelet e o melhor conjunto de vetor de característica como sendo 3 nível de decomposição, Haar e $c A_{3}$, respectivamente. Ainda com a base de exploração, a metologia aqui proposta para a escolha do tamanho do mapa foi aplicada, na definição do tamanho do mapa para ser $10 \times 10$.

Após as definições anteriores, o modelo de máquina classificadora proposto foi explorado para avaliar a robustez quanto a variações de rotação, translação, e rotação e translação. Avaliou-se também a comparação do extrator de características por análise wavelets com outro extrator de características apresentado na literatura, IR. O classificador SOM também foi comparado ao classificador Knn. Os resultados destes experimentos iniciais foram satisfatórios e encorajadores para continuidade de outro experimento, usando agora a base de validação que é mais complexa que a anterior, número de classes e tamanho da base de imagens maiores.

Usando esta outra base de imagens, repetiu-se a metodologia para escolha da família wavelet, do melhor nível de decomposição, do conjunto de coeficientes e definição do tamanho do mapa SOM, pois a modalidade da imagem é outra (raio-x) e o número de classes aumentou bruscamente (de 4 para 116 classes). Após definir o tamanho do mapa, experimentos de classificação foram conduzidos e comparados ao principal resul- 
tado apresentado na literatura. Neste experimento, observou-se que usando apenas o melhor conjunto de coeficiente como características da imagem, os resultados deste trabalho não eram competitivos frente aos resultados da literatura. Porém, este conjunto de coeficiente de aproximação combinado aos demais coeficientes na forma de momentos de $\mathrm{Hu}$, os resultados passaram a ser melhores que os anteriores e próximos aos da literatura. E, ainda com a base de validação, comparou-se o classificador SOM ao classificador Knn, e os resultados de taxas de acerto foram equivalentes, porém, o tempo de recurso computacional é bastante favorável ao SOM. Uma segunda comparação entre os classificadores foi feita investigando o seu desempenho ao retornar, de um conjunto de dez imagens, ao menos uma da mesma classe, com resultado bastante positivo ao classificador SOM.

De maneira geral, os resultados alcançados com a proposta são satisfatórios diante dos experimentos realizados e frente a outros resultados apresentados na literatura. Uma discussão mais ampla dos resultados e um balanço da metodologia proposta são feitos no capítulo seguinte. 


\section{Discussão e Conclusão}

O trabalho apresentou uma proposta de categorização de imagens médicas para recuperação de imagens por conteúdo (CBIR) e também para mineração de dados. A categorização automática, ou simplesmente categorização como preferido neste trabalho, envolve uma primeira etapa fundamental para a extração de características. Para tanto, usou-se a análise de multi-resolução, da qual wavelets é um tipo, para três níveis de decomposição, considerando os coeficientes de aproximação como vetores de características. Para esta escolha, apresentou-se uma proposta de metodologia que auxilia na definição da família wavelet, nível de decomposição e conjunto de coeficientes. Nesta metodologia, utilizaramse medidas de qualidade SOM e medidas de qualidade usadas em técnicas de agrupamento de dados para avaliação da qualidade de agrupamento. Para definir a sensibilidade de cada uma destas medidas, foi utilizada a taxa de acerto do classificador. Concluiu-se que as medidas tradicionais de qualidade do SOM não são aplicáveis na definição do nível de decomposição wavelets mais adequado e do conjunto de coeficientes. Por outro lado, a medida de qualidade para técnicas de agrupamento $(I D B)$ se mostrou interessante nessas escolhas.

Após as definições referentes à análise por wavelets, foram realizados experimentos de classificação usando uma base de dados do Instituto do Coração (InCor), com 397 imagens distribuídas em 4 classes. Chamados de exploratórios, os experimentos apresentaram bons resultados quando submetidos a testes de robustez à invariância (rotação, translação e rotação e translação) e quando comparados a outro método da literatura.

Uma segunda etapa de experimentos foi feita quando se conseguiu ter acesso à mesma base de dados utilizadas pelos outros grupos tomados como principais referências (LEHMANN 
et al., 2005), (DESELAERS et al., 2006). A base da Universidade de Medicina de Aachen, Aachen, Alemanha é composta por 10.000 imagens distribuídas em 116 classes do código IRMA. O resultado apresentado usando a metodologia proposta foi inferior aos resultados apresentados pelos outros grupos.

Porém, o vetor de características utilizado no modelo proposto era composto pelos coeficientes de aproximação $\left(c A_{3}\right)$. Para aumentar o desempenho da taxa de classificação, tentou-se combinar outra técnica de processamento de imagens.

Na aplicação de wavelets, a cada nível de decomposição a imagem passa por um conjunto de filtros (passa-alta e passa-baixa) e sofre um rescalamento para redução do número de colunas e de linhas da imagem pela metade.

Com a escolha dos coeficientes de aproximação $\left(c A_{3}\right)$, detalhes da imagem são descartados $\left(c D_{n}^{h}, c D_{n}^{v}\right.$ e $\left.c D_{n}^{d}\right)$. Pairava então, a dúvida se estes detalhes não faziam falta no processo de discriminação. Porém, se eles fossem incorporados, a dimensão do vetor de características aumentaria muito. Para considerá-los, pensou-se em contabilizá-los resumidamente na forma de momentos de Hu. Assim, cada conjunto de coeficientes de detalhes foi representado por um vetor de dimensão 7 (momentos), onde os momentos de 1 a 6 visam manter a representação da forma, robusta à variação da imagem, e o sétimo momento visa garantir a distorção e o espelhamento da imagem.

Com tal combinação, os resultados obtidos tornaram-se bastante competitivos com relação ao melhor resultado em que se usa a técnica chamada Histograma Esparsos baseados em Patches. A pequena diferença de taxa de classificação entre a técnica proposta neste trabalho e a obtida na referência (DESELAERS et al., 2006) pode ser desprezível, ao analisarem-se as diferenças de complexidade de recursos computacionais e de complexidade matemática entre as duas técnicas.

Outra comparação que merece ser destacada é a facilidade para se encontrar, na literatura, conceitos sobre wavelets e momentos de $\mathrm{Hu}$ (CASTELLI; BERGMAN, 2001),(GONZALEZ; WOODS, 2007), além de estarem disponíveis em rotinas de cálculo nas principais ferramentas de simulação como o MatLab. A forma de combinar estas duas técnicas foi 
descrita nesta tese a partir da metodologia para escolher o conjunto de coeficientes principais e a combinação dos coeficientes que seriam descartados, que foram contabilizados no vetor de características pelos momentos de Hu. Contudo, a metodologia proposta é uma técnica de simples reprodução e implementação e requer pouco recurso computacional. Em contraste, a proposta dos Histogramas Esparsos baseados em Patches é uma técnica ainda pouco explorada na literatura, o que dificulta a sua reprodutibilidade e exige maior recurso computacional para seu uso.

Para a fase de categorização, foi definido o classificador baseado em mapas autoorganizáveis (SOM). Esforços para o uso do mapa SOM como classificador foram conduzidos, pois ele trabalha bem como organizador de dados, o que justifica seu extenso uso em CBIR. Esta característica de ordenação pode ser comprovada com os resultados experimentais aqui apresentados. Outra vasta aplicação de SOM está em mineração de dados (SASSI; SILVA; DEL-MORAL-HERNANDEZ, 2007), (SASSI; SILVA; DEL-MORAL-HERNANDEZ, 2008). SOM é usado em visualização de dados de alta dimensão a partir do mapa bidimensional (VESANTO; ALHONIEMI, 2000),(SASSI; SILVA; DEL-MORAL-HERNANDEZ, 2007), (BOSCARIOLI; SILVA; DEL-MORAL-HERNANDEZ, 2008), como mostrado no Capítulo 4, Figura 4.4 .

Vale ressaltar que a classificação usando SOM nesta abordagem de categorização de imagens médicas é um trabalho desbravador. Uma possível explicação para seu uso pouco freqüente é a forma de empregá-lo neste tipo de tarefa. Nesta tese, apresentaram-se quatro facetas diferentes de sua utilização na classificação (a partir dos rótulos dos neurônios, definidos por votação ou frequência e a partir do neurônio como uma referência para a região do espaço de características com padrões mais semelhantes, classificando pelo rótulo do padrão mais próximo ou estendido em termos de pertinência). Discutiu-se também que, dependendo da forma como utilizado, o resultado em termos de taxa de acerto pode ser baixo, principalmente em aplicações em que as fronteiras de decisão não são bem definidas, grande desafio aqui enfrentado.

Por esta razão, foi proposto um método alternativo de usar SOM como classificador, 
no qual foram exploradas: 1 - sua capacidade de quantização vetorial, segundo a qual cada neurônio representa um conjunto de vetores; e 2 - sua capacidade de manutenção topológica, segundo a qual neurônios vizinhos tendem a representar vetores ou padrões semelhantes. Com isto, o neurônio passa a trabalhar como um pré-processador, pois o número de neurônios do mapa será sempre menor que o número de imagens do conjunto de treinamento ou padrões de treinamento, o que reduz o número de comparações à ordem do tamanho do mapa.

A escolha do tamanho do mapa também foi assunto explorado na presente pesquisa. Não existe na literatura um consenso para o número de neurônios a ser usado em um mapa SOM. Tentou-se aqui adotar uma metodologia usando medidas de qualidade do SOM e medidas de qualidade de técnicas de agrupamento. Porém, nenhuma delas foi suficientemente robusta às variações do tamanho do mapa, o que mostra a dificuldade de tal definição. Por isto, a taxa de classificação foi usada para definir o tamanho do mapa.

Após a definição de tamanho, aplicou-se SOM nos experimentos de classificação. Os resultados de taxa de acerto foram comparados com os resultados do classificador Knn. Enquanto o resultado de taxa de acerto para o $K n n, 83,1 \%$, foi ligeiramente melhor que para o SOM, 82,8\%, o tempo gasto para a classificação com o Knn é de 1,8 segundos, enquanto o tempo gasto para a classificação com o SOM é de 0,02 segundos. Porém, quando os experimentos foram feitos para avaliar se os métodos propostos respondiam frente a uma nova imagem de teste e, dentre as 10 mais semelhantes, para ao menos uma imagem da mesma classe, o classificador Knn obteve a taxa de acertos de $93,4 \%$ e o classificador SOM a taxa de acertos de $94,1 \%$.

A combinação de coeficientes wavelets e momentos de Hu com o mapa SOM, chamada aqui de máquina classificadora, com explorações na literatura em alguns de seus aspectos, foi exaustivamente experimentada, para verificar sua robustez em trabalhar com imagens rotacionadas, transladadas e com ambas as variações. Também foram feitas comparações com outras abordagens, sempre se tomando por base os melhores resultados da literatura.

Como conclusão, pode-se dizer que os resultados são encorajadores para implementar 
a proposta desta tese em outras aplicações reais, além das já ilustradas aqui, e explorar o uso de SOM como classificador e técnica para recuperação de imagens por conteúdo.

Embora todo o estudo feito no trabalho tenha mostrado a potencialidade do categorizador em imagens médicas, ele pode ser extensível a outros tipos de imagens. Desta maneira, outras aplicações podem ser exploradas baseadas neste estudo. Alguns exemplos podem ser como uma ferramenta para uso na área de segurança pública, geoprocessamento, internet e outros. Na segurança pública, seria útil para encontrar, em uma base de dados com imagens de todos os detentos e ex-detentos, o suspeito mais semelhante a partir de um retrato falado ou para, também a partir de uma foto, encontrar pessoas desaparecidas em rodoviárias, aeroportos, ruas equipadas com câmeras. Na área de geoprocessamento, apresentar regiões previamente classificadas para o especialista decidir se é uma área de desmatamento, preservação ou outra categoria que venha a ser criada, a partir de uma foto de satélite. A aplicação na web poderia ser como uma ferramenta cuja chave de busca fosse a imagem para encontrar informações. Com o crescente aumento e facilidade de armazenar imagens, principalmente com a tecnologia 3G (giga) para celulares, a geração de imagens será algo bastante corriqueiro. Usá-las para encontrar outras informações poderá ser alternativa aos sistemas de busca tradicionais baseados em texto.

\subsection{Contribuições apresentadas na tese}

O estudo apresentou uma nova abordagem para categorização de imagens médicas, alternativa às outras encontradas na literatura, envolvendo wavelets com momentos de $\mathrm{Hu}$ e mapas auto-organizáveis. Esta combinação em uma máquina classificadora se mostrou bastante promissora quando comparada com a melhor abordagem publicada na literatura até o presente momento.

A metodologia para definir um vetor de características usando wavelets é um assunto pouco encontrado na literatura, as raras informações dizem apenas que se utilizou de um conjunto específico de coeficientes wavelets como características de imagens. Este estudo apresentou uma metodologia para tal escolha. Além desta metodologia, apresentou-se 
uma abordagem para combinação destes coeficientes, de forma que todos sejam aproveitados, sem elevar exageradamente a dimensão do vetor. Na abordagem proposta, utilizaram-se os momentos de Hu para compensação.

Foram apresentados usos alternativos do SOM como classificador e uma alternativa de classificação, usada e explorada neste estudo com resultados motivadores.

Apresentou-se também uma metodologia de escolha do tamanho do mapa SOM. Na literatura, a maioria dos trabalhos que utiliza SOM determina um tamanho sem o uso de uma metodologia bem definida e realiza o estudo. Existem algumas heurísticas a respeito, mas nenhuma definição de como o mapa deve ser escolhido. Por fim, uma metodologia para análise de robustez do modelo, através da qual são feitas modificações em imagens reais para simular rotação, translação e ambos e para definir as propriedades do modelo. Este é um estudo interessante para aplicações com imagens médicas, mas poderia também ser de interesse de pesquisadores que trabalham com reconhecimento de faces, por exemplo.

\subsection{Trabalhos Futuros}

Como trabalho futuro ou complementação a esta proposta, podem ser considerados estudos adicionais de seleção de características. Esta é uma linha de pesquisa interessante, que permite avaliar um vetor de características e decidir quais os elementos deste vetor são redundantes para discriminação entre classes. Tal estudo, que não tem sido o foco das linhas de pesquisa recentes do grupo, pode ser explorado em estudos futuros.

Outro assunto bastante interessante e desafiador é avaliar a correlação entre imagens agrupadas com base em vetores de características e dados textuais do paciente. Há a percepção de que pode haver relação entre imagens do mesmo grupo; por exemplo, sexo,

idade, etnia, classe social, ou outros aspectos dos pacientes. Seu interesse reside também na viabilização de novas revelações de determinadas patologias e sua predominância em regiões específicas, tipo de sexo em que tais patologias aparecem, por exemplo. Evidente que, para este estudo, é necessário que o hospital onde a pesquisa for desenvolvida tenha 
um sistema de informação implementado, que permita associar dados do paciente aos dados textuais.

Combinar informações textuais a informações extraídas das imagens (características) como forma de avaliar o aumento de taxa de acerto de uma classificação ou, então, aumentar a precisão de sistemas de recuperação de imagens por conteúdo. Contudo, este é um assunto bastante desafiador, pois envolve processamento de linguagem natural para extração de informação em dados textuais.

Utilizar SOM com dados categorizados ou textuais de diagnóstico clínico para encontrar relações de palavras em determinadas patologias é outra temática de interesse. Para isto, é necessário também ter diagnósticos digitais processados por técnicas de linguagem natural.

Explorar SOM para recuperação de imagens por conteúdo. Como o modelo aqui proposto para classificação também poderia ser usado para a recuperação de imagens por conteúdo, esse seria também um estudo interessante de se fazer, que envolveria estudos profundos sobre algoritmos de estrutura de dados para construir o SOM em árvore ou grafo orientado para facilitar a recuperação e também o emprego de técnicas para filtrar informações relevantes de acordo com a experiência do usuário (relevance feedback).

Aplicar outros algoritmos de classificação, podendo envolver aprendizado (simbólico ou conexionista ou estatístico) para comparar taxas de acerto. Ou ainda, estender o modelo para dar respostas em grau de pertinência (fuzzy), o que seria interessante para um usuário final da aplicação.

Uma pesquisa que envolve a aplicação de dinâmica rica (caos) em neurônios dos mapas auto-organizáveis já foi iniciada dentro do próprio grupo de pesquisa (SILVA; SANDMANN; DEL-MORAL-HERNANDEZ, 2008) e pode ser uma alternativa ao SOM, usado nesta tese em sua máquina classificadora. Este é um estudo que tem uma inspiração biológica, cujos estudos mostram que o sistema olfatório do coelho opera em caos quando é apresentado a ele um cheiro desconhecido e opera em períodos estáveis quando o cheiro é conhecido (FREEMAN, 1992). Esta característica foi implementada em um modelo do SOM, no 
qual os neurônios atuam de forma semelhante, ou seja, para padrões desconhecidos o neurônio opera em caos e, para padrões conhecidos, eles operam em períodos estáveis. Nesta abordagem, na qual o caos passa a ser o critério de neurônio vencedor, há um maior aproveitamento dos neurônios, pois todos os neurônios têm poder de competição e há um melhor reconhecimento de grupos. Além destas duas importantes características, estudos foram iniciados para analisar sua capacidade em aprendizado continuado (SILVA; SANDMANN; DEL-MORAL-HERNANDEZ, 2008). Nestes estudos preliminares, foram feitos experimentos de caracterização e comparação dessa arquitetura. Pretende-se, em estudos futuros, analisar e expandir o uso desta abordagem em problemas de data mining. 


\section{Referências Bibliográficas}

BöHM, C.; BERCHTOLD, S.; KEIM, D. Searching in high-dimensional spaces: Index structures for improving the performance of multimedia databases. ACM Comput. Surv., v. 33, p. 322-373, 2001.

BOONE, J. M.; SESHAGIRI, S.; STEINER, R. M. Recognition of chest radiograph orientation for picture archiving and communications systems display using neural networks. J Digital Imaging, v. 3, p. 190-193, 1992.

BOSCARIOLI, C.; SILVA, L. A. da; DEL-MORAL-HERNANDEZ, E. Análise de agrupamentos utilizando mapas auto-organizáveis em agricultura de precisão. Congresso Brasileiro de Agricultura de Precisão - ConBAP 2006, São Pedro, SP, p. 11-16, 2006.

BOSCARIOLI, C.; SILVA, L. A. da; DEL-MORAL-HERNANDEZ, E. Clustering de dados de sensores a partir de mapas auto-organizáveis. Proceedings of $5^{\circ}$ Congresso Ibero-americano de Sensores - IBERSENSOR 2006, Montevideo, p. 1-5, 2006.

BOSCARIOLI, C.; SILVA, L. A. da; DEL-MORAL-HERNANDEZ, E. Using self organizing maps and nearest-neighbor to data clustering. The 2008 International Conference on Artificial Intelligence (ICAI'08), Las Vegas, USA, p. 463-467, 2008.

CASTANóN, C. A. B. Extração de características em imagens médicas utilizando Wavelets. São Carlos, São Paulo: Universidade de São Paulo, 2003.

CASTELli, V.; BERGMAN, L. Image Databases- Search and Retrieval of Digital Imagery. 1a. ed. New York: John Wiley Professio, 2001.

CLOUGH, P.; MüLLER, H.; SANDERSON, M. The clef 2004 cross-language image retrieval track. In Proc. $5^{\text {th }}$ Workshop Cross-Language Evaluation Forum, CLEF 2004, v. 3491, p. 597-613, Sep. 15-17 2004.

CONSEIL, S.; BOURENNANE, S.; MARTIN, L. Comparison of fourier descriptors and hu moments for hand posture recognition. European Signal Processing Conference (EUSIPCO), v. 1, n. 1, p. 1-6, 2007.

COSTA, J. A. F.; ANDRADE-NETTO, M. L. de. Segmentação de mapas autoorganizáveis com espaçoo de saída 3-d. Sba Controle \& Automação Sociedade Brasileira de Automatica, v. 18, p. 150-162, 2007.

DAVIES, D. L.; BOULDIN, D. W. A cluster separation measure. IEEE Trans. Patt. Anal. Machine Intell., PAMI-1, p. 224-227, 1979.

DESELAERS, T.; HEGERATH, A.; KEYSERS, D.; NEY, H. Sparse patch-histograms for object classification in cluttered images. Springer Berlin Journal of Pattern Recognition, v. 4174/2006, n. 2, p. 202-211, 2006. 
DOI, K. Diagnostic imaging over the last 50 years research and development in medical imaging science and technology. Phys. Med. Biol., v. 51, p. R5-R27, 2006.

DUDA, R.; HART, P.; STORK, D. Pattern Classification and Scene Analysis. Wiley, NY: John Wiley Professio, 2000.

DUNCAN, J. S.; AYACHE, N. Medical image analysis: Progress over two decades and the chalenges ahead. IEEE PAMI, v. 11,2, p. 85-105, 2000.

EAKINS, P. J. Towards intelligent image retrieval. Pattern Recognition, v. 35, p. 3-14, 2003.

FELIPE, J. C. Desenvolvimento de métodos para extração, comparação e análise de características intrínsecas de imagens médicas, visando à recuperação perceptual por conteúdo. São Carlos, São Paulo: Tese de Doutorado apresentada a Universidade de São Paulo, 2005.

FREEMAN, W. J. Tutorial on neurobiology: from single neuron to brain chaos. International Journal of Bifurcation and Chaos, 1992, v. 2, p. 451-482, 1992.

FURUIE, S.; M.S.REBELO; M.A.GUTIERREZ; R.A.MORENO; G.H.M.B.MOTTA; N.BERTOZZO; F.B.NARDON; J.C.B.FIGUEIREDO; P.P.M.OLIVEIRA;

U.TACHINARDI. Prontuário eletrônico de pacientes: integrando informações clínicas e imagens médicas. Revista Brasileira de Engenharia Biomédica, v. 19, p. 103-115, Dezembro 2003.

FURUIE, S. S.; REBELO, M. F. S.; MORENO, R. A.; SANTOS, M.; BERTOZZO, N.; MOTTAL, G. H. M. B.; GUTIERREZ, M. A. Integrating medical images and clinical information. Proceedings of Fourth International Conference on Information and Communication Technology (ICICT 2006), Cairo, v. 2670, p. 555-563, 2006.

GONZALEZ, R. C.; WOODS, R. E. Digital Image Processing. Upper Saddle River, NJ: Prentice Hall, 2007.

GÄUlD, M. O.; KOHONEN, M.; SCHUBERT, H.; WEIN, B. B.; LEHMAN, T. M. Quality of dicom header information for image categorization. Proceedings SPIE, v. 4685, p. 280-287, 2002.

HAN, J.; KAMBER, M. Data Mining: Concepts and Techniques. New York: Morgan Kaufmann Publishers, 2001.

HAYKIN, S. Neural networks: A comprehensive foundation. Upper Saddle River, NJ: Prentice Hall, 1999.

HU, M.-K. Visual pattern recognition by moment invariants. TRANSACTIONS ON INFORMATION THEORY, v. 49, n. 1, p. 179-187, 1961.

HUANG, H. K. PACS and imaging informatics: Basic principles and applications. 1. ed. New York: JOHN WILEY PROFESSIO, 2004.

JAIN, A. K.; DUIN, R. P. W.; MAO, J. Statistical pattern recognition: A review. IEEE Transactions on Pattern Analysis and Machine Intelligence, v. 22, n. 1, p. 4-36, 2000. 
KASKI, S. Dimensionality reduction by random mapping: Fast similarity method for clustering. In: (IJCNN98), P. of IEEE International Joint Conference on N. N. (Ed.). Anchorage, AK, USA.: [s.n.], 1998. v. 1, p. 413-418.

KELLER, J. M.; GRAY, M. R.; GIVENS, J. A. A fuzzy k-nearest neighbor algorithm. IEEE Transaction on Systems, Man and Cybernetics, v. 15, n. 4, p. 580-585, 1995.

KEYSERS, D.; DAHMEN, J.; NEY, H.; WEIN, B. B.; LEHMANN, T. M. Statistical framework for model-based image retrieval in medical applications. J Electronic Imaging, v. 1, p. $59-68,2003$.

KHOTANZAD, A.; HONG, Y. H. Invariant image recognition by zernike moments. IEEE Transaction on Pattern Analysis and Machine Intelligence, v. 12, n. 5, p. 489-497, 1999.

KIVILUOTO, K. Topology preservation in self-organizing map. Finland, 1995.

KOHONEN, T. Self-Organizing Maps. Third extended edition. Berlin, Heidelberg, New York: Springer, 2001.

KOIKKALAINEN, P.; KOSKELA, M.; LAAKSO, S.; OJA, E. Picsom - content-based image retrieval with self-organizing maps. Elsevier Science, v. 21, p. 1199-1207, 2000.

KOIKKALAINEN, P.; OJA, E. Self-organizing hierarchical feature maps. Proceedings of IEEE International Joint Conference on Neural Networks (IJCNN99), San Diego, CA, USA, v. 2, p. 279-284, 1990.

KOSKELA, M. Interactive image retrieval using self-organizing maps. Dissertação (Mestrado) - Helsinki University of Technology, Espoo, Finland, November 2003.

LEHMANN, T. M.; GüLDA, M. O.; DESELAERSB, T.; KEYSERSB, D.; SCHUBERTC, H.; SPITZERA, K.; NEYB, H.; WEINC, B. B. Automatic categorization of medical images for content-based retrieval and data mining. Computerized Medical Imaging and Graphics, v. 29, p. 143-155, 2005.

MALLAT, S. Multifrequency channel decompositions of images and wavelet models. IEEE Transaction on Acoustics, Speech, and Signal Processing, v. 37, n. 12, p. 2091-2110, December 1989.

M.A.SANTOS; FURUIE, S. Base de imagens para avaliação de algoritmos de processamento de imagens. In: . Ribeirão Preto: IX CBIS - Congresso Brasileiro de Informática em Saúde, 2004.

MATSUMOTO, Y.; UMANO, M.; INUIGUCHI, M. Visualization with voronoi tessellation and moving output units in self-organizing map of the real-number system. IEEE World Congress on Computational Intelligence. International Joint Conference on Neural Network, Hong Kong, China, p. 3428-3434, 2008.

MEDASANI, S.; KRISHNAPURAM, R. Categorization of image databases for efficient retrieval using robust mixture decomposition. IEEE Workshop on Content-Based Access of Image and Video Libraries, p. 50-54, 1998. 
MüLLER, H.; N.MICHOUX; BANDON, D.; GEISSBUHLER, A. A review of content-based image retrieval systems in medical applications-clinical benefis and future directions. International Journal of Medical Informatic, v. 73, p. 1-23, 2004.

MORENO, R. A.; FURUIE, S. S. A contextual medical image viewer. IEEE Transactions on Information Technology in Biomedicine, Las Vegas, p. 583-592, 2007.

NG, R.; SEDIGHIAN, A. Evaluating multi-dimensional indexing structures for images transformed by principal component analysis. SPIE Storage and Retrieval for Image and Video Databases, San Diego, USA., v. 2670, 1996.

OH, K.; KANEKO, K.; MAKINOUCHI, A. Image classification and retrieval based on wavelet-som. Proceedings of the 1999 International Symposium on Database Applications in Non-Traditional Environments, v. 38, p. 164-167, 1999.

OJA, M.; KASKI, S.; KOHONEN, T. Bibliography of self-organizing map (som) papers: 1998-2001. v. 3, p. 1-156, 2003.

PIETKA, E.; HUANG, H. K. Orientation correction for chest images. J Digital Imaging, v. 3 , p. $185-189,1992$.

PINHAS, A.; GREENSPAN, H. A continuous and probabilistic framework for medical image representation and categorization. Proc SPIE, v. 5371, p. 230-238, 2003.

RAHMAN, M. M.; BHATTACHARYA, P.; DESAI, B. C. A framework for medical image retrieval using machine learning and statistical similarity matching techniques with relevance feedback. IEEE Transactions on information technology in biomedicine, v. 11, n. 1, p. 58-69, 2007.

SANTOS, M.; FURUIE, S. S. Medical image database for software and algorithm evaluation. In: . San Diego - CA: SPIE, 2006.

SASSI, R. J.; SILVA, L. A. da; DEL-MORAL-HERNANDEZ, E. Neural networks and rough sets: a comparative study on data classification. The 2006 International Conference on Artificial Intelligence - ICAI, Las Vegas, p. 3428-3434, 2006.

SASSI, R. J.; SILVA, L. A. da; DEL-MORAL-HERNANDEZ, E. A hybrid architecture for the knowledge discovery in databases: Rough sets theory and artificial neural nets self-organizing maps. 4th CONTECSI International Conference on Information Systems and Technology Management, São Paulo, SP, p. 34-44, 2007.

SASSI, R. J.; SILVA, L. A. da; DEL-MORAL-HERNANDEZ, E. Validação do conhecimento descoberto pela arquitetura híbrida (teoria dos rough sets e rede self-organizing maps) através de uma rede multilayer perceptrons usando uma base de dados de consumidores. 5th CONTECSI International Conference on Information Systems and Technology Management, São Paulo, SP, p. 4-10, 2008.

SAUX, B. L.; BOUJEMAA, N. Unsupervised robust clustering for image database categorization. IEEE Computer Society, v. 01, p. 259-262, 2002.

S.DEB; Y.ZHANG. An overview of content-based image retrieval techniques. Advanced Information Networking and Applications, v. 1, p. 59-64, 2004. 
SILBERSCHATZS, A.; KORYH, H.; SUDARSHAN, S. Sistema de Banco de Dados. Rio de Janeiro, RJ: [s.n.], 2006.

SILVA, L. A. da; DEL-MORAL-HERNANDEZ, E.; RANGAYYAN, R. M. Classification of breast masses using a committee machine of artificial neural networks. Journal of Electronic Imaging, v. 17, n. 1, p. 13-17, 2008.

SILVA, L. A. da; MORENO, R.; DEL-MORAL-HERNANDEZ, E.; FURUIE, S. Mapa de características auto-organizável para sistemas de recuperação de imagens por conteúdo. Proceedings of CBEB 2006 - XX Congresso Brasileiro de Engenharia Biomédica, p. 254-257, 2006.

SILVA, L. A. da; MORENO, R. A.; FURUIE, S. S.; DEL-MORAL-HERNANDEZ, E. Medical image categorization based on wavelet transform and self-organizing map. Seventh International Conference on Intelligent Systems Design and Applications, ISDA2007, Rio de Janeiro, RJ, p. 353-356, 2007.

SILVA, L. A. da; SANDMANN, H.; DEL-MORAL-HERNANDEZ, E. A self-organizing architecture of recursive elements for continuous learning. IEEE World Congress on Computational Intelligence. International Joint Conference on Neural Network, Hong Kong, China, p. 2784-2791, 2008.

SMEUlDERS, A. W. M.; WORRING, M.; SANTINI, S.; GUPTA, A.; JAIN, R. Content-based image retrieval at the end of the early years. IEEE Transaction Pattern on Machine Intelligence, v. 12, n. 22, p. 1349-1380, 2000.

SOMToolbox. SOM Toolbox, a function package for Matlab 5 implementing the Self-Organizing Map (SOM). Abril 2007. Http://www.cis.hut.fi/projects/somtoolbox/.

TRAINA, A. J. M.; ROSA, N. A.; TRAINA-JR, C. Integrating images to patient electronic medical records through content-based retrieval techniques. 16th IEEE Symposium on Computer-based Medical Systems (CBMS2003), New York, USA, p. 163-168, 2003.

VESANTO, J.; ALHONIEMI, E. Clustering of the self-organizing map. IEEE Transaction on Neural Network, v. 11, p. 586-600, 2000.

WEBER, R.; SCHEK, H.-J.; BLOTT, S. A quantitative analysis and performance study for similarity-search methods in high-dimensional spaces. p. 194-205.

WHITE, D.; JAIN, R. Similarity indexing: Algorithms and performance. San Diego, USA, v. 2670, 1996.

WU, S.; RAHMAN, M.; CHOW, T. Content-based image retrieval using hierarchical self-organizing quadtree map. The journal of Pattern Recognition Society, v. 38, p. 707$722,2005$.

Y.RUI; HUANG, T. Image retrieval: Current techniques,promising directions, and open issues. Journal of Visual Communication and Image Representation, v. 10, p. 39-62, 1999. 
ZHANG, D. S.; LU, G. Content-based shape retrieval using different shape descriptors: A comparative study. IEEE International Conference on Multimedia and Expo, p. 317-320, 2001.

ZHANG, H. J.; ZHONG, D. Scheme for visual feature-based image indexing. Storage and Retrieval for Image and Video Databases (SPIE), v. 2420, p. 36-46, 1995.

ZUCHINI, M. H. Aplicações de Mapas Auto-Organizáveis em Mineração de Dados e Recuperação de Informação. Campinas, São Paulo: Universidade Estadual de Campinas, 2003. 


\section{Apêndice A - Índice de Davies-Boldin}

De acordo com o índice de validação de Davies-Bouldin, o melhor agrupamento minimiza a eq. A.1:

$$
I D B=\frac{1}{C} \sum_{k=1}^{C} \max _{l \neq k}\left\{\frac{S c\left(Q_{k}\right)+S c\left(Q_{l}\right)}{d_{c e}\left(Q_{k}, Q l\right)}\right\}
$$

onde C é o número de grupos, Sc é a distância entre as amostras dos grupos $Q_{k}$ e $Q_{l}$ baseada na distância para o centróide, A.2

$$
S c\left(Q_{k}\right)=\left\{\frac{1}{N_{k}} \sum_{j=1}^{N_{k}}\left|c_{k}-x_{j}\right|^{p}\right\}^{\frac{1}{p}}
$$

onde $x_{j} \in Q_{k}, N_{k}$ é o número de amostras no agrupamento $Q_{k}$ e $c_{k}=\frac{1}{N_{k}} \sum_{x_{i} \in Q_{k}} x_{i}$ A distância entre grupos $d_{c e}$, também baseada em centróide, é dada por:

$$
d_{c e}\left(Q_{k}, Q_{l}\right)=\left\{\sum_{k=1}^{d}\left|c_{k}-x_{k}\right|^{p}\right\}^{\frac{1}{p}}
$$

onde $d$ é a dimensão do vetor $x_{k}$

Portanto, valores do índice de Davies-Bouldin menores que um representam agrupamentos separados, enquanto valores maiores que um representam grupos possivelmente cruzados. 


\section{Apêndice B - Metodologia para segmentação do mapa SOM}

A proposta para segmentação do mapa SOM feita por Vesanto e Alhoniemi (VESANTO E ALHONIEMI, 2000) utiliza o k-médias, método tradicional de agrupamento de dados. O esquema desta segmentação está ilustrado na Figura B.1.

No esquema da figura está mostrado resumidamente que a rede SOM é treinada a partir de uma base de vetores de características, gerando os vetores de pesos do Mapa SOM. Com base nestes vetores de características, aplica-se o k-médias, variando o número de k e, a cada variação, o índice de Davies-Bouldin (IDB) (DAVIES; BOULDIN, 1979) é calculado. O IDB, apresentado no Anexo A, é uma medida que considera a relação da dispersão intra-grupo e a dispersão inter-grupo. Assim, o menor valor de $I D B$ indica que o número de grupos no vetor de pesos ocorrerá quando a dispersão inter-grupo for pequena e a dispersão intra-grupo for grande. A partir desta informação, é aplicado o

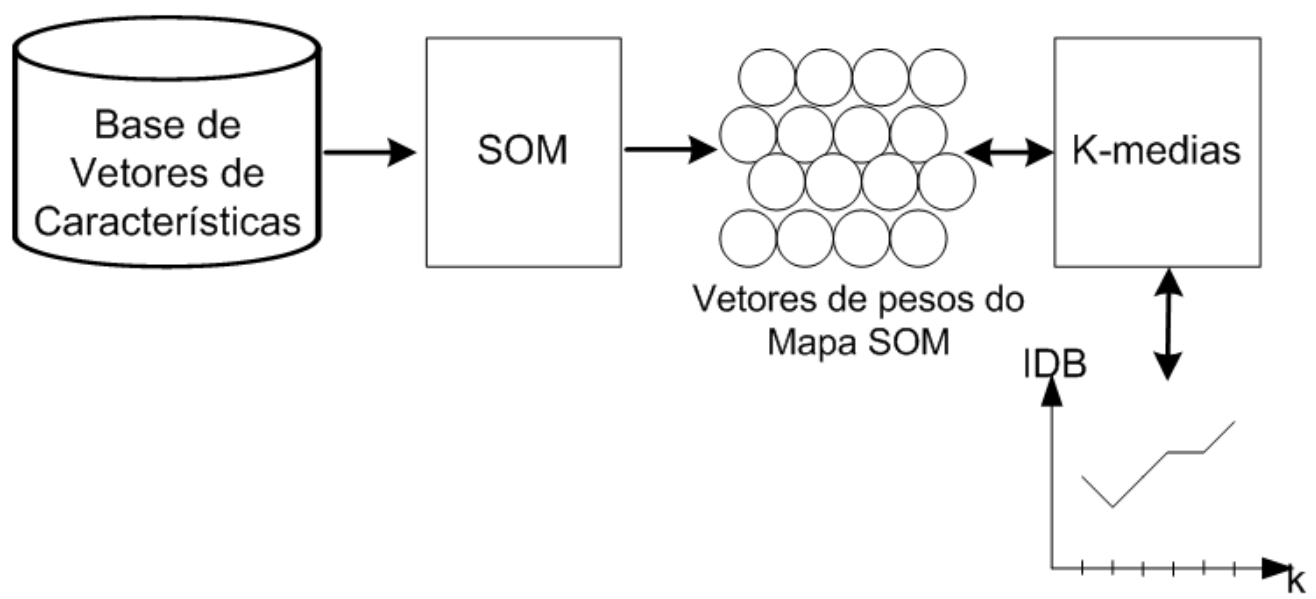

Figura B.1: Esquema para segmentação do mapa SOM (VESANTO; ALHONIEMI, 2000). 
k-médias, sendo o valor de k utilizado aquele que resultou em menor valor de $I D B$ e, assim, rotula-se o mapa.

Na metodologia anteriormente descrita de segmentação do mapa, o menor índice indica o número de grupos potencial e a segmentação do mapa é feita. Neste trabalho, como se conhece o número de grupos, o cálculo do $I D B$ é feito para um único valor de $\mathrm{k}$ apenas. 


\section{Anexo A - Produção bibliográfica}

A seguir, são listadas todas as publicações obtidas durante o programa de doutorado e relacionadas à tese.

\section{A.1 Publicação em revista}

1.Leandro Augusto da Silva, Emilio Del-Moral-Hernandez e Rangaraj Mandaraj Rangayyan. Classification of breast masses using a committee machine of artificial neural networks. Journal of Electronic Imaging, v. 17, n. 1, p. 13-17, 2008.

\section{A.2 Publicações em capítulos de livro}

1.Clodis Boscarioli, Leandro Augusto da Silva e Emilio Del-Moral-Hernandez. Aplicación de Redes Neuronales Artificiales a la Minería de Datos. Capítulo 14 del livro: Metodos de processamento avanzado e Inteligencia Artificial en Sistemas Sensores y Biosensores (pp. 13).

2.Leandro Augusto da Silva, Ramom Alfredo Moreno, Sergio Shiguemi Furuie e Emilio Del-Moral-Hernandez. Cluster-based Classification using Self-Organizing Maps for Medical Image Database. Chaper from Intelligent Image Processing Processing Book. Published in SCI Springer.

\section{A.3 Publicações em congressos internacionais}

1.Renato José Sassi, Leandro Augusto da Silva e Emilio Del-Moral-Hernandez. Neural Networks and Rough Sets: a Comparative Study on Data Classification. In: 
The 2006 International Conference on Artificial Intelligence - ICAI 06, Las Vegas, 2006.

2.Clodis Boscarioli, Leandro Augusto da Silva e Emilio Del-Moral-Hernandez. Clustering de dados de sensores a partir de mapas auto-organizáveis. Proceedings of $5^{\circ}$ Congresso Ibero-americano de Sensores - IBERSENSOR 2006, pp.1-5, Montevideo.

3.Leandro Augusto da Silva, Ramom Alfredo Moreno, Sergio Shiguemi Furuie e Emilio Del-Moral-Hernandez. Medical Image Categorization Based on Wavelet Transform and Self-Organizing Map. ISDA 2007. Seventh International Conference on Intelligent Systems Design and Applications, pp. 353-356. Rio de Janeiro, 20-24 Oct. 2007.

4.Renato José Sassi, Leandro Augusto da Silva e Emilio Del-Moral-Hernandez. A Hybrid Architecture for the Knowledge Discovery in Databases: Rough Sets Theory and artificial neural nets Self-Organizing Maps. 4th CONTECSI International Conference on Information Systems and Technology Management. 30 May-01 June, 2008 USP/São Paulo/SP.

5.Renato José Sassi, Leandro Augusto da Silva e Emilio Del-Moral-Hernandez. Validação do conhecimento descoberto pela Arquitetura Híbrida (Teoria dos Rough Sets e rede Self-Organizing Maps) através de uma rede Multilayer Perceptrons usando uma base de dados de consumidores. 5th CONTECSI International Conference on Information Systems and Technology Management. 04-06 June, 2008 USP/São Paulo/SP

6.Clodis Boscarioli, Renato José Sassi, Leandro Augusto da Silva e Emilio DelMoral-Hernandez. A Methodology for Data Mining to Support Customer Relationship Management. 5th CONTECSI International Conference on Information Systems and Technology Management. 04-06 June, 2008 USP/São Paulo/SP.

7.Clodis Boscarioli, Leandro Augusto da Silva e Emilio Del-Moral-Hernandez. 
Using self Organizing Maps and Nearest-Neighbor to Data Clustering. The 2008 International Conference on Artificial Intelligence (ICAI'08). pp. 463-467. Las Vegas, USA, July 14-17, 2008.

8.Leandro Augusto da Silva, Humberto Sandmann e Emilio Del-Moral-Hernandez. A Self-Organizing Architecture of Recursive Elements for Continuous Learning. International Joint Conference on Neural Networks (IJCNN 2008). pp. 2784-2791. June 1-6, 2008. Hong-Kong.

\section{A.4 Publicações em congressos nacionais}

1.Leandro Augusto da Silva, Ramom Alfredo Moreno, Sergio Shiguemi Furuie e Emilio Del-Moral-Hernandez. Mapa de características auto-organizável para sistemas de recuperação de imagens por conteúdo. Proceedings of CBEB 2006 - XX Congresso Brasileiro de Engenharia Biomédica, pp.254-257, 20006, São Pedro-SP.

2.Clodis Boscarioli, Leandro Augusto da Silva e Emilio Del-Moral-Hernandez. Análise de agrupamentos utilizando mapas auto-organizáveis em agricultura de precisão. Congresso Brasileiro de Agricultura de Precisão - ConBAP 2006, São Pedro - SP.

3.Renato José Sassi, Leandro Augusto da Silva e Emilio Del-Moral-Hernandez. A Methodology using Neural Networks to Cluster Validity Discovered from a Marketing Database. 10th SBRN2008 Brazilian Symposium on Neural Networks. 26-30 October 2008. Salvador, Bahia. 


\section{Anexo B - Descrição dos programas para categorização de imagens}

Foram gerados dois programas com interfaces para exemplificar a utilização do projeto. O primeiro foi construído usando a ferramenta de programação de interface do Matlab (GUI

- Guide User Interface) e o segundo usando conceitos de programação para internet.

O primeiro deles, em MatLab, está ilustrado na Figura B.1.

Cada objeto numerado na interface ilustrada na Figura B.1 está detalhado a seguir:

1.) classe da imagem de teste.

2.) distância euclidiana entre a imagem de teste e o vetor de pesos do neurônio vencedor.

3.) número do neurônio vencedor.

4.) botão para escolha de uma imagem para teste.

5.) classificação pelo rótulo do neurônio vencedor (votação).

6.) classificação pela imagem mais próxima.

7.) classificação pelo rótulo do neurônio vencedor (histograma).

8.) classificação por grau de pertinência com base no conjunto de imagens que os quatro neurônios vencedores representam.

9.) número de imagens comparadas para a classificação (máximo de 50). 


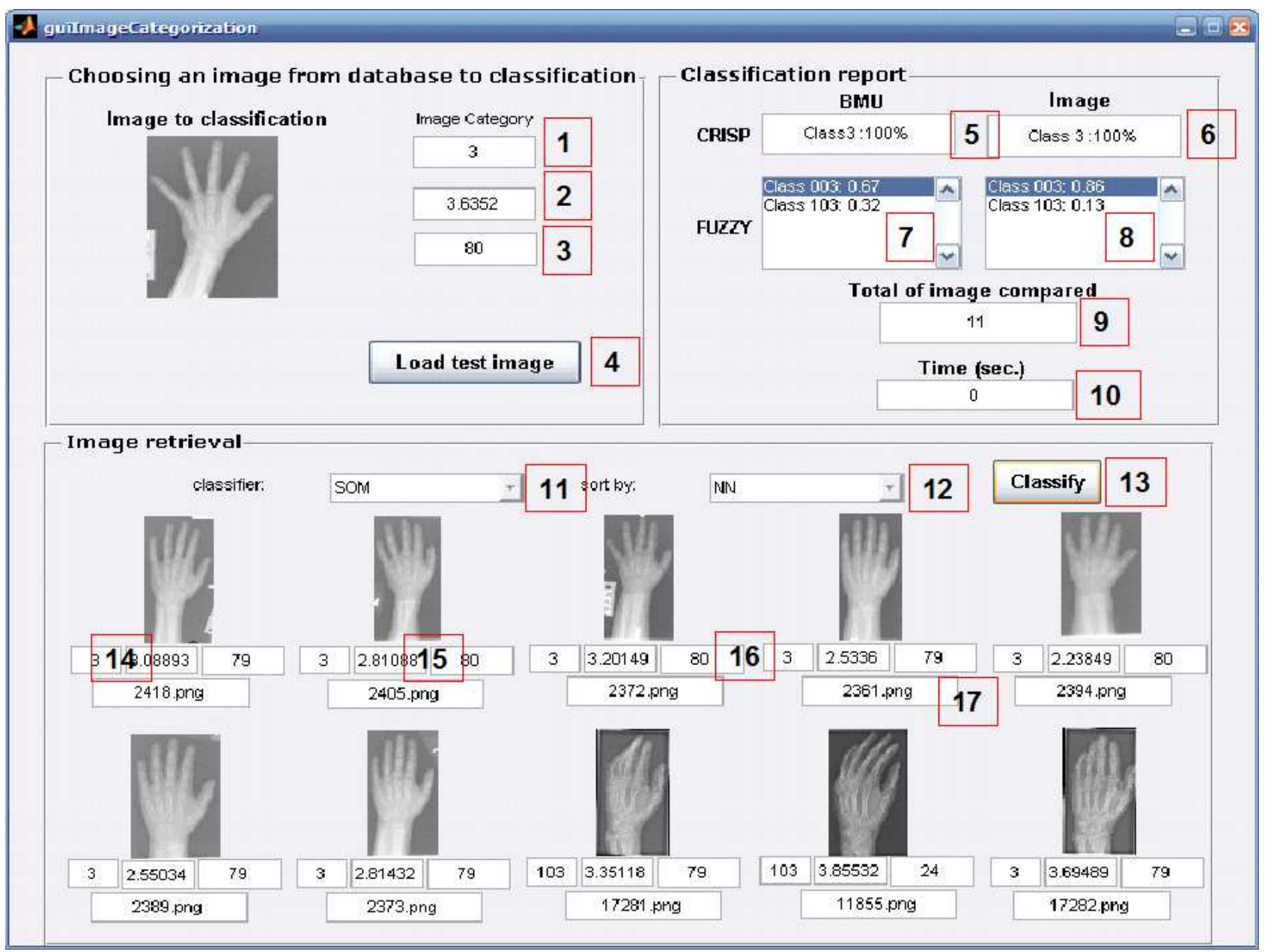

Figura B.1: Interface para classificação automática desenvolvida no MatLab 
10.) tempo gasto para a classificação.

11.) escolha do tipo de classificador (possibilidade de inserção de outros classificadores).

12.) escolha da forma de ordenação das imagens mais parecidas (mais próximas à imagem de teste e outra opção é pela proximidade com o neurônio vencedor).

13.) botão para fazer a classificação e exibição das 10 imagens mais parecidas.

14.) categoria da imagem de treinamento.

15.) distância euclidiana entre o vetor de característica da imagem e o vetor de pesos do neurônio vencedor.

16.) número do neurônio vencedor.

17.) nome do arquivo da imagem de treino.

Para operar o programa, primeiro é necessário escolher uma imagem para a classificação (item 4). O programa suporta imagens em formato DICOM ou PNG. Para a classificação, é necessário selecionar o classificador (item 11) e a ordem em que as 10 imagens semelhantes serão retornadas (item 12). Após as definições anteriores, a classificação pode ser iniciada (item 13). Primeiramente, os resultados de classificação (itens 5, 6, 7 e 8) e tempo gasto (item 10) são exibidos ao usuário. Após os resultados da classificação, as 10 imagens mais parecidas são exibidas na interface.

A interface aqui apresentada é extensível para desenvolvimentos futuros. Alguns itens podem ser incorporados e outros podem ser retirados. O item 9 é um exemplo de item que poderia ser retirado, já que a informação contida nele não é relevante para o uso final da interface.

Em relação às formas de classificação, apesar de pouco discutida a maneira de apresentar respostas em termos de pertinência (Fuzzy), a interface já foi preparada para esse resultado. Para exemplificar este tipo de resultado, aproveitou-se o classificador FuzzyKnn disponível no Matlab. 
Uma segunda interface, projetada para estar disponível na internet, foi desenvolvida por alunos do segundo ano da Escola Politécnica da Universidade de São Paulo (Alexandre Luiz Chiuffa, João Renato Molnar, Leandro Makoto Neves Hoshina, Nattan Inácio de Oliveira Lima) Figura B.2. O programa é um projeto para exemplificar a aplicação do categorizador na WEB. A tecnologia envolvida foi programação para internet simples (HTML, CSS e Java Script). As opções de uso são simples:

1.) escolha da imagem de teste.

2.) ao passar o mouse sobre a imagem de treino, as informações textuais do paciente são exibidas e ao clicar o botão direito do mouse, a imagem de treino é colocada ao lado da imagem de teste.

Contudo, apesar da simplicidade no funcionamento, o programa ilustra como as informações textuais do paciente podem ser combinadas com a respectiva imagem. Para esta proposta, as informações do paciente foram estruturadas no formato XML (eXtensible Markup Language) Figura B.3.

O programa está disponível para visita no seguinte endereço:

http://www.lsi.usp.br/ leandro/VisualizadorContextual/programa.html. 


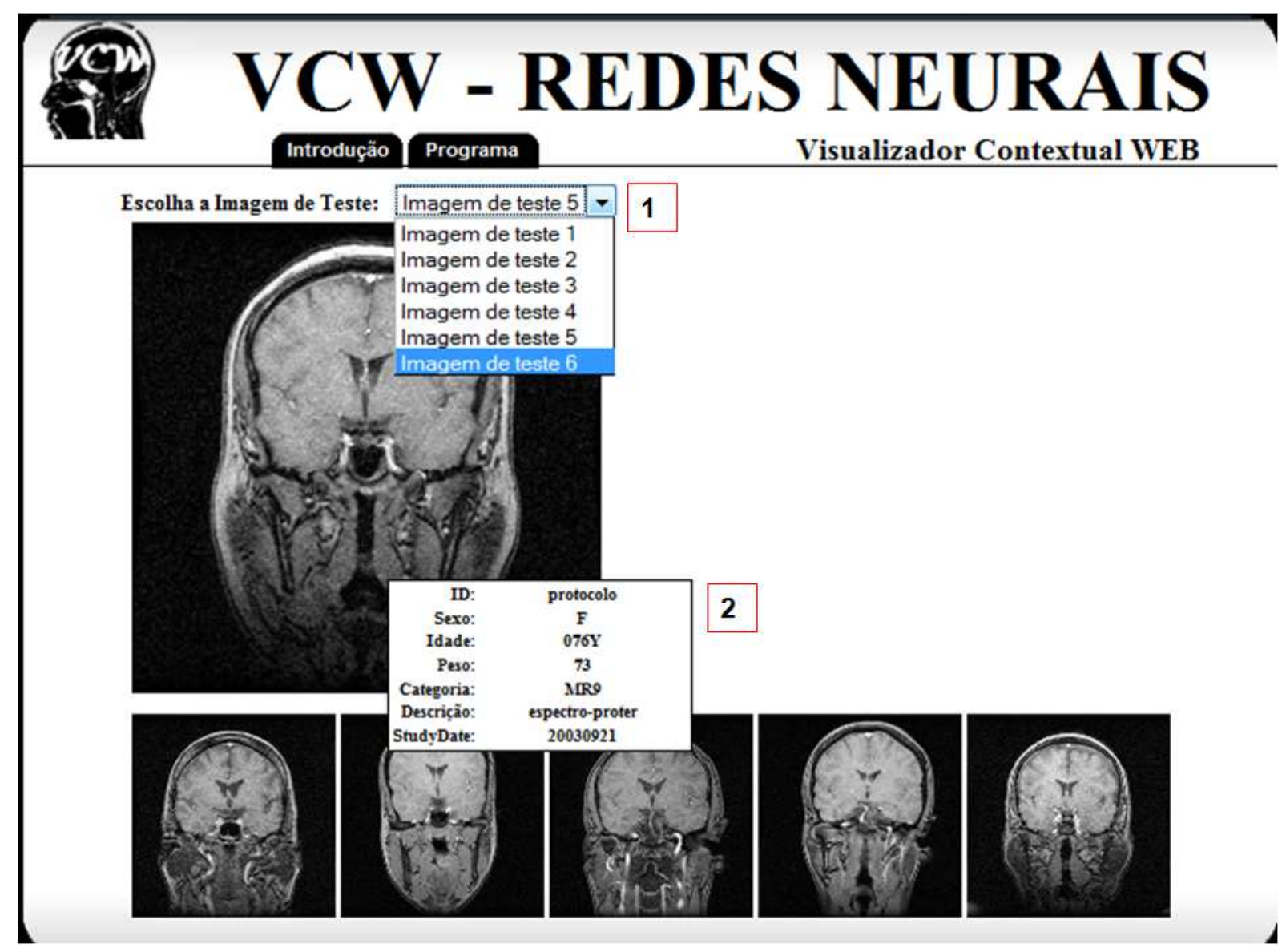

Figura B.2: Interface para classificação automática desenvolvida com programação WEB. 


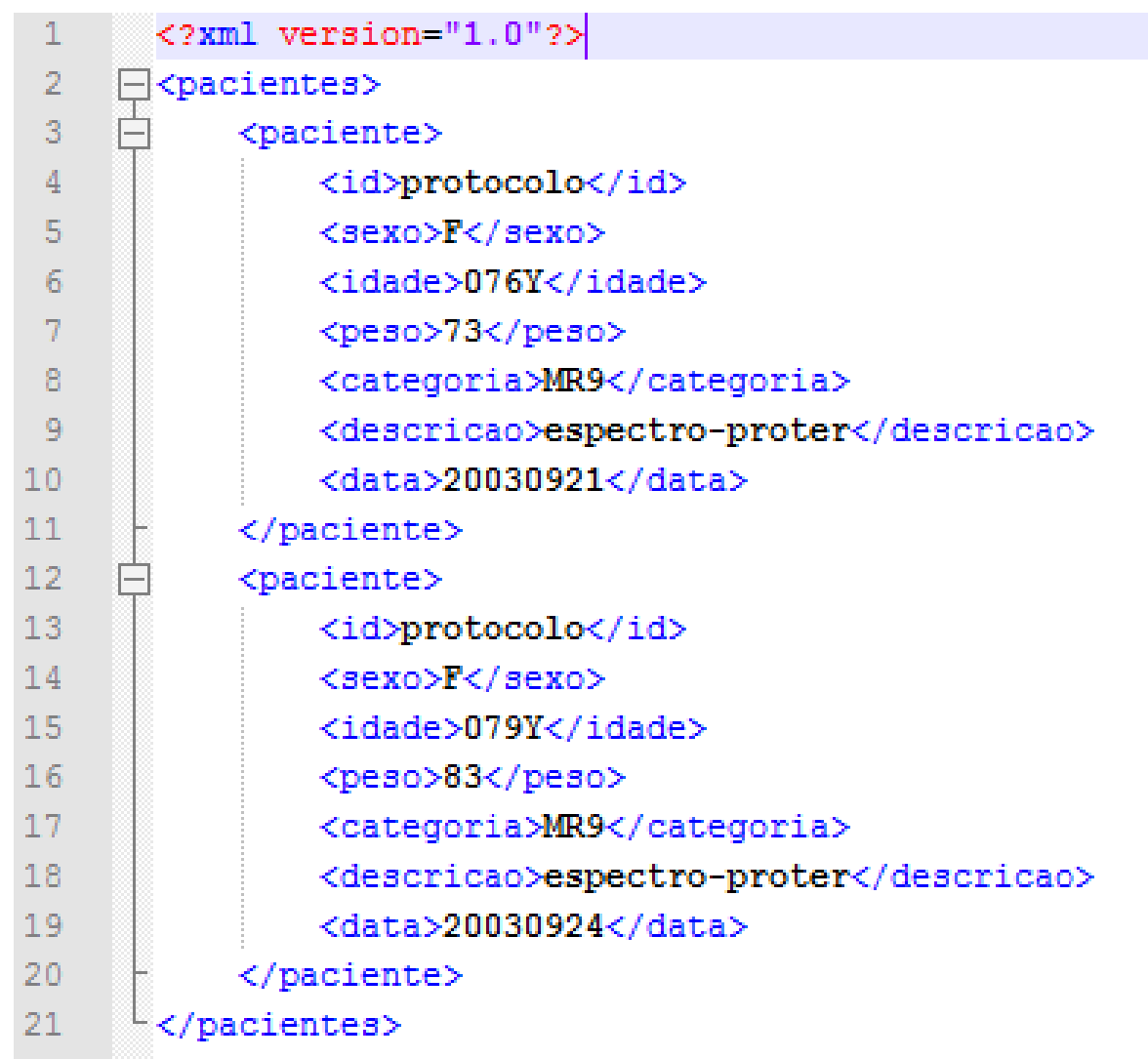

Figura B.3: Exemplo de arquivo XML para estruturação das informações do paciente. 